Theaterpolitik ist der Sammelname für alles Drum und Dran, das am Theater hängt und mit der eigentlichen Aufgabe des Theaters, Theater zu spielen, nichts zu tun hat.

Arthur Kahane ${ }^{1}$

Don't let us play at Politics [...] the politics of the Theatre are futile. Edward Gordon Craig 2

\title{
1. Theaterpolitik
}

Arthur Kahane, Dramaturg und Mitarbeiter Max Reinhardts am Deutschen Theater in Berlin, hatte, ebenso wie der Theaterreformer Edward Gordon Craig, keine hohe Meinung von der Theaterpolitik. Für ihn war sie ein Sammelbegriff für alle die Dinge, mit denen sich jeder Theaterdirektor unweigerlich auseinanderzusetzen hatte, obwohl sie ihn doch nur ablenkten vom Eigentlichen des Theaters. Dass jemand, der vor allem spielen und inszenieren wollte, die Theaterpolitik, das heißt die Gesetze, Verordnungen und Regulierungen, durch die der Staat Einfluss auf das Theater nahm, angefangen bei der Konzessionierung, über bau- und sicherheitspolizeiliche Überwachung bis hin zur Zensur, als störende Einmischung empfand, die ihn an seiner „eigentlichen Aufgabe“ hinderte, ist leicht nachzuvollziehen. Wie Kahane empfanden die meisten Theaterunternehmer und -direktoren.

Der Staat wiederum sah im Theater, wo viele Menschen zusammenkamen und Emotionen angesprochen wurden, eine potentielle Gefahr für die öffentliche Ordnung, weshalb es mehr noch als andere Gewerbe reguliert und überwacht werden musste. Dennoch wäre es falsch, Theater und Politik rein als Antagonisten $\mathrm{zu}$ betrachten. Manchmal waren es die Theaterdirektoren selbst oder ihre Interessenvertretungen, die nach dem Staat riefen. Mitunter forderten Schauspieler oder Zuschauer sein Eingreifen. Theaterpolitik wirkte sich auf alle Aspekte des Theaterbetriebs aus und betraf alle am Theater beteiligten Gruppen. Sie legte die Rahmenbedingungen fest, innerhalb derer die Theater als kommerzielle Unternehmen tätig waren. Deshalb muss sie am Anfang dieser Geschichte stehen.

Ausgangspunkt ist die Liberalisierung der Theatergesetzgebung in Großbritannien und Preußen um die Mitte des 19. Jahrhunderts, in deren Zuge die rechtlichen Grundlagen geschaffen wurden, die dann die Rahmenbedingungen bildeten, innerhalb derer sich die weitere Entwicklung vollzog. Dem geht das erste Unterkapitel nach. Das zweite betrachtet die Zensurgesetzgebung und -praxis, denn in Großbritannien wie in Preußen verlangte der Staat, dass jedes Theaterstück vor der Aufführung zur Begutachtung vorgelegt wurde. Umgekehrt aber behandelte auch das Theater politische Themen auf der Bühne. Um welche es sich dabei handelte, wie sie dargestellt wurden und wie dies trotz der Zensur möglich war, danach fragt das dritte Unterkapitel.

1 KaHANE, Theater, S. 66.

2 CRAIG, The Theatre Advancing, S. xlix. 
Bis heute hat der Staat nicht einmal als Gesetzgeber das Interesse für die Kulturmission des Theaters im erforderlichen Umfange aufgebracht. Sein Interesse war noch immer vorwiegend negativer Natur. Er beschränkte durch die Zensur die Freiheit der Kunstausübung. Im übrigen überließ er das Theater der gewerblichen Freiheit, so bedenklich auch ihre Folgen sich gestalteten.

Ludwig Seelig ${ }^{3}$

Moreover, democratic Government [...] has left the welfare of the stage to the mercy of the mere speculator, and as a result the theatre of to-day is controlled by those who keep from the public the representation of what is best in life, or at least of what is most appropriate, solely for considerations of personal gain.

William Poel ${ }^{4}$

\subsection{Gesetzgebung}

Bis ins frühe 19. Jahrhundert hinein hatte der Betrieb eines Theaters, zumindest soweit es das Stadtzentrum von London und Berlin anging (für vor den Toren der Stadt gelegene Theater galten andere Regeln), ein königliches Privileg zur Voraussetzung. Da ein solches fast nie gewährt wurde, besaßen die im Zentrum ansässigen Bühnen faktisch ein Monopol auf Theaterunterhaltung. Vor dem Hintergrund des allgemeinen Liberalisierungsschubes im 19. Jahrhundert stellte der britische Staat, später auch der preußische, die Theatergesetzgebung auf eine neue, liberalere Basis. Das feudale Privilegiensystem wurde durch ein modernes Konzessionierungssystem ersetzt: zuerst 1843 mit dem Theatre Act in Großbritannien, dem Mutterland des Liberalismus, dann 1869 mit der Reform der Gewerbeordnung in Preußen. Viele Studien über das Theater in London und Berlin beginnen deshalb mit diesen Jahren. ${ }^{5}$ Beide Gesetzeswerke hoben die zuvor existierenden, restriktiven Bestimmungen auf und schufen neue, vergleichsweise liberale rechtliche Voraussetzungen, unter denen seitdem die Theater betrieben wurden. An die Stelle eines königlichen Privilegs trat eine Konzession.

Die Bedeutung und Tragweite der neuen Gesetzgebung werden allerdings nur verständlich, wenn sie vor dem Hintergrund des vorangegangenen Systems gesehen werden, weshalb auch die rechtliche Situation vor der Novellierung betrachtet werden muss. Zugleich markierten die neuen Gesetze keineswegs einen Endpunkt, sondern läuteten einen grundsätzlich veränderten Umgang des Staates mit dem Theater ein. Eine vollständige „Theaterfreiheit“, von der zeitgenössisch oft die Rede war, brachten auch sie nicht, denn eine Theaterkonzession war immer an bestimmte Voraussetzungen und an die Einhaltung von Regeln

3 SeELIG, Geschäftstheater oder Kulturtheater?, S. 32.

4 Poel, What is wrong with the Stage?, S.9.

5 Vgl. Nicoll, English Drama, S.5f.; DaVIs, The Economics, S. 16-18; Leonhardt, PiktoralDramaturgie; FREYDANK (Hrsg.), Theater als Geschäft. 
geknüpft. ${ }^{6}$ Vor allem im Deutschen Reich wurden seit den 1880er Jahren die Bedingungen für die Konzessionsgewährung sukzessive verschärft. Auch in Großbritannien gab es eine lange, immer wieder aufflackernde Debatte über die Ausgestaltung der Konzession, die zur Einsetzung mehrerer parlamentarischer Untersuchungsausschüsse führte. Diese fortgesetzte Beschäftigung der Behörden und Parlamente belegt für sich bereits, welche Bedeutung dem Theater staatlicherseits beigemessen wurde. Eine neue Qualität erlangte die Einflussnahme des Staates nach dem Ersten Weltkrieg in Deutschland, als das Reich die vormals im Besitz der Krone befindlichen Bühnen als Staatstheater übernahm, und dann erneut mit der Machtübernahme der Nationalsozialisten. Diese Entwicklung zeichnet das folgende Kapitel nach.

\section{Liberalisierung}

Die ersten ständigen Theater Londons, das Red Lion und The Theatre, befanden sich vor den Toren der Stadt in Stepney und Whitechapel. Das Globe Theatre, an dem Shakespeare beteiligt war und in dem viele seiner berühmtesten Stücke uraufgeführt wurden, lag unweit des heutigen Nachbaus auf dem der City of London gegenüberliegenden Themseufer in Southwark. ${ }^{7}$ Da Theater als unmoralisch galt, wurde es nicht in der Stadt geduldet, weshalb sich die Bühnen außerhalb der Stadtmauern ansiedelten. Unter der Regierung Oliver Cromwells wurden dann 1642 alle Theater geschlossen. ${ }^{8}$ So kam es, dass es in London keine Bühne mehr gab, als Charles II. 1660 aus dem holländischen Exil nach Großbritannien zurückkehrte. Schon drei Monate nach seiner Thronbesteigung verlieh er an die beiden Höflinge Thomas Killgrew und William Davenant Patente, die es ihnen gestatteten, in London Theater zu spielen. Diese Patente waren nicht an ein bestimmtes Theater oder einen bestimmten Ort geknüpft, führten aber zur Etablierung des Theatre Royal Drury Lane (1663) und des Theatre Royal Covent Garden (1732). Das royal im Titel bezog sich allerdings lediglich auf das royal patent, das königliche Privileg. Im Gegensatz zu den in dieser Zeit entstehenden kontinentalen Hoftheatern handelte es sich um private, kommerzielle, von der Krone unabhängige Unternehmen. Das gilt auch für das Theatre Royal Haymarket, das als drittes Theater 1766 ein königliches Patent erhielt. ${ }^{9}$

Um die patent theatres vor der wachsenden Konkurrenz zu schützen, verabschiedete das Parlament 1737 den Licensing Act. Da er jedoch den Einflussbereich des Lord Chamberlain, des für die Theater zuständigen königlichen Hofkämmerers, auf Westminister beschränkte, führte er unabsichtlich dazu, dass sich außerhalb dieses Distrikts immer mehr sogenannte Nebentheater (minor theatres) an-

6 HaHn, Das deutsche Theater, S. 38; Max Martersteig, Theater-Manchesterthum, DiE ZuKUNFT 5 (1893), S. 462-466; JACOBSOHN, Das Theater der Reichshauptstadt, S. 7.

7 Vgl. Sutcliffe, London, S. 27-28; ReXroth, Grenzen der Stadt.

8 Vgl. SEnELICK, Closure of Theatres, S. 223.

9 Vgl. Donohue, Introduction, S. 4-14; Rowell, Victorian Theatre, S. 12f.; BоотH, Theatre, S. 6; DAVIS, The Economics, S. 17-20. 
siedelten. Neben ihrer peripheren Lage waren sie noch dadurch benachteiligt, dass sie nicht alle Genres aufführen durften, denn die als aristokratisch geltenden Gattungen Oper und Tragödie blieben Drury Lane und Covent Garden vorbehalten, weshalb sich die Nebentheater mit neu entstandenen dramatischen Mischformen, dem sogenannten illegitimate drama, begnügen mussten. Auf diese Weise wurde die Trennung der Kultur in hoch und nieder per Gesetz festgeschrieben. ${ }^{10}$

Im ersten Drittel des 19. Jahrhunderts gründeten private Theaterunternehmer weitere solcher minor theatres, bis es 1843 mehr als zwei Dutzend von ihnen gab. In der Folge begann sich die kulturelle Geographie der Stadt zu verändern. So verschwammen die Unterschiede zwischen Haupt- und Nebentheater zunehmend. Der Erfolg der neuen Gattungen beispielsweise führte dazu, dass diese auch Eingang auf die Bühnen von Drury Lane und Covent Garden fanden. In den 1830er Jahren begann dann eine Kampagne gegen das Monopol der Haupttheater, bei der sich die Anwälte der Nebentheater die zeitgenössische Freihandelsrhetorik zunutze machten. ${ }^{11}$

Im Zuge liberaler Reformen, die im Reform Act von 1832 kulminierten, setzte das Parlament 1832 einen Untersuchungsausschuss ein, das Select Committee on Dramatic Literature unter der Leitung des Politikers und Schriftstellers Edward Bulwer-Lytton, das den Zustand der dramatischen Literatur und die bestehenden Vorschriften zur Regulierung der Theater überprüfen sollte. ${ }^{12}$ Nachdem ein erster, von dem Komitee ausgearbeiteter Gesetzesentwurf 1833 im House of Lords gescheitert war, wurde 1843 der Theatre Regulation Act (kurz: Theatre Act) verabschiedet. Er hob das Monopol von Drury Lane, Covent Garden und Haymarket auf. Jedes Theater in London konnte nun jedes Genre zur Aufführung bringen. In gewissem Sinn aber war der Theatre Act ein Pyrrhus-Sieg für die Nebentheater, denn diese wurden nun ebenfalls der Gewalt des Lord Chamberlain unterstellt. Damit galten für sie dieselben Zensurbestimmungen wie für die Haupttheater in der Innenstadt. Davon abgesehen änderte sich durch den Theatre Act zunächst wenig. Da viele Nebentheater ohnehin seit Längerem gegen die bestehenden Gesetze verstoßen oder Wege gefunden hatten, sie zu umgehen, legitimierte der Theatre Act lediglich die ohnehin existierende Praxis. Zur Überraschung all derjenigen, die für die Theaterfreiheit gestritten hatten, führte er weder zu einer Belebung der dramatischen Literatur noch zur Gründung neuer Bühnen. ${ }^{13}$

In Berlin gab es bis ins 18. Jahrhundert hinein überhaupt kein ständiges Theater. Umherreisende Wandertheatergruppen, die sowohl vor bürgerlichem Publi-

10 Vgl. Moody, Theatrical Revolution, S. 199-215; dies., Illegitimate Theatre, S. 10-47; STAMM, Geschichte, S.292; siehe auch Rosenfeld, Theatre; BAer, Theatre and Disorder; Burling, Summer Theatre.

11 Vgl. Davis, The Economics, S. 23, 35; siehe auch BARKER, A Theatre for the People.

12 Report (1909); siehe auch StePhens, The Censorship, S. 9 f.; ders., The Profession of the Playwright, S. 90-91; KIFT, Victorian Music Hall, S. 90f.; DAvis, The Economics, S. 33-36; MoodY, Illegitimate Theatre, S. 45-47.

13 Vgl. Stamm, Geschichte, S. 310; Davis, The Economics, S. 18-19; Moody, Illegitimate Theatre, S. 206. 
kum auf provisorischen Bretterbühnen als auch am Hof auftraten, waren die einzige Form von Theaterunterhaltung. Das änderte sich erst unter der Regentschaft von König Friedrich II., der 1741 den Bau der Königlichen Hofoper (der heutigen Staatsoper Unter den Linden) veranlasste. Ihr folgte 1776 das in der Nähe gelegene Königliche Schauspielhaus (das heutige Konzerthaus). Wie die britische Hauptstadt besaß nun auch Berlin zwei zentral gelegene, repräsentative Theaterbauten, die allerdings im Gegensatz zu London nicht als kommerzielle Unternehmen geführt wurden, sondern bis 1918 Teil des Hofes waren. ${ }^{14}$ Ähnlich wie in London verfügten die Hoftheater über ein Monopol. Da der Bau eines neuen Theaters einer königlichen Erlaubnis bedurfte, der König diese aber regelmäßig versagte, waren die Hoftheater weitgehend vor Konkurrenz geschützt. Doch siedelten sich auch in Berlin außerhalb der Stadtmauern Sommertheater an. ${ }^{15}$ Sie wurden privat - meist von Gastwirten - betrieben und bestanden aus einfachen, provisorischen Bretterbühnen unter freiem Himmel.

Im Zuge der preußischen Reformen wurden die Theater kurzzeitig dem Kultusministerium unterstellt. Aber schon 1810 übernahm die Abteilung für Gewerbepolizei im Ministerium des Inneren die Aufsicht. ${ }^{16}$ Damit wurde das Theater zum ersten Mal als Gewerbe eingestuft, eine Entscheidung, die folgenreich blieb für seine Entwicklung bis ins 20. Jahrhundert. An die Stelle des feudalistischen Privilegiensystems, bei dem der Fürst nach Belieben eine Konzession gewähren oder versagen konnte, traten gesetzliche Regelungen. Nun durfte „niemand[em] der Gewerbeschein versagt werden, welcher ein Attest der Polizeibehörde seines Ortes über seinen rechtlich[en] Lebenswandel beibringt “. 17

Die neue Theaterfreiheit währte jedoch nur kurz. Bereits die preußische Gewerbeordnung von 1811 verschärfte die Bestimmungen wieder. Dort hieß es: „Schauspieldirektoren darf der Gewerbeschein nur mit Genehmigung des allgemeinen Polizeidepartments erteilt werden. Das Genehmigungsinstrument muß Zeit und Ort bestimmt ausdrücken, für welche es gültig sein soll“'. ${ }^{18}$ Die nächste Verschärfung erfolgte 1834 mit der Einführung der sogenannten Bedürfnisfrage. Ausschlaggebend für die Erteilung einer Konzession waren danach nicht nur „die persönliche Rechtlichkeit und sonstige Qualifikation des Unternehmers“, sondern auch „die örtlichen Umstände und sonstigen allgemeinen polizeilichen Rück-

${ }^{14}$ Freydank, Theater in Berlin, S. 36-80; Hosfeld et al., Friedrichs Traum; Quander (Hrsg.), 250 Jahre Opernhaus; MƯlLER et al. (Hrsg.), Apollos Tempel.

15 Vgl. Jansen und Lorenzen, Possen, Piefke und Posaunen; Louis, Vom Elysium zum Prater.

16 Verordnung über die veränderte Verfassung aller obersten Staatsbehörden in der Preußischen Monarchie vom 27. Oktober 1810, Gesetzsammlung Für Die KÖniglich-Preussischen StAaTEN, 1810, S. 3 .

${ }^{17}$ Edikt über die Einführung einer allgemeinen Gewerbesteuer vom 2. Januar 1810, in: ebd., S. 79; siehe auch KLEIN, Der preußische Staat, S. 31.

18 Gesetz über die polizeilichen Verhältnisse der Gewerbe in Bezug auf das Edikt vom 9. November 1810 wegen Einführung einer allgemeinen Gewerbesteuer vom 7. September 1811, ebd., S.263-265; siehe auch OPET, Deutsches Theaterrecht, S.24f.; MARTERSTEIG, Das deutsche Theater, S.349; KLeIN, Der preußische Staat, S.34; Asmussen, Die Geschichte des deutschen Theaterrechts, S. $38 \mathrm{f}$. 
sichten bei Beurtheilung der Zulässigkeit solcher Anlagen“ ${ }^{19}$ Mit den „örtlichen Umstände[n]“ war gemeint, dass die Polizei nur dann eine Konzession erteilte, wenn sie zu der Überzeugung kam, dass in dem entsprechenden Stadtteil ein Bedarf vorlag, den nicht bereits ein anderes Theater befriedigte. Die Entscheidung darüber, ob ein Bedarf vorlag oder nicht, war höchst subjektiv und bot den Behörden einen Vorwand, um jede Neugründung im Keim zu ersticken. ${ }^{20}$

Am einfachsten ließ sich ein neues Theater eröffnen, wenn die Krone dessen Gründung unterstützte. So ging selbst das erste ,bürgerliche' Theater Berlins, das 1824 von Karl Friedrich Cerf gegründete Königsstädtische Theater, auf eine Initiative Friedrich Wilhelms III. zurück, der auf einer Reise nach Frankreich Gefallen am dortigen Vaudeville-Theater gefunden hatte. Obwohl es als privat geführtes und finanziertes Theater begann, war es bald von königlichen Subventionen abhängig, sodass ihm eher die Stellung einer inoffiziellen Hofbühne als eines Geschäftstheaters zukam. Der Fall Cerf zeigt, dass es sehr viel einfacher war, eine Konzession zu erhalten, wenn ein fürstliches Interesse bestand. Da spielte es auch keine Rolle, dass Cerf als ehemaliger Pferdehändler und Offizier weder über die gesetzlich verlangte Qualifikation noch über die nötigen finanziellen Mittel für den Betrieb eines Theaters verfügte. ${ }^{21}$ Ähnlich verhielt es sich mit der anderen privaten Theatergründung dieser Jahre, dem 1844 unmittelbar vor dem Brandenburger Tor gebauten Kroll'schen Etablissement, zu dem Friedrich Wilhelm IV. den Anstoß gab. Wie diese beiden Beispiele zeigen, stand selbst hinter solchen Theatern, die offiziell als private Unternehmen galten, letztlich die Krone. ${ }^{22}$

Die Neuauflage der preußischen Gewerbeordnung von 1845 enthielt eine erneute Verschärfung des Theaterparagraphen. Demnach bedurften die Schauspielunternehmer nun „einer besonderen Erlaubnis des Oberpräsidenten der Provinz, in welcher sie ihre Vorstellungen geben wollen. Diese Erlaubnis darf ihnen nur nach vorgängigem Nachweise gehöriger Zuverlässigkeit und Bildung erteilt werden, kann jedoch auch dann, wenn sie dieser Bedingung entsprechen, nach dem Ermessen des Oberpräsidenten versagt werden“. ${ }^{23}$ Anstelle der örtlichen Polizei war nun der jeweilige Oberpräsident für die Erteilung einer Konzession zuständig. Obschon die Bedürfnisfrage weiter gültig blieb, flüchtete sich der Gesetzgeber nicht länger in Hilfskonstruktionen, um der Ablehnung eines Antrags einen Schimmer von Rechtsstaatlichkeit zu geben, sondern erklärte den Oberpräsiden-

19 Amts-Blatt der Königlichen Regierung Zu Potsdam und Der Stadt Berlin, Stück 46, 14. 11. 1834, Nr.55; siehe auch ITODA, Berlin \& Tokyo, S. 51-63; Hoelger, Reglementierung, S. 27.

20 Vgl. NöBel, ,Damals war's...', S. 46f.; ItodA, Berlin \& Tokyo, S. 51 f.; Hoelger, Reglementierung, S. 27-33.

21 Vgl. Walther, Berliner Theater, S. 80-90; FreYdank, Theater in Berlin, S. 271-290.

22 Vgl. Freydank, Theater in Berlin, S. 238-240; Wieke, Vom Etablissement zur Oper; MaAs, Das Friedrich-Wilhelmstädtische Theater, S. 186; ITODA, Berlin \& Tokyo, S. 34-35; WIEKE, Vom Etablissement zur Oper, S. 9-12; LouIs, Vom Elysium zum Prater, S. 22-38.

$23 \$ 47$ der Preußischen Gewerbeordnung vom 17. Januar 1845, GESETZSAMMLUNG FÜR DIE KÖniglich-Preussischen StaAten, 1845, Blatt 41-78, hier S.41; siehe auch Opet, Deutsches Theaterrecht, S. 24-25. 
ten zu der allein maßgeblichen Autorität, die nach eigenem Ermessen eine Konzession erteilen oder - wie in der Mehrheit der Fälle - versagen konnte. „Ist der Oberpräsident etwa aus religiösen Rücksichten ein Gegner des Theaters überhaupt, “ entrüstete sich der liberale Ökonom Otto Wolff noch 1863, „,wird er möglichst wenig Konzessionen ertheilen; vielleicht ebenso wird er verfahren, wenn er umgekehrt ein besonderer Freund des Theaters ist“ ${ }^{24}$

Musste zuvor zumindest theoretisch jedem Antragsteller, der den vorgeschriebenen Nachweis erbrachte, eine Konzession erteilt werden, war dies „ein weiterer Schritt zurück zum alten Privilegiensystem". ${ }^{25}$ Doch ging es der preußischen Regierung weniger darum, die Uhr zurückzudrehen, als ein Medium zu kontrollieren, das große Menschenmengen anzog und die Gefühle der Zuschauer ansprach. Noch war in aller Erinnerung, dass die belgische Revolution von 1830 in einer Vorstellung der national-romantischen Oper La Muette de Portici im Brüsseler Opernhaus begonnen hatte. ${ }^{26}$ Wie in London entschied der preußische Staat überdies nicht nur über die Erteilung von Theaterkonzessionen, er reglementierte auch die Art der Bühnenunterhaltung. So waren Tragödie, Oper und Ballett allein den Hoftheatern vorbehalten. Alle anderen Theater waren an Operette, Schauspiel, Lustspiel, Posse und Vaudeville verwiesen. Die Trennung von Hoch- und Volks- beziehungsweise Populärkultur hatte also auch in Berlin rechtliche Ursachen. ${ }^{27}$

Die vormärzliche Konzessionierungspraxis machte die Eröffnung eines weiteren Theaters in Berlin bis auf Weiteres unmöglich. Die einzige Alternative war das Ausweichen vor die Tore der Stadt, da hierfür Konzessionen freigiebiger gewährt wurden. Der Theaterhistoriker Max Martersteig erklärt dies damit, dass von derart weit abgelegenen Theatern, keine Konkurrenz für die Hoftheater zu befürchten war. ${ }^{28}$ Er verstand die Konzessionierungspraxis also vor allem als ein ökonomisches Instrument. Hinzu kamen jedoch auch hier politische Überlegungen, denn bei einem Aufruhr in einem außerhalb gelegenen Theater konnte ein Übergreifen auf die Stadt leichter verhindert werden. Allerdings hüteten sich Vorstadttheater zumeist vor der Politik und brachten in erster Linie unverfängliche Unterhaltung. Oft waren sie Teil eines Restaurationsbetriebes und das Schauspiel bloßes Beiwerk, das die Stadtbevölkerung anlocken sollte. ${ }^{29}$ Dennoch bildeten sie die Keimzelle des späteren Berliner Geschäftstheaters. Mit dem zunehmenden Wachstum der Stadt entwickelten sich manche von ihnen - wie das Friedrich-Wilhelmstädtische Theater $-\mathrm{zu}$ regulären Bühnen.

24 Otto Wolff, Das Theater und die Volkswirthschaft, ViertelJAhresSCHRIFT FÜr VOLKSWIRTHSCHAFT UND Culturgeschichte 1 (1863), S. 96; siehe auch Martersteig, Das deutsche Theater; S.349f.; KleIN, Der preußische Staat, S.45f.; Asmussen, Die Geschichte des deutschen Theaterrechts, S. 39 .

${ }^{25}$ KLEIN, Der preußische Staat, S. 46.

26 Vgl. SLATIN, Opera and Revolution.

27 Vgl. NÖBEL, ,Damals war's...', S. 46f.; LeONHARDT, Piktoral-Dramaturgie, S. 124; ITODA, Berlin \& Tokyo, S. 51 .

${ }^{28}$ Vgl. Martersteig, Das deutsche Theater, S. $349 \mathrm{f}$.

${ }^{29}$ Vgl. Jansen und Lorenzen, Possen, Piefke und Posaunen; Louis, Vom Elysium zum Prater. 
Aufgrund der rigiden Theaterpolitik im Vormärz blieb die Zahl der Theater sehr beschränkt. Erst unter dem Druck der revolutionären Ereignisse von 1848 erteilten die preußischen Behörden vorübergehend großzügiger Konzessionen für Sommer- und seltener für Wintertheater. Doch auf die Zugeständnisse der neuen, liberalen Regierung folgte bald nach dem Scheitern der Revolution auch im Bereich des Theaters die weitgehende Wiederherstellung der alten Ordnung. Von den sechs Schauspieldirektoren, die sich 1848 um eine Konzession bewarben, erhielt nur Friedrich Wilhelm Deichmann eine Genehmigung, mit der er das Friedrich-Wilhelmstädtische Theater (das spätere Deutsche Theater) eröffnete. ${ }^{30}$ Die Forderung nach einer Liberalisierung blieb deshalb auch nach der Revolution so aktuell wie in den Jahrzehnten zuvor. Otto Wolff verlangte 1863 die „Beseitigung des Tragödien-Monopols der Berliner Hofbühne, die Aufhebung des Konzessionszwanges, und die Beseitigung der Theater-Censur".31 Dass Wolff weder als Unternehmer noch auf irgendeine andere Weise am Theater beteiligt war, unterstreicht, wie sehr dessen fortgesetzte Reglementierung gegen das Empfinden des liberalen Bürgertums verstieß. Im Monopol der Hoftheater und im Konzessionierungszwang sah Wolff einen ungehörigen Eingriff in den Markt, während die Abschaffung der Zensur sowieso Bestandteil der liberalen Agenda war. Dieser gesellschaftliche Rückhalt war wichtig für den langfristigen Erfolg der Theaterunternehmer bei ihrem Kampf für eine gesetzliche Neuordnung der Theaterbestimmungen. Tatsächlich blieb die Agitation für die Theaterfreiheit nicht ohne Folgen. Der von einer wirtschaftlichen Konjunktur begleitete und stimulierte gesellschaftliche Aufbruch in den Jahrzehnten nach der Revolution führte schließlich auch zu einer Liberalisierung der Theatergesetzgebung. ${ }^{32}$

Durch die Reform der Gewerbeordnung für den Norddeutschen Bund von 1869 wurde die Theatergesetzgebung auf eine neue rechtliche Basis gestellt. Nach $\$ 32$ war Schauspielerunternehmern eine Konzession nur dann zu versagen, wenn „Thatsachen vorliegen, welche die Unzuverlässigkeit des Nachsuchenden in Beziehung auf den beabsichtigten Gewerbebetrieb darthun. Beschränkungen auf bestimmte Kategorien theatralischer Darstellungen sind unzulässig“. ${ }^{33}$ Diese Bestimmung ähnelte nicht nur im Wortlaut dem Edikt von 1811, sie stellte auch faktisch die Gewerbefreiheit im Bereich des Theaters wieder her. Durch die Reform der Gewerbeordnung ließ der preußische Staat erkennen, dass er seine bisherige, restriktive Haltung aufgab und bereit war, Theaterkonzessionen in einem größeren Maßstab zu erteilen. Zusätzlich dazu vereinfachte er das Genehmigungsverfahren. Hatte die Berliner Polizei noch 1868 bloß einen von sechs

30 Vgl. WahnRau, Berlin, S. 404-408; MaAs, Das Friedrich-Wilhelmstädtische Theater; HeInRICH-Jost, Auf ins Metropol, S. 11-12; FreydanK, Theater in Berlin, S. 254-269; NöBel, ,Damals war's...', S. 47-49; Louis, Vom Elysium zum Prater, S. 25.

31 Otto Wolff, Das Theater und die Volkswirthschaft, VIERTELJAHRESSCHRIFT FÜr VOLKSWIRTHSCHAFT UND CULTURGESCHICHTE 1 (1863), 2. Bd., S. 90-108, hier S. 104.

32 Zum historischen Kontext vgl. SIEMANN, Gesellschaft im Aufbruch.

${ }^{33}$ Gewerbeordnung für den Norddeutschen Bund vom 21. Juni 1869, Bundes-GeseTZBLATT DeS NORDDEUTSCHEN BUNDES, 1869, Nr. 26, S. 245-282, hier S. 254. 
Konzessionsanträgen genehmigt, kamen 1869 auf 34 genehmigte Anträge nur noch neun Ablehnungen, im folgenden Jahr auf 37 nur drei. ${ }^{34}$ Dazu trug ebenfalls bei, dass die Bedürfnisfrage, auf die sich die Polizei bislang bei der Versagung der Genehmigung zumeist berufen hatte, abgeschafft worden war. Jedem Bürger, der nun um eine Konzession nachsuchte, musste sie gewährt werden, sofern nicht die „Unzuverlässigkeit des Nachsuchenden“ erwiesen war. Diese Klausel war aber in der Praxis kaum anwendbar, da dazu die konzessionierende Behörde die Unzuverlässigkeit hätte belegen müssen. Darüber hinaus hob $\$ 32$ die Beschränkungen „theatralischer Darstellung“ auf, womit das Monopol der Hoftheater auf Tragödie, Oper und Ballett gemeint war. Jedes Theater konnte nun jedes beliebige Genre zur Aufführung bringen - freilich nicht jedes beliebige Stück, denn die Stücke unterlagen weiterhin der Zensur. ${ }^{35}$

Trotz eines eindeutigen Trends zur Liberalisierung waren weite Kreise des Bürgertums, vor allem des Bildungsbürgertums, mit der Neuordnung der Theatergesetzgebung unzufrieden. Sie hatten sich eine Unterstellung des Theaters unter eine eigene staatliche Behörde erhofft, da es in ihren Augen wie Schulen oder Museen der Bildung und Erziehung diente. Deshalb wäre es aus ihrer Sicht die Pflicht des Staates gewesen, für die Pflege und Finanzierung des Theaters aufzukommen. Der Philologe Christian Gaehde sprach für viele Bürger, wenn er erklärte, dass „infolge der Gewerbefreiheit, der Niedergang des deutschen Theaters als Kunstinstitution" eingesetzt hatte. ${ }^{36}$ Sofern das Theater einen gesellschaftlich-repräsentativen Charakter besaß, übten ihn weiterhin die Hoftheater aus. Das bürgerliche Theater war seit 1869 ein kommerzielles Unternehmen, das den Gesetzen von Angebot und Nachfrage gehorchte. ${ }^{37}$

Damit bestand seit 1869 in Berlin eine rechtliche Situation, die sich kaum von derjenigen in London unterschied. Die Bestimmungen der Gewerbeordnung und des Theatre Act wichen in Details voneinander ab, dennoch hatten sie dieselbe Wirkung: sie beendeten das feudale Privilegiensystem und schufen eine transparente rechtliche Grundlage für die Gründung und den Betrieb von Theatern. Dies war die Voraussetzung für den im letzten Drittel des 19. Jahrhunderts einsetzenden Theaterboom. Dass der Theatre Act rund 30 Jahre vor der Reform der Gewerbeordnung verabschiedet wurde, ist auf unterschiedliche politische Bedingungen zurückzuführen. Zur selben Zeit als der britische Staat liberale Reformen durchführte, versuchten die konservativen kontinentalen Regierungen, den Liberalismus im Keim zu ersticken. Ein wichtiger Unterschied war, dass der Theatre Act das Theater als eigenständige Institution behandelte und einem Minister der Krone unterstellte, während in Preußen das Theater als Gewerbe eingestuft wurde.

\footnotetext{
${ }^{34}$ Vgl. LAB, A Pr. Br. Rep. 030-05-1657.

35 Vgl. Opet, Deutsches Theaterrecht, S. 25; Wahnrau, Berlin, S. 457-459; Asmussen, Die Geschichte des deutschen Theaterrechts, S. 40-42; FrEYDANK, Theater in Berlin, S. 286-312; LEONHARDT, Piktoral-Dramaturgie, S. 124f.; ITODA, Berlin \& Tokyo, S. 58.

${ }^{36}$ GAEHDE, Das Theater, S. 89.

37 Vgl. BAYERDÖRFER, Theater und Bildungsbürgertum; ZIELSKE, Zwischen monarchischer Idee und Urbanität; MöLLER, Zwischen Kunst und Kommerz.
} 
Und schließlich verloren die preußischen Hoftheater zwar ihr Monopol auf Oper und Tragödie, behielten als staatlich subventionierte Theater aber eine Sonderstellung, für die es keine Entsprechung in Großbritannien gab. Wie der folgende Abschnitt zeigen wird, kam es dann zwar in den folgenden Jahrzehnten immer wieder zu Verschärfungen, die 1843 beziehungsweise 1869 errichtete Rechtslage wurde jedoch bis in die Zwischenkriegszeit hinein nicht mehr grundsätzlich verändert.

\section{Reglementierung}

Spätestens seit der Mitte des 19. Jahrhunderts begannen in London immer mehr Kneipen, Unterhaltung in Form von Musik, Gesang und Tanz, aber auch kurzen Sketchen anzubieten, woraus mit der Zeit die Music Hall hervorging. Den Theaterbetreibern war diese Konkurrenz ein Dorn im Auge, weshalb es zu einem Konflikt kam, der dem zwischen den patent und minor theatres zu Beginn des Jahrhunderts ähnelte. Hauptstreitpunkt war die unterschiedliche Konzessionierung der beiden Sparten. Eine Theaterkonzession wurde vom Lord Chamberlain erteilt und enthielt die Erlaubnis, Theaterstücke jeder Art aufzuführen, versagte jedoch ausdrücklich den Ausschank von Alkohol und das Rauchen im Zuschauerraum. Die Music Halls hingegen wurden von lokalen Behörden (den magistrates) konzessioniert, genau so wie die Kneipen, aus denen sie hervorgegangen waren und zwar für den Ausschank von Alkohol. Nicht enthalten in dieser Lizenz war das Recht, Theaterstücke aufzuführen, weshalb sie auch die Zensur nicht betraf. Zwar kam es gerade in der Frühzeit aufgrund der unklaren Rechtslage mitunter vor, dass ein und dasselbe Etablissement beide Konzessionen führte, doch schlossen diese sich eigentlich gegenseitig aus. ${ }^{38}$ Jede der beiden Parteien fühlte sich gegenüber der anderen im Nachteil, die Theater, weil sie keinen Alkohol ausschenken, die Music Halls, weil sie keine längeren Stücke oder Ballette aufführen durften.

Aufgrund der Konflikte zwischen Theatern und Music Halls sowie den unklaren Zuständigkeiten setzte das Parlament 1866 einen Untersuchungsausschuss ein, das Select Committee on Theatrical Licenses and Regulations, das den Auftrag hatte, die bestehende Gesetzeslage zu überprüfen. ${ }^{39}$ In seinem Abschlussbericht kam es zu dem Ergebnis: „That the present system of double jurisdiction under which theatres are licensed by the Lord Chamberlain, and music halls, and other places of public entertainment, by the magistrates, is inconvenient and unsatisfactory“. ${ }^{40}$ Das Komitee schlug deshalb vor, dass in Zukunft der Lord Chamberlain allein für die Vergabe der Lizenzen zuständig sein sollte. An der Trennung zwischen Schank- und Theaterlizenz sollte festgehalten, den Music Halls aber erlaubt werden, Theateraufführungen abzuhalten. In diesem Zug sollte die Zensur

38 Vgl. KIFT, Victorian Music Hall, S. 90-91; DAVIS, The Economics, S. 59-69.

${ }^{39}$ Vgl. RePORT (1866).

${ }^{40}$ Ebd. 
auf die Music Halls ausgeweitet werden. ${ }^{41}$ Diese Vorschläge resultierten in einem Gesetzesentwurf, der aber im Parlament keine Mehrheit fand. ${ }^{42}$ Die Praxis, dass zwei unterschiedliche Behörden für die Erteilung der Lizenzen zuständig waren, blieb bestehen. Die Unterschiede zwischen den beiden Sparten wurden vielmehr noch verschärft durch ein neues Gesetz zur Regulierung der Öffnungszeiten von Restaurants und Kneipen, dem Licensing Act von 1872.

Seit den 1880er Jahren bezichtigen sich aufgrund einer immer schärferen Konkurrenz Music Hall- und Theaterbetreiber immer häufiger gegenseitig, die Grenzen des unter der jeweiligen Lizenz Erlaubten zu überschreiten. ${ }^{43}$ So beschwerte sich 1880 ein Theatermanager beim Lord Chamberlain über Susby's Music Hall, die nicht nur Ballette aufführe, sondern Spektakel, die denen von Drury Lane in nichts nachstünden: „In fact it is simply a large theatre with no Licence“.44 Wenige Monate später beklagte sich umgekehrt der Anwalt der Music Hall Proprietors Protection Association im Namen seiner Organisation über das Her Majesty's Theatre, das anstelle von Theaterstücken ein Varieté-Programm böte, woraufhin der Lord Chamberlain diese Praxis untersagte. ${ }^{45}$

Konflikte und Beschuldigungen dieser Art gab es unzählige, sodass der Lord Chamberlain ständig gezwungen war, zwischen den Betreibern der Theater und der Music Halls zu vermitteln. Zunehmend geriet er auch vonseiten des Parlamentes unter Druck, in dem 1908 ein - allerdings erfolgloser - Gesetzentwurf eingebracht wurde, der zum Ziel hatte, die Theater vollständig aus seinem $\mathrm{Zu}$ ständigkeitsbereich herauszulösen und den lokalen Behörden zu unterstellen. ${ }^{46}$ Erneut wurde ein Untersuchungsausschuss einberufen. Primär ging es beim Joint Select Committee of the House of Lords and the House of Commons on the Stage Plays (Censorship) von 1909 zwar um die Theaterzensur, doch daneben befasste sich das Komitee auch mit der „controversy which has been proceeding from many years between the managers of theatres and the managers of music halls as to the right of the latter to produce, sketches ““. $47 \mathrm{Da}$ es ohnehin allgemeine Praxis sei, dass die Music Halls „sketches“ zur Aufführung brachten, empfahl das Komitee, nur noch eine Lizenz zu vergeben: „a single licence for both classes of houses, giving them the freedom to produce whatever entertainment may best conform to the tastes of the public which they serve". 48 Abermals wurden tagelang Zeugen und Gutachter vernommen und Gesetzesentwürfe ausgearbeitet, die jedoch wiederum so lange von den zuständigen Ministerien und im Parlament verschleppt wurden, bis auch diese Vorschläge im Sand verliefen,

${ }^{41}$ Ebd., S. iiif.

42 Vgl. DAvis, The Economics, S. $51 \mathrm{f}$.

${ }^{43}$ Vgl. ebd., S. 64.

${ }^{44}$ Brief an den Lord Chamberlain, 22.9.1880, TNA, LC 1/371.

45 Brief des Lord Chamberlain Office an H. A. Graham, Esq., 11.3.1881, TNA, LC 1/384.

46 Bill to abolish the powers of the Lord Chamberlain in respect of Stage Plays and to transfer to the Local Authority the powers of the Lord Chamberlain in respect of the Licensing of Theatres in London, Public BILls, 1908, Bd. V, Nr. 411, S. 551-559.

47 RePORT (1909), S. xv.

${ }^{48}$ Ebd., S. xvi. 
sodass letztlich die Arbeitsteilung, die sich zwischen dem Lord Chamberlain und dem London County Council herauskristallisiert hatte, unangetastet blieb. ${ }^{49}$ Nachdem mit Herbert Beerbohm Tree sogar die führende Figur des Londoner Theaters dafür plädiert hatte, Music Halls Theaterstücke aufführen zu lassen, ging allerdings das London County Council 1912 dazu über, dies zu gestatten - für die Zensur jedoch blieb weiterhin der Lord Chamberlain zuständig. ${ }^{50}$

Ebenso wenig wie der Theatre Act in Großbritannien markierte die Reform der Gewerbeordnung für das Deutsche Reich einen Schlusspunkt der Debatte über die Konzessionierung der Theater. Das Berliner Polizeipräsidium gab zwischen 1870 und 1880146 Konzessionen aus, von denen nur ein knappes Drittel an Theaterdirektoren oder Schauspieler, die Mehrzahl aber an Personen ging, die in den Augen der Polizei „mit der Kunst wenig oder nichts zu schaffen“ hatten. ${ }^{51}$ Nicht nur die Polizei bedauerte, „daß die Ertheilung der Concession nur in verschwindend kleiner Zahl versagt werden konnte" ${ }^{52}$ Auch vielen Konservativen erschien „die übergroße Vermehrung“ der Theater als ein „bedenklicher Uebelstand“. ${ }^{53}$ Der Staatsbeamte Ludwig Hahn veröffentlichte 1880 eine Streitschrift über Das deutsche Theater und seine Zukunft, in der er für die Mehrzahl der nach 1869 entstandenen Bühnen zu dem Schluss kam, „daß ihre gesammte Einrichtung und Leitung, ihr Repertoire und ihre Leistungen mit höheren Gesichtspunkten der dramatischen Kunst absolut nichts gemein haben ". 54

Als die konservative Reichstagsfraktion im selben Jahr einen Antrag auf Änderung des $\$ 32$ der Gewerbeordnung stellte, bezogen sich ihre Sprecher explizit auf Hahns Schrift, um die Notwendigkeit schärferer Gesetze zu untermauern. ${ }^{55}$ Dem Antrag lagen auch Petitionen der Genossenschaft dramatischer Autoren und Komponisten und des Präsidiums der Genossenschaft deutscher Bühnenangehöriger bei. Unklar ist allerdings, ob die Konservativen auf diese Petitionen reagierten oder ob sie sich ihrer lediglich bedienten. Jedenfalls sollte der Antrag die bisherige Regelung aufheben, der zufolge eine Theaterkonzession zu erteilen war, „wenn nicht Thatsachen vorliegen, welche die Unzuverlässigkeit des Nachsuchenden in Beziehung auf den beabsichtigten Gewerbebetrieb darthun". Stattdessen sollte die Konzession versagt werden, „wenn die Behörde aufgrund von Thatsachen die Überzeugung gewinnt, daß der Nachsuchende die zu dem beabsichtigten Gewerbebetrieb erforderliche Zuverlässigkeit, insbesondere in sittlicher, artistischer und finanzieller Hinsicht nicht besitzt “.56 Damit wäre die Gesetzeslage genau umgedreht worden: Hatte bislang die Polizeibehörde den Nachweis der

${ }^{49}$ Vgl. Thomas et al., Theatre Censorship, S. 69-107.

${ }^{50}$ Vgl. Burrows, Legitimate Theatre, S. $100 \mathrm{f}$.

51 VerWALTUNGS-BERICHT, S. 92.

52 Ebd.

53 ThUdichum, Bismarcks parlamentarische Kämpfe, S. 291.

${ }^{54}$ HaHN, Das deutsche Theater, S. 39.

55 Vgl. Verhandlungen des Reichstags, 4. Legislaturperiode, III. Session 1880, 2. Bd., Stenographische Berichte von der 38. Sitzung (26.4.1880), S.919-939, hier S. 924.

56 Ebd., S. 921. 
Unzuverlässigkeit des Antragstellers zu erbringen, wäre nun dieser gezwungen gewesen, seine Unbescholtenheit zu beweisen.

Der Protest der liberalen Abgeordneten war vorprogrammiert. Mit Eugen Richter, Mitglied der Fortschrittspartei, Bannerträger des Liberalismus und Kontrahent Bismarcks, schickten sie einen ihrer besten Redner in den Ring. Während die konservativen Antragsteller in die allgemeine Klage über den Niedergang des Theaters einstimmten, argumentierte Richter, die Berliner Theaterverhältnisse hätten sich nach der Reform von 1869 nicht verschlechtert, sondern verbessert. Ihm zufolge ging es den Konservativen mit ihrem Antrag auch gar nicht um das „Prinzip der Sittlichkeit“, sondern „um die Unterdrückung der billigen Volkstheater durch die Hoftheater". 57 Tatsächlich war den Hoftheatern infolge der Reform erstmals eine ernstzunehmende Konkurrenz erwachsen. Richter sah deshalb die Gesetzesvorlage als aristokratische Klientelpolitik. Dass der Gesetzesantrag einen Nachweis künstlerischer Zuverlässigkeit verlangte, wendete Richter in eine Spitze gegen Botho von Hülsen, den Intendanten der Berliner Hoftheater, der als „einfacher Gardeoffizier [...] seine Befähigung für das Theater dadurch dargelegt“" habe, dass „er im kleineren Kreise auf Liebhabertheatern ein gewisses Talent“ bewies. ${ }^{58}$ Der nationalliberale Abgeordnete Eduard Lasker maß dem Gesetzesvorschlag weit weniger Bedeutung zu, sah in ihm aber einen Angriff „der Reaktion“ gegen die liberale Gewerbeordnung. ${ }^{59}$

Die liberalen Parteien stimmten geschlossen gegen das Gesetz, unterlagen aber der Majorität von Konservativen und Zentrum. Das Reichsgesetz vom 15. Juli 1880 ergänzte $\$ 32$ der Gewerbeordnung wie geplant um die Bestimmungen zur Zuverlässigkeit des Theaterunternehmers. ${ }^{60}$ Die neue Fassung ermöglichte es der Polizei, die Konzessionen zu versagen, wenn der Antragsteller den Nachweis seiner Zuverlässigkeit nicht erbringen konnte. Ungeklärt blieb, wie er dieser Anforderung Folge zu leisten hatte. Darüber hinaus gestattete die Streichung des früheren Schlusssatzes von $\$ 32$, die Konzession auf bestimmte Gattungen zu beschränken. Tatsächlich änderte sich aber durch das Gesetz nur wenig. Das erweckt den Eindruck, den Konservativen sei es bei ihrem Gesetzesantrag weniger um die Sache gegangen, als darum, das liberale Reformwerk rückgängig zu machen. Auch im Bereich der Theaterpolitik trat Ideologie vor Realpolitik. ${ }^{61}$

Kaum war die überarbeitete Gewerbeordnung in Kraft getreten, kamen erneut Forderungen nach ihrer Verschärfung auf. ${ }^{62}$ In der Zwischenzeit hatte sich die

57 Ebd., S. 927.

58 Ebd., S.934; dieser Vorwurf findet sich schon bei Otto Wolff, Das Theater und die Volkswirthschaft, VIERTELJAHRESSCHRIFT FÜR VOLKSWIRTHSCHAFT UND CUlTuRGESCHICHTE 1 (1863), 2. Bd., S. 90-108, hier S. 95.

59 Vgl. ebd., S. 934-936, siehe auch Thudichum, Bismarcks parlamentarische Kämpfe, S. 293.

60 Gesetz, betreffend die Abänderung des $\$ 32$ der Gewerbeordnung vom 15. Juli 1880, REICHSGeSETZBLATT, 1880, Nr. 18, S. 179.

61 Vgl. Thudichum, Bismarcks parlamentarische Kämpfe, S. 292.

62 Vgl. Verhandlungen des Reichstags, V. Legislaturperiode, II. Session 1882/83, 2. Bd., Stenographische Berichte von der 3. Sitzung (5.5.1882), S. 15-38 und 5. Sitzung (8.5.1882), S. 4372 und 3. Bd., 59. Sitzung (6.4.1883), S. 1693-1724. 
Theaterlandschaft weiter ausdifferenziert. Neben die Theater im engeren Sinne war nun eine Vielzahl von Varietés getreten, die unter Begriffen wie Tingeltangel, Singspielhalle oder Spezialitätentheater firmierten. Sie waren das deutsche Äquivalent der britischen Music Hall und boten wie diese keine Theaterstücke im klassischen Sinne, sondern ein Programm aus Akrobatik, Tanz und Gesang. ${ }^{63}$ Gegen diese neuen Etablissements glaubte die Politik einschreiten zu müssen. Durch die Amendierung der Gewerbeordnung schuf der Reichstag 1883 eine neue Lizenz nach $\$ 33 \mathrm{a}$ :

Wer gewerbsmäßig Singspiele, Gesangs- und deklamatorische Vorträge, Schaustellungen von Personen oder theatralische Vorstellungen, ohne daß ein höheres Interesse der Kunst oder Wissenschaft dabei obwaltet, in seinen Wirthschafts- oder sonstigen Räumen öffentlich veranstalten oder zu deren öffentlicher Veranstaltung seine Räume benutzen lassen will, bedarf zum Betriebe dieses Gewerbes der Erlaubniß ohne Rücksicht auf die etwa bereits erwirkte Erlaubniß zum Betriebe des Gewerbes als Schauspielunternehmer. ${ }^{64}$

Wie in Großbritannien gab es nun auch in Deutschland zwei verschiedene Lizenzen: eine für Theater und eine für Varietés, allerdings mit dem Unterschied, dass diese aufeinander aufbauten, denn wer eine Singspielhalle betreiben wollte, benötigte eine Theaterlizenz nach $\$ 32$ und zusätzlich eine nach $\$ 33 a$. In den Augen des Gesetzgebers unterschieden sich die Varietés von den Theatern dadurch, dass ihnen „kein höheres Interesse der Kunst“ zugrunde lag, er differenzierte also zwischen hoher und niederer Kultur. In der Praxis verschwammen die Unterschiede. Das Metropol-Theater beispielsweise, in dem die französische Kabarett-Sängerin Yvette Guilbert auftrat und das mitunter sogar Ringkämpfe ausrichtete, ähnelte in vielem mehr einem luxuriösen Varieté nach Art der Folies-Bergère oder des Empire Theatres of Varieties als einem Theater. ${ }^{65}$ Die Formulierung vom höheren Kunstinteresse gab deshalb „häufig genug Stoff zur Heiterkeit“, denn wie sie zu fassen sein sollte, blieb offen. ${ }^{66}$ In den Augen der Schaubühne war diese Unterscheidung „kautschukartig, unbestimmt“ und öffnete „behördlicher Willkür Tür und Tor" ${ }^{67}$ Genau dies war jedoch das Ziel der Bestimmung: Sie sollte der Polizei einen größeren Spielraum geben, die Gründung neuer Varietés einzudämmen. Diese Strategie ging allerdings nicht auf, denn deren Zahl nahm weiterhin stetig zu. ${ }^{68} \mathrm{Ob}$ ein Etablissement Alkohol ausschenkte oder nicht, spielte in der Debatte im Unterschied zu Großbritannien keine Rolle, gab es in Deutschland doch genügend Theater, „in welchen während der Vorstellung geraucht und getrunken werden darf“ 69

${ }^{63}$ Vgl. BuCHNER, Varieté; GƯNTHER, Geschichte des Varietés; JANSEN, Varieté; Ret, Tingel-Tangel.

${ }^{64}$ Gesetz, betreffend Abänderung der Gewerbeordnung, in: ReichSGeSETZBLATT, Bd. 1883, S. 159176, hier S. 160.

65 Zum Programm des Metropol-Theaters siehe LAB, A. Pr. Br. Rep. 030-50-707 und 708.

${ }^{66}$ Die Arbeiten an einem Reichstheatergesetz, Die SChaubƯhne 5 (1909), 1. Bd., S.362-366, 391-395, 423-426, hier S. 365.

67 Ebd.

${ }^{68}$ Vgl. Hoelger, Reglementierung.

${ }^{69}$ Urteil des Oberverwaltungsgerichts vom 15. Mai 1902, zit. n. GoldBAUM, Theaterrecht, S. 39. 
Offen blieb die Frage, wie die Polizei feststellen wollte, ob ein Antragsteller in „sittlicher, artistischer und finanzieller Hinsicht“ zuverlässig war, ein Problem, das bereits bei der Verhandlung des Gesetzes im Reichstag für Kritik gesorgt hatte. $^{70}$ Eine preußische Ministerialverfügung empfahl deshalb 1893, „den Vorstand eines der beiden Bühnenvereine [...] um Auskunft zu ersuchen "71 Gemeint waren der Deutsche Bühnenverein und die Genossenschaft Deutscher Bühnenangehöriger, das heißt die Interessenvertretungen der Theaterdirektoren und der Schauspieler. ${ }^{72}$ Das Berliner Polizeipräsidium folgte dieser Aufforderung. Als Richard Schultz beispielsweise 1897 eine Konzession für das Metropol-Theater beantragte, forderte die Behörde bei der Genossenschaft Deutscher Bühnenangehöriger ein Gutachten an. Die Genossenschaft empfahl Schultz ohne Vorbehalte für die Position, da dieser nicht nur als Schauspieler, sondern auch als Leiter einer Theatertournee und des Berliner Central-Theaters erhebliche Erfahrungen gesammelt habe und nicht negativ aufgefallen sei. ${ }^{73}$ Als sich nach dessen Ausscheiden 1919 sein Kompagnon Fritz Paul Jentz um eine Konzession bewarb, empfahl die Genossenschaft, ihm diese zu versagen, da er bislang nur mit den geschäftlichen Belangen des Theaters zu tun gehabt hatte. Erst als Jentz angab, einen künstlerischen Leiter bestellen zu wollen, ließ sie ihre Bedenken fallen. ${ }^{74}$

Um seine finanzielle Vertrauenswürdigkeit nachzuweisen, musste ein Theaterunternehmer anfangs im Rahmen seines Konzessionsantrags die nötigen Mittel zum Betrieb des Theaters nachweisen. Dies erwies sich jedoch zunehmend als nicht praktikabel, denn die nötigen Mittel waren, wie Max Epstein wusste, „natürlich zu verschaffen“: „Gute Freunde waren immer bereit; aber die Sachen hatten ein Nachspiel. Unten auf der Strasse waren alle Eingänge des Präsidiums mit Gläubigern besetzt, die dem Direktor das Geld auf einige Minuten geliehen hatten und die nun ängstlich aufpassten, dass er nicht etwa durch einen anderen Ausgang ins Freie gelangte “. ${ }^{5}$ Der Nachweis der Betriebsmittel war folglich kein geeignetes Mittel, um die finanzielle Zuverlässigkeit eines Antragstellers sicherzustellen. Da es immer öfter zu Theaterpleiten kam, bei denen meist die Schauspieler die Leidtragenden waren, wurde die finanzielle Frage immer wichtiger. Deshalb setzte sich die Praxis des Sperrfonds durch: Jeder Theaterunternehmer musste zur „Sicherung des Personals [...] bei der Polizei eine größere Kaution hinterleg[en] [...], die bei Zahlungsunfähigkeit des Direktors verfiel und unter

70 Verhandlungen des Reichstags, 4. Legislaturperiode, III. Session 1880, 2. Bd., Stenographische Berichte von der 38. Sitzung (26.4.1880), S.919-939, hier S.934f.

${ }^{71}$ Ministerial-Blatt 53 (1893), S. 104; siehe hierzu Opet, Deutsches Theaterrecht, S. 57; GoldBAUM, Theaterrecht, S. 32 .

$72 \mathrm{Zu}$ den Interessenvertretungen siehe die entsprechenden Abschnitte in Kapitel 3.2 und 4.1.

${ }^{73}$ Vgl. Gutachten der Genossenschaft Deutscher Bühnenangehöriger, LAB, A. Pr. Br. Rep. 03005 Nr. 3061.

74 Vgl. Gutachten der Genossenschaft Deutscher Bühnenangehöriger, LAB, A Pr. Br. Rep. 030-05 Nr. 2375.

${ }^{75}$ Epstein, Theater als Geschäft, S. 35. 
die Schauspieler verteilt wurde" ${ }^{76}$ So musste Fritz Paul Jentz 1919 eine Kaution von 100000 Mark hinterlegen, als er das Metropol-Theater übernahm. ${ }^{77}$ Dieses Verfahren wurde international als vorbildlich betrachtet. Die Actors Association, die Interessenvertretung der britischen Schauspieler, wollte ein Gesetz durchsetzen, „such as exists in Germany, which compels every person embarking on a theatrical enterprise to deposit in safe keeping a sum of money sufficient to cover all salaries for a given period“ ${ }^{78}$

Eine weitere Amendierung des Theaterparagraphen der Gewerbeordnung erfolgte erst 1896. Dabei wurde festgelegt, dass jeder, der „dramatische Vorstellungen irgendwelcher Art“ abhalten wollte, einer Genehmigung nach $\$ 32$ bedurfte, wodurch vor allem Theateraufführungen in Gastwirtschaften ein Riegel vorgeschoben werden sollte. ${ }^{79}$ Abgesehen von der Wiedereinführung der Bedürfnisfrage während des Ersten Weltkrieges änderte sich danach an der Theatergesetzgebung bis 1934 nichts Wesentliches. ${ }^{80}$ Die Diskussionen um die gesetzliche Behandlung der Theater gingen allerdings weiter. Vor allem die Genossenschaft Deutscher Bühnenangehöriger rief kontinuierlich nach der Verabschiedung eines umfassenden Reichstheatergesetzes. ${ }^{81}$ Diese Forderungen wurden auch immer wieder im Reichstag aufgegriffen, wobei vor allem die soziale Situation der Bühnenangehörigen im Mittelpunkt stand. ${ }^{82}$ Zur Verabschiedung eines solchen umfassenden Gesetzes kam es jedoch nicht. ${ }^{83}$ Auch die Hoffnung der Schauspieler nach 1918, dass die Republik ihren Forderungen nachkommen würde, erfüllte sich nicht. Ein Reichsbühnengesetz erwies sich trotz zahlreicher Ansätze letztlich als nicht durchsetzungsfähig. ${ }^{84}$ Die Gewerbeordnung blieb deshalb während der gesamten Weimarer Republik die rechtliche Grundlage für die Konzessionierung und den Betrieb von Theatern. ${ }^{85}$

Die unterschiedlichen Konzessionen, ihre Anforderungen und Bestimmungen mögen im Einzelnen verwirrend sein, wichtig ist vor allem, dass sowohl in London wie in Berlin zwei verschiedene Konzessionen existierten. An die Stelle der

76 Bernauer, Das Theater, S. 166; siehe auch EPSTEIN, Theater als Geschäft, S. 35-36; GoldBAUM, Theaterrecht, S. 32-36; AssmanN, Die Theaterspielerlaubnis, S. 18-20.

77 Vgl. die Polizeiakte von Jentz, LAB, A Pr. Br. Rep. 030-05 Nr. 2375.

78 Armstrong, Actor's Companion, S. 165.

79 Vgl. Dritter Verwaltungsbericht, S. 377; Hoelger, Reglementierung, S. 39.

80 Vgl. SteinbaCH, Gewerbeordnung, S. 45.

81 Vgl. Wie dringend notwendig ein Reichstheatergesetz ist, DER NEUE WEG 39 (1910), S.68; siehe auch HochDORF, Die deutsche Bühnengenossenschaft, S. 204 f., 247.

82 66. Bericht betreffend Erlaß eines Reichstheatergesetzes, VERHANDLUNGEN DES REICHSTAGS, 12. Legislaturperiode, II. Session 1911, 4. Bd., Stenographische Berichte von der 166. Sitzung (4.5. 1911), S.6356-6358; Resolution Nr. 237, Anlagen zu den Stenographische Berichte über die Verhandlungen des Reichstags, 13. Legislaturperiode, I. Session, Bd. 298, S. 222 f.

${ }^{83}$ Vgl. SeELIG, Reichstheatergesetz; WolfF, Der Entwurf; Reichstheatergesetz, Die SCHAUbüHne 9 (1913), 1. Bd., S. 11-13, 69-74; siehe auch GIESING, Ibsens Nora, S. 277.

84 Antrag Nr. 284 und Antrag Nr. 366, Anlagen zu den Stenographischen Berichten über die Verhandlungen des Reichstags, III. Wahlperiode 1924, Bd. 398.

85 Vgl. Gregori, Der Schauspieler, S. 130; SteinbaCH, Gewerbeordnung, S. 45; Hoffmann, Theaterrecht. 
alten Unterscheidung zwischen patent theatres und minor theatres beziehungsweise zwischen Hoftheatern und Vorstadtbühnen trat die zwischen Theatern und Varietés. Obwohl das bestehende Konzessionssystem für viele unbefriedigend war, war doch insofern gegenüber dem frühen 19. Jahrhundert ein Fortschritt erzielt worden, als das alte Privilegiensystem durch ein modernes, gesetzlich kodifiziertes und transparentes Verfahren ersetzt worden war. Wer immer ein Theater oder eine Music Hall betreiben wollte, der wusste, an welche Institution er sich zu wenden hatte, und für alle Konzessionäre galt dasselbe Recht. Freilich war in London die Situation noch komplizierter als in Berlin, da mit dem Lord Chamberlain und den städtischen Behörden unterschiedliche Institutionen für die Konzessionierung zuständig waren.

Gegen Ende des 19. Jahrhunderts entstand dann mit dem Kino abermals eine neue Unterhaltungssparte. Da Filme anfangs vor allem auf Jahrmärkten und in Varietés zu sehen waren und damit an Orten, die bereits staatlich überwacht wurden, stellte sich zunächst die Frage nach einer neuen Konzession nicht. Das änderte sich allerdings mit dem Bau der ersten Kinos. In Berlin wurden diese nach $\$ 33 \mathrm{~b}$ der Gewerbeordnung wie Varietés konzessioniert. ${ }^{86}$ In London kontrollierten die lokalen Behörden die Kinos, wobei sie sich auf den Disorderly House Act von 1751 beriefen. Eine klare Rechtslage wurde erst mit dem Cinematograph Act von 1909 geschaffen. Dieser führte eine verpflichtende Lizenz ein, erließ verbindliche feuerpolizeiliche Vorschriften und gab den Behörden das Recht, den Kinos Auflagen zu machen und deren Einhaltung zu überwachen. ${ }^{87}$ Aus der Sicht des Gesetzgebers war das Kino zunächst nicht mehr als eine weitere Vergnügungsstätte, die kontrolliert werden musste, um die Sicherheit des Publikums und die Wahrung der öffentlichen Ordnung sicherzustellen. Dabei orientierte er sich an den bestehenden Gesetzen: In Deutschland wurde bloß der Geltungsbereich der Gewerbeordnung erweitert; in Großbritannien wurde zwar mit dem Cinematograph Act ein neues Gesetz erlassen, dessen Bestimmungen aber erinnerten stark an diejenigen für Theater und Music Halls. Die Erfahrungen, die der Gesetzgeber im Laufe des 19. Jahrhunderts mit diesen Medien gesammelt hatte, prägten also auch seinen Umgang mit dem neuen Medium Kino.

\section{Theaterpolizei}

Für die tägliche Arbeit der Theater spielten der Theatre Act und die Gewerbeordnung eine weit geringere Rolle als die sicherheits- und feuerpolizeilichen Bestimmungen, die von den städtischen Behörden erlassen wurden. Brände in Theatern mit zum Teil hohen Opfern an Menschenleben gab es bis zum Ende des 19. Jahrhunderts immer wieder. In den hundert Jahren zwischen 1797 und 1897 kam es

${ }^{86}$ Vgl. Hellwig, Rechtsquellen, S.37; ders., Öffentliches Lichtspielrecht, S. 8; BiretT (Hrsg.), Verzeichnis in Deutschland gelaufener Filme, S. 20, 94.

87 Vgl. Kunn, Cinema, Censorship and Sexuality, S.15-17; Chanan, The Dream That Kicks, S. $158-160$. 
weltweit zu 1115 größeren Theaterbränden, von denen 139 in Großbritannien, 101 in Deutschland und 93 in Frankreich zu verzeichnen waren. ${ }^{88}$ Zwei der schlimmsten Brandkatastrophen ereigneten sich im Jahr 1881: der Brand des Stadttheaters von Nizza kostete 200, der des Ringtheaters in Wien 450 Menschen das Leben. ${ }^{89}$ Obwohl auch zuvor schon Bestimmungen zur Brandvermeidung existiert hatten, wurden sie danach grundlegend überarbeitet und die bestehenden Theater einer Überprüfung unterzogen. ${ }^{90}$

In London war der Lord Chamberlain neben der Konzessionierung anfangs auch für die feuerpolizeiliche Sicherheit der Theater verantwortlich. ${ }^{91}$ Diese Funktion trat er jedoch an das Metropolitan Board of Works (MBW) ab, jenen 1855 gegründeten Zweckverband, der sich aus Vertretern der einzelnen Londoner Gerichtsbezirke zusammensetzte und eine bis dahin nicht vorhandene bezirksübergreifende kommunale Verwaltung bilden sollte. ${ }^{92}$ Die Verabschiedung des Metropolis Management and Building Act Amendment Act von 1878 bevollmächtigte das MBW, Vorschriften zur baulichen und feuerpolizeilichen Sicherheit der Theater zu erlassen und ihre Einhaltung durch regelmäßige Inspektionen zu überwachen - und das auch bei den Theatern, die bereits vom Lord Chamberlain lizenziert worden waren. Das Gesetz untersagte überdies die Eröffnung neuer Theater oder Music Halls, ohne dass das MBW zuvor bestätigt hatte, dass diese den Vorschriften entsprachen. Im Falle eines Missstandes besaß es die Vollmacht, den Besitzer des Gebäudes zur Behebung desselben zu zwingen. ${ }^{93}$ Überdies musste nunmehr jeder Theaterbetreiber Baupläne vorlegen, die von einem Architekten des MBW begutachtet wurden. Das galt ebenso für bereits existierende Gebäude oder architektonische Veränderungen. ${ }^{94}$ Erst wenn das MBW seine Zustimmung erteilt hatte, gewährte der Lord Chamberlain die Lizenz oder erneuerte sie. Wegen Korruption und Misswirtschaft wurde das MBW 1888 abgeschafft. An seine Stelle trat nun das effektivere London County Council (LCC), die erste, ganz London umfassende und direkt gewählte Gemeindebehörde. ${ }^{95}$ Sie übernahm vom MBW die Kompetenzen zur Regulierung und Überwachung der Theater, mit denen sie einen eigenen Ausschuss, das Theatre and Music Halls Committee, beauftragte. MBW und LCC waren darum bemüht, die Anzahl der Sitzplätze in den Theatern $\mathrm{zu}$ verringern, um so deren sichere Entleerung im Brandfall zu garantieren. Im

88 Vgl. SACHS, Modern Opera Houses and Theatres, S. 127-132.

89 Ebd., S. 133.

90 Vgl. UnRUH, Theaterbau und Bühnentechnik, S. 124; siehe auch HofFMANN, Die Theaterbauten, S. 22-27; ZIELSKE, Deutsche Theaterbauten, S. 41-42; FrEYDANK, Theater in Berlin, S. 305; BоoтH, Theatre, S. 67-70; BuCK, Thalia in Flammen, S. 171-183; DAVIs, The Economics, S. 7584; ITODA, Berlin \& Tokyo, S. 105-107.

91 Vgl. DaVIS, The Economics, S. 78.

92 Vgl. PORTER, London, S. 240-242.

93 Vgl. Metropolis Management and Building Acts Amendment Act (41/42 Victorianc. 32), in: FLETCHer (Hrsg)., The London Building Acts, S.267-301; siehe auch RePORT (1892), S.iv; Stuart, Variety Stage, S. 211 f.; Schumacher (Hrsg.), Naturalism and Symbolism, S. 30 f.

94 Vgl. PORTER, London, S. 240-242.

95 Vgl. ebd., S. 240, 256. 
Drury Lane sank sie von 3000 auf 2500, im Britannia Theatre von 3923 auf 3450, im Standard Theatre von 3400 auf 2800 und im St. James's Theatre von 1220 auf 1000. Die neu lizenzierten Theater im West End besaßen ohnehin selten mehr als 1200 Sitzplätze. ${ }^{96}$

Nach den Brandkatastrophen von Nizza und Wien wurden die feuerpolizeilichen Bestimmungen weiter verschärft. ${ }^{97}$ Seitdem waren auf der Rückseite jeder Lizenz die Rules and Regulations with Regard to Theatres in the Jurisdiction of the Lord Chamberlain abgedruckt. Sie umfassten zunächst 32 Punkte, von denen sich rund die Hälfte auf die feuerpolizeiliche Sicherheit bezogen: Jeder Bereich des Zuschauerraums musste über zwei Ausgänge verfügen, die nicht versperrt sein durften, außerdem mussten Vorkehrungen für das Löschen von Feuern getroffen werden. ${ }^{98}$ Die Betreiber der Theater empfanden die Vorschriften als Gängelei. John Hollingshead etwa warf den städtischen Behörden vor, ihrerseits die Gesundheit der Theaterbesucher zu gefährden: „Where one person was burnt to death in a theatre fire in half a century [...] by reason of faulty exits, many hundreds are now killed every year [...] by pneumonia and kindred diseases, caught in the theatres with ,extra exits“" 99

Die Einhaltung der Bestimmungen wurde durch eine jährliche Inspektion sichergestellt. Neben dieser Generalinspektion wurden die Theater im Bedarfsfall besichtigt. So beschwerte sich 1900 ein Theaterbesucher über die Überfüllung im Gaiety Theatre, woraufhin das LCC das Theater inspizierte und die Richtigkeit des Vorwurfs feststellte. Manager George Edwardes wurde auf die Bestimmungen hingewiesen und verwarnt. Dennoch erwies sich bei erneuter Inspektion, dass der Missstand nicht behoben worden war. ${ }^{100}$ Dieses Spiel wiederholte sich in regelmäßigen Abständen: auf Beschwerden folgten Inspektionen, die für vorübergehende Abhilfe sorgten, bis es erneut zu Beschwerden kam. ${ }^{101}$ Die Lizenz des ebenfalls von George Edwardes geleiteten Daly's Theatre wurde 1904 fast nicht erneuert, weil es die Anforderungen des London County Council nicht erfüllt hatte. ${ }^{102}$

Wie diese Beispiele zeigen, nahm das Theatre and Music Halls Committee seine Aufsichtspflicht über die Theater sehr ernst. Darüber hinaus fügte es den zu beachtenden Regeln von Jahrzehnt zu Jahrzehnt neue hinzu, bis sie sich 1925 auf 90 Punkte verdreifacht hatten - ein deutliches Zeichen für die zunehmende

96 Bоотн, Theatre, S. 68.

97 Vgl. ZIELSKE, Deutsche Theaterbauten, S. $41 \mathrm{f}$.

98 Rules and Regulations with Regard to Theatres in the Jurisdiction of the Lord Chamberlain, 29. 9. 1881, TNA, LC 1/385; nachgedruckt in: SCHUMACHER (Hrsg.), Naturalism and Symbolism, S. 364-367.

99 Hollingshead, Gaiety Chronicles, S. 348.

100 Brief des London County Council an das Lord Chamberlain's Office, 29.3. 1900, TNA, LC $1 / 730$.

101 Vgl. Briefwechsel zwischen LCC und Lord Chamberlain's Office, 3.3., 4.3. und 5.3. 1909, BL, 83495 A; Briefe des LCC an das Lord Chamberlain's Office, 2.9. und 29.9. 1909, BL, 83495 A.

102 Brief des Lord Chamberlain's Office an George Edwardes, 24. 12. 1904, BL, 83513 A. 
Regulierung der Theater durch Gesetze und Vorschriften. ${ }^{103}$ Die Zeiten, in denen ein Theatermanager weitgehend selbst für sein Theater und dessen Sicherheit zuständig war, waren vorbei. Nun war er nicht mehr nur dem Lord Chamberlain gegenüber rechenschaftspflichtig und musste die Stücke, die er aufführen wollte, zur Zensur vorlegen; er musste auch den Regeln der städtischen Behörden genügen, die immer neue Vorschriften erließen und sein Theater regelmäßig inspizierten.

In Berlin sah es kaum anders aus, denn auch hier traten neben die Gewerbeordnung, die die Konzessionierung der Theater regelte, eine Reihe von Verordnungen, angefangen bei der Polizeiverordnung über öffentliche Theater und ähnliche Vorstellungen vom 10. Juli 1851. ${ }^{104}$ Ihre Bestimmungen unterschieden sich kaum von denen der dreißig Jahre später veröffentlichten Rules and Regulations. Die meisten von ihnen betrafen die Feuersicherheit der Theatergebäude. Darüber hinaus waren vor dem Bau eines neuen Theaters Pläne vorzulegen, die in sicherheits- und feuerpolizeilicher Hinsicht geprüft wurden. Wie das LCC konnte auch das Polizeipräsidium bei bereits bestehenden Bauten nachträgliche Anordnungen erlassen, eine Möglichkeit, von der es „vielfach und in ausgedehntem Umfange Gebrauch“ machte. ${ }^{105}$ Noch vor der Brandkatastrophe in Wien hatte die Berliner Polizei die Allgemeinen ortspolizeilichen Vorschriften über die Feuerpolizei in den Theatern Berlins erlassen. ${ }^{106}$ Nun hielt der preußische Innenminister Robert Viktor von Puttkamer den Polizeipräsidenten von Berlin, Guido von Madai, aufgrund der „inzwischen eingetretene[n] erschütternde[n] Katastrophe im Ringtheater in Wien“ dazu an, die wenige Monate zuvor erlassenen Bauvorschriften auch in die Tat umzusetzen. Die „als erforderlich erkannten Maßregeln zum Schutze des Publikums“ sollten sofort ergriffen und die „Schutz- und SicherheitsApparate “ beim Beginn jeder Vorstellung überprüft werden. ${ }^{107}$ Daraufhin führte die Polizei 1881 eine Generalrevision sämtlicher Berliner Theater durch, in deren Anschluss sie zum Teil erhebliche bauliche Veränderungen verfügte. ${ }^{108}$ Dass die Polizei bei der Durchsetzung der Bestimmungen keineswegs zimperlich war, zeigt der folgende Brief an die Direktion des Belle-Alliance-Theaters:

In Ergänzung der ortspolizeilichen Vorschriften über die Feuerpolizei in den Theatern Berlin's vom 29. Juni 1881 wird hiermit angeordnet, daß die gesammte Holzconstruction der Bühne, das Holzwerk aller Requisiten und Decorationen, die Soffiten und Gaze sowie die zur Neuanfertigung von Decorationen zu verwendende Leinwand durch Imprägnierung unentflammbar zu machen sind. Die stattgefundene Imprägnierung ist durch einen Stempel des betreffenden

103 Rules and Regulations with Regard to Theatres in the Jurisdiction of the Lord Chamberlain, 1925, TNA, BT 31/31087/25934.

104 Vgl. Amtsblatt, Stück 29, 18.7. 1851; Verwaltungs-Bericht, S. 65; siehe auch Hoelger, Regulierung, S.23f.

105 VerWALTUNGS-Bericht, S. 65.

106 Allgemeine ortspolizeiliche Vorschriften über die Feuerpolizei in den Theatern Berlins, ebd., S. 67-69.

107 Innenminister Puttkamer an Polizeipräsident von Madai, LAB, A Pr. Br. Rep. 030-05 241, zit. nach ITODA, Berlin \& Tokyo, S. $105 \mathrm{f}$.

108 Ebd. 
Fabrikanten an einer sichtbaren Stelle der imprägnierten Gegenstände erkennbar zu machen. Sollte die Direktion dieser Anordnung nicht innerhalb 4 Wochen nachgekommen sein, so werden die gesetzlichen Zwangsmaßregeln zur Anwendung gebracht und eventl. die Schließung des Belle-Alliance-Theaters in Erwägung genommen werden. ${ }^{109}$

Anders als das London County Council und der Lord Chamberlain, die oft die Manager viele Male ermahnten und vorluden, drohte die Berliner Polizei selbst bei nur geringen Verstößen mit der Schließung eines Theaters. Wie in London nahm auch in Berlin die Zahl der einzuhaltenden Regeln und Bestimmungen über die Jahre immer weiter zu, allen voran durch die Polizei-Verordnung betreffend die bauliche Anlage und die innere Einrichtung von Theatern, Circusgebäuden und öffentlichen Versammlungsräumen vom 31. Oktober 1889. ${ }^{110}$ Aus den 15 Paragraphen der Polizeiverordnung von 1851 waren nun 87 geworden, die detaillierte Vorschriften zur Anlage der Theater, zur Beleuchtung, Heizung und zu den Feuerlöscheinrichtungen machten. Damit hatte sich der Umfang der Tätigkeiten der Theaterpolizei so erweitert, dass das Innenministerium 1900 eine eigene Unterabteilung für Theaterangelegenheiten ins Leben rief, die für die Konzessionierung der Theater, die Zensur der Stücke, die Einhaltung der bau- und feuerpolizeilichen Maßnahmen und die Überwachung des Billetthandels zuständig war. ${ }^{111}$ Die wachsende Regulierung wurde von den Theaterdirektoren begreiflicherweise kritisch gesehen, dennoch war sie nicht ohne Erfolg, denn weder in London noch in Berlin kam es nach 1900 zu größeren Theaterbränden, wie sie zu Beginn des 19. Jahrhunderts noch an der Tagesordnung gewesen waren.

\section{Verstaatlichung}

In Großbritannien kam die Theatergesetzgebung mit dem Theatre Act von 1843 und dem Licensing Act von 1872 weitgehend zum Abschluss. Die Empfehlungen und Gesetzesentwürfe der verschiedenen Untersuchungsausschüsse scheiterten sämtlich am Parlament und an den zuständigen Ministerien und Behörden. Wenngleich das London County Council über den Verordnungsweg immer stärker in den Theaterbetrieb eingriff, blieben die gesetzlichen Regelungen aus viktorianischer Zeit bis zum Zweiten Weltkrieg und über diesen hinaus weitgehend unverändert in Kraft. Auch in Deutschland änderte sich trotz der sukzessiven Verschärfung der Anforderungen an die Theaterunternehmer bis zum Ersten Weltkrieg relativ wenig. Bestimmungen wie der Nachweis der Zuverlässigkeit oder der Sperrfond verhinderten letztlich nicht, dass immer mehr neue Theater und Varietés eröffneten.

109 Brief des Polizeipräsidiums an die Direktion des Belle-Alliance-Theaters, 20. 10. 1885, LAB, A Pr. Br. Rep. 030-03-451.

110 Polizei-Verordnung betreffend die bauliche Anlage und die innere Einrichtung von Theatern, Circusgebäuden und öffentlichen Versammlungsräumen, 31.10.1889, CENTRALBLATT Der Bauverwaltung 9 (1898), Nr. 48, S. 447-456; siehe auch Zweiter VerWaltungs-Bericht, S. 69.

111 Vgl. Dritter Verwaltungsbericht, S. $372 \mathrm{f}$. 
Nach dem Krieg kam es dann zu mehreren wichtigen Veränderungen. Zwar blieben die Theater weiterhin der Gewerbeordnung unterstellt, aber der Staat wurde nun erstmals selbst zum Theaterbetreiber. Mit der Ausrufung der Republik und der Abdankung Wilhelms II. stellte sich nämlich die Frage, was zukünftig mit den Hoftheatern passieren sollte. Noch am Abend des 9. November 1918 trat im Reichstagsgebäude der Rat der Intellektuellen zusammen, der hauptsächlich aus Künstlern der Avantgarde bestand und der ein Manifest veröffentlichte, das die Übernahme der Hoftheater durch den Staat forderte. ${ }^{112}$ Am folgenden Tag legte Georg von Hülsen-Haeseler, der Generalintendant der Königlichen Schauspiele, seine Ämter nieder, woraufhin Oper und Schauspielhaus am 14. November dem neu gebildeten preußischen Ministerium für Wissenschaft, Kunst und Volksbildung unterstellt wurden. ${ }^{113}$ Diese Entscheidung bedeutete einen weitreichenden Paradigmenwechsel, denn die Hoftheater waren zwar letztlich aus Steuermitteln unterhalten worden, unterstanden aber allein dem Kaiser, der den Intendanten benannt und persönlich in den Betrieb der Bühnen eingegriffen hatte. ${ }^{114}$ Nun übernahm zum ersten Mal der preußische Staat Theater in eigener Regie. Zu ihnen gehörten auch die ehemaligen Hofbühnen in Kassel und Wiesbaden und seit 1923 das Schiller-Theater in Charlottenburg sowie seit 1924 die Staatsoper am Platz der Republik. Ursprünglich waren die Pläne sogar noch ehrgeiziger gewesen. Ein Entwurf zu einem Rahmengesetz über die Kommunalisierung von Wirtschaftsbetrieben von 1919 hatte vorgesehen, alle Theater zu verstaatlichen, ein Vorhaben, das schon damals kaum realistisch war und nach dem Kapp-Putsch endgültig aufgegeben wurde. ${ }^{115}$ Nur Abgeordnete der Kommunistischen Partei forderten noch 1924, der „Reichstag wolle beschließen: Sämtliche Stätten gewerbsmäßiger Bühnenkunst, Film- und Varietédarbietungen sowie die gesamte Filmproduktion [...] in die Hand des Reichs“ zu überführen - wenn schon nicht die Industrie, dann sollte wenigstens die Kultur Staatsmonopol sein. ${ }^{116}$ Die SPD unterstützte diese Bestrebungen nicht. Das werten Manfred Boetzkes und Marion Queck in ihrer Geschichte des Berliner Theaters in der Weimarer Republik als eine „Niederlage für die sozialdemokratische Kulturtheateridee“.117

Mit der Übernahme der Hoftheater durch den Staat erfüllte sich eine Forderung, die deutsche Intellektuelle seit langer Zeit erhoben hatten. So hatte Maximilian Harden schon 1888 gemeint, das Theater bedürfe nur zweier Dinge, um zu florieren: „Geld vom Staat und Interesse vom Publikum“.118 Der Verleger August Scherl empfahl 1898, die Theater müssten „losgelöst [...] von allen pekuniären Interessen“ geführt werden, wozu „die Stadt Berlin [...] die Theater bauen und in

112 Vgl. LaQueur, Weimar, S. 139.

113 Vgl. OтTо, Lindenoper, S. 258-261.

114 Vgl. FÖRSTER, Kulturpolitik im Dienst der Legitimation.

115 Vgl. Entwurf zu einem Rahmengesetz über die Kommunalisierung von Wirtschaftsbetrieben; siehe auch BoETZKES und QUECK, Die Theaterverhältnisse, S. 698.

116 Antrag Hoernle, Torgler und Genossen, Anlagen zu den Stenographischen Berichten über die Verhandlungen des Reichstags, III. Wahlperiode, 1924/25, Bd.399, Nr. 778.

117 BoetZKes und QuecK, Die Theaterverhältnisse, S. 699.

118 Harden, Berlin als Theaterhauptstadt, S. 10. 
eigene Verwaltung übernehmen“ müsse. ${ }^{119}$ Und auch Ludwig Seelig, Vertreter des Kartells der Verbände der deutsch-österreichischen Bühnen- und Orchestermitglieder, forderte, Staat und Gemeinden müssten „das Theater im ganzen planmäßig und nach großen Gesichtspunkten organisieren und dotieren“.120

Bis zum Ersten Weltkrieg konnten solche Forderungen kaum auf Realisierung hoffen, doch mit der Revolution und der Frage nach der Zukunft der Hoftheater bekamen sie neue Bedeutung - der „Schrei nach Sozialisierung“ des Theaters wurde lauter. ${ }^{121}$ Der Ökonom Hermann Levy war einer der wenigen, der die Forderung nach Verstaatlichung kritisch sah, denn auch für das Theater gelte: noch nie habe „das Staatsmonopol billig gearbeitet“.122 Sein Einwand erwies sich schon bald als zutreffend, denn die von Jahr zu Jahr steigenden Subventionen entwickelten sich schnell zu einer Belastung für den preußischen Staat. Schon 1920 musste er Zuschüsse im Bereich von neun Millionen Reichsmark gewähren, allein zwischen 1926 und 1929 stiegen die Subventionen um 40 Prozent. ${ }^{123}$ Dass der privatwirtschaftliche Sektor durch die Verstaatlichung unberührt blieb, wie Boetzkes und Queck meinen, stimmt nicht, denn die Subventionen hatten eine erhebliche Wettbewerbsverzerrung zur Folge. Zudem waren die Berliner Hoftheater keineswegs die einzigen Bühnen, die von der öffentlichen Hand übernommen wurden. Auch viele Stadttheater, die im Kaiserreich meist als Pachtbetriebe geführt worden waren, wurden nach 1919 kommunalisiert. ${ }^{124}$

Die Verstaatlichung, die mit der Übernahme der Hoftheater 1918 begonnen hatte, schritt nach der Machtübernahme der Nationalsozialisten 1933 rapide voran. Die Nationalsozialisten waren es auch, die die Forderung nach einer Herauslösung des Theaters aus der Gewerbeordnung erfüllten, in dem sie am 15. Mai 1934 ein Reichstheatergesetz verabschiedeten. Dort hieß es in $\$ 1$ Absatz 1: „Die im Reichsgebiet unterhaltenen Theater unterstehen hinsichtlich der Erfüllung ihrer Kulturaufgabe der Führung des Reichsministers für Volksaufklärung und Propaganda als zuständigem Minister" ${ }^{125}$ In der Praxis veränderte sich allerdings nur die Zuständigkeit, wobei die Zulassungsbedingungen gleichzeitig erheblich verschärft wurden. Die Konzession wurde nun nicht mehr von der Polizei, sondern von einer „sich künstlerisch inspiriert gerierenden Behörde“ vergeben. ${ }^{126}$

119 SCHERL, Berlin hat kein Theaterpublikum, S. 14.

120 SEELIG, Geschäftstheater oder Kulturtheater?, S. 27.

121 Hermann Levy, Gedanken über Theater und Wirtschaft, Das Junge Deutschland 3 (1920), Nr.5/6, S. 177-185, hier S. 179; siehe auch Julius Bab, Die Sozialisierung des Theaters, DiE NEUE RundSCHAU 24 (1913), Nr.3, S.417-425; Max Epstein, Sozialisierung des Theaters, DIE WeltbÜhne 14 (1918), Bd.2, S.580-584; Richard Rosenheim, Sozialisierung des Theaters, ebd. 15 (1919), Bd. 1, S. 90-93; NeSTRIEPKE, Sozialisierung des Theaters.

122 Ebd.

123 Vgl. SChultze, Untersuchungen, 1. Bd., S. 353; Dussel, Ein neues, ein heroisches Theater?, S. 25.

124 Vgl. Nestriepke, Die Kommunalisierung; Zielske, Theaterbauten, S.66; Hermand und Trommler, Die Kultur der Weimarer Republik, S. 193.

125 Theatergesetz vom 15. Mai 1934, ReichsgesetzBLATt, Teil 1, 1934, Nr. 56, S. 411-413, hier S. 411.

126 Dussel, Ein neues, ein heroisches Theater?, S. 59; siehe auch Hoffmann, Theaterrecht; HerTERICH, Theater und Volkswirtschaft; AsMUsSEN, Die Geschichte des deutschen Theaterrechts, S. 97-100. 
Das bereits durch Inflation und Weltwirtschaftskrise schwer in Bedrängnis geratene Berliner Geschäftstheater war damit angezählt. In den folgenden Jahren übernahm das Propagandaministerium schrittweise immer mehr Theater. Hatten sich vor dem Ersten Weltkrieg etwa 90 Prozent aller deutschen Theater in privater Hand befunden, hatte sich das Verhältnis bereits in der Weimarer Republik umgekehrt: schon in der Spielzeit 1933/34 betrug der Anteil der kommunalen oder staatlichen Theater 82,8 Prozent, bis 1937/38 erhöhte er sich auf 90,2 Prozent. ${ }^{127}$ Bald schlug auch die letzte Stunde für das Metropol-Theater. Am 24. Juli 1937 schrieb Joseph Goebbels in sein Tagebuch: „Ich will Metropoltheater in Berlin kaufen. Und ganz groß darin herauskommen. Führer begeistert von meinem Plan“.128 Am 1.August 1938 wurde es vom Propagandaministerium übernommen. ${ }^{129}$

Auch in Großbritannien gab es immer wieder Stimmen, die nach einem stärkeren staatlichen Engagement im Bereich des Theaters riefen. Die Überlegungen der beiden Theaterreformer William Archer und Harley Granville-Barker zu einem ,National Theatre' beispielsweise waren kaum ohne staatliche Unterstützung vorstellbar. ${ }^{130}$ Nicht zufällig orientierten sie sich dabei am deutschen Theater, das sie vor Ort in Berlin studiert und über das sie in der Heimat begeistert berichtet hatten. ${ }^{131}$ Dass sie Deutschland als Vorbild empfahlen, war allerdings nicht geeignet, ihrem Vorschlag mehr Rückhalt in der Bevölkerung zu verschaffen. In einer Parlamentsdebatte über ein subventioniertes Nationaltheater malte ein Politiker das Schreckgespenst der ,Preußifizierung ' an die Wand. ${ }^{132}$ Der Theaterhistorikerin Tracy Davis zufolge war ein staatlich subventioniertes Theater im 19. Jahrhundert in Großbritannien undenkbar. ${ }^{133}$

Nach dem Ersten Weltkrieg aber, als die Kommerzialisierung des Londoner Theaters noch einmal an Fahrt gewann, machte sich vermehrt Unmut laut, in den sich nun auch immer wieder Forderungen nach einem stärkeren staatlichen Engagement mischten. Der Theaterreformer William Poel beispielsweise bedauerte, dass der Staat die Bühne der Willkür der Spekulanten überlassen habe und verwies auf das Vorbild des Kontinents. ${ }^{134}$ Der Theaterkritiker Huntly Carter warnte vor der Vertrustung der Theaterbetriebe und pries die Vitalität des deutschen

127 Vgl. Rickelt, Schauspieler und Direktoren, S. 11; STURY, Deutsche Theaterstatistik, S. 20-22, siehe auch DaIBER, Schaufenster der Diktatur, S. 13; Brauneck, Bühne, 4. Bd., S. $501 \mathrm{f}$.

128 FrÖHLICH, Tagebücher, 1. Teil, 4. Bd., S. 231.

129 Vgl. DrewniaK, Das Theater im NS-Staat, S. 59.

130 Vgl. Archer und Granville-BARKer, A National Theatre; siehe auch Davis, The Economics, S. 233; dies., The Independent Theatre; dies., The Show Business Economy.

131 Archer, The Theatrical ,World' of 1896, S. xiii; A Correspondent (= Harley GranvilleBarker), The Theatre in Berlin, The Times 19.11.1910, S. 6; ders., The Theatre in Berlin, ThE Times 21.11. 1910, S. 12.

132 Zit. nach Whitworth, National Theatre, S. 106; siehe auch KrUGER, The National Stage, S. 125; WeINGÄrTnER, The Arts as Weapons of War, S. 45-48.

133 Davis, The Show Business Economy, S. 42; ähnlich: KenNedy, British Theatre, 1895-1946, S. 17.

134 Vgl. PoEL, What is Wrong with the Stage?, S.9. 
Theaters, für die er im Wesentlichen die Verstaatlichung verantwortlich machte. ${ }^{135}$ Noch war dies die Meinung einer Minderheit, bald nach dem Ausbruch des Zweiten Weltkrieges erfolgte aber auch in Großbritannien der kulturpolitische Paradigmenwechsel. Die Gründung des Council for the Encouragement of Music and Arts (CEMA) 1940 ebnete den Weg für eine staatliche Kulturfinanzierung in großem Umfang und, langfristig, für die Entstehung eines subventionierten Theaters. ${ }^{136}$

\section{Zwischenfazit}

Vergleicht man die britische und die preußische Theaterpolitik zwischen der Mitte des 19. Jahrhunderts und dem Ersten Weltkrieg, fallen bei allen Unterschieden im Detail viele Gemeinsamkeiten auf - umso mehr, wenn man bedenkt, dass das viktorianische Großbritannien lange Zeit als liberales Musterland, das Kaiserreich dagegen als repressiv und obrigkeitsstaatlich galt. Denn weder führte die zeitlich frühere Liberalisierung der Theatergesetzgebung in Großbritannien zu einer vollständigen Theaterfreiheit, noch setzten der preußische Staat und die Berliner Polizei einseitig auf eine Politik der Unterdrückung. Tatsächlich ähnelten sich die Konzessionierung, die Regulierung und die Kontrolle der Theater an beiden Orten auffällig, ohne dass allerdings ein Austausch zwischen ihnen auf diesem Gebiet nachweisbar ist.

Der klischeehaft zugespitzten Gegenüberstellung von einem Laissez-faireTheater einerseits, einem öffentlich getragenen Theater andererseits, widerspricht auch, dass in Großbritannien ein Beamter der Krone für das Theater zuständig war, während es in Deutschland vom Gesetzgeber als Gewerbe eingestuft wurde. In der Praxis jedoch machten solche Feinheiten kaum einen Unterschied. In Berlin war das Konzessionierungsverfahren etwas strenger, dafür galt hier die Konzession auf unbestimmte Zeit. In London musste der Theaterdirektor zwar nicht seine sittliche, artistische und wirtschaftliche Eignung nachweisen, dafür erhielt er seine Lizenz immer nur auf ein Jahr und war kontinuierlich auf das Wohlwollen des Lord Chamberlain angewiesen. Eine weitere Gemeinsamkeit war die rechtliche Unterscheidung zwischen Theatern und Varietés, für die es in beiden Städten unterschiedliche Konzessionen gab. Die Vergabekriterien allerdings verweisen wiederum auf nationale Besonderheiten. Eine Music Hall definierte sich in den Augen des britischen Gesetzgebers primär dadurch, dass hier Alkohol ausgeschenkt wurde. Der deutsche Gesetzgeber machte die Unterscheidung zwischen einem Theater und einem Varieté dagegen von der Frage abhängig, ob ein ,höheres Interesse der Kunst' vorhanden war oder nicht. Dahinter stand die Differenzierung zwischen Hoch- und Populärkultur, die so in Großbritannien keine Rolle spielte.

135 Vgl. Carter, The New Spirit, S. 164-169.

136 Vgl. BeCKER, Kulturfinanzierung, S.2-3; zum Kontext siehe auch WeInGÄRTNER, The Arts as Weapons of War; HeINRICH, Entertainment, Propaganda, Education. 
Eine Gemeinsamkeit war wiederum, dass die einmal erreichten Regelungen kaum noch verändert wurden. Die Gewerbeordnung blieb bis zum Theatergesetz von 1934, der Theatre Act sogar bis über den Zweiten Weltkrieg hinaus intakt. Dennoch waren beide nicht unumstritten. In Großbritannien entzündeten sich die Debatten primär an Sachfragen wie der geteilten Zuständigkeit von Lord Chamberlain und LCC sowie der Konkurrenz zwischen Theatern und Music Halls. In Deutschland war die Diskussion sehr viel stärker politisch aufgeladen. Die Liberalen verteidigten mit der Gewerbeordnung ihre Wirtschafts- und Kunstpolitik, die Konservativen benutzten die Verschärfung des Theaterparagraphen, um ihre Macht zu demonstrieren. Bei der Theaterpolitik ging es also stets ebenso sehr um Politik wie um das Theater. Vor allem größere Richtungswechsel wie die Liberalisierung der Theatergesetzgebung waren Ausdruck eines veränderten politischen Großklimas.

Die Liberalisierung der Theatergesetzgebung beseitigte das traditionelle Privilegiensystem, das in London die patent theatres, in Berlin die Hoftheater begünstigt hatte, nahm diesen das Monopol auf Tragödie und Oper und schuf eine einheitliche, transparente Rechtslage. Keineswegs aber brachte sie völlige Freiheit. Ganz abgesehen von der Zensur, die in beiden Städten unangetastet blieb, nahm der staatliche Zugriff auf das Theater beständig zu, denn die Direktoren mussten nun eine Fülle von Auflagen und Regeln beachten und die Theater wurden regelmäßig inspiziert. Allerdings wäre es falsch, die staatlichen Maßnahmen als Repressalien zu verstehen, mit denen die Behörden den Direktoren das Leben schwer machen wollten. Die Quellen zeigen zum einen, dass viele Hinweise auf Missstände von Zuschauern kamen, zum anderen, dass die Behörden sich als Anwälte des Publikums verstanden. Wenn ein Vertreter der Berliner Theaterpolizei in den zwanziger Jahren schrieb, dass die „moderne Theaterpolizei“ ihre Aufgabe darin sah, „der besonderen Gefährdung des Lebens und der Gesundheit der am Theater Beteiligten zu begegnen", scheint das durchaus ein ehrliches Bekenntnis gewesen zu sein. ${ }^{137}$

Ein wichtiges Berliner Spezifikum war allerdings das Hoftheater, für das es keine Londoner Entsprechung gab. Bis zum Ersten Weltkrieg fiel es kaum ins Gewicht, da die Geschäftstheater überwogen und die Hoftheater sich an ihnen orientierten: „Berlin hat nur noch Geschäftstheater, das Hoftheater mit einbegriffen“, meinte der Kritiker Paul Linsemann. ${ }^{138}$ Langfristig gesehen aber waren sie von entscheidender Bedeutung, denn sie bildeten die Keimzelle für das Staatstheater der Weimarer Republik. Vor dem Hintergrund eines allgemein zunehmenden Staatsinterventionismus nahm in den zwanziger und dreißiger Jahren der staatliche Einfluss auf das Theater entschieden zu. Immer mehr Bühnen wurden kommunalisiert und verstaatlicht. In der Zeit des Nationalsozialismus wurde diese Politik fortgeführt und noch weiter forciert. Selbst solche Bühnen, die offiziell

137 Adriani, Moderne Theaterpolizei. Zwei Vorträge auf der Internationalen Polizeikonferenz zu Berlin, Die DeUTSCHe BÜHNe 14 (1926), S. 245-252, hier S. 245.

138 Linsemann, Die Theaterstadt Berlin, S. 7. 
als privatwirtschaftliche Unternehmen weiter bestanden, wurden gleichgeschaltet und staatlich kontrolliert. Da nach dem Zweiten Weltkrieg das Theater in der Bundesrepublik und in der DDR größere Autonomie erhielt, das Prinzip des subventionierten Staatstheaters aber nicht infrage gestellt wurde, müssen die Ursprünge des heutigen deutschen Theatersystems in der Weimarer Republik und im Nationalsozialismus gesucht werden. Während sich sonst im Feld der Theaterpolitik kaum Austausch zwischen London und Berlin ausmachen lässt, fungierte Deutschland hier als Vorbild. Zumindest verwiesen die Anwälte eines staatlich subventionierten Theaters in Großbritannien schon früh und häufig auf das deutsche Modell. 
Wir deutschen Bühnenschriftsteller stehen unter sittenpolizeilicher Kontrolle. [...] Jedes Wort, das wir schreiben, muß, ehe es von der Bühne herab Lauf und Gestalt annehmen darf, auf seinen konfiszierlichen Inhalt amtlich geprüft und gestempelt werden.

Lothar Schmidt ${ }^{139}$

The stage alone remains under a censorship of a grotesquely unsuitable kind. No play can be performed if the Lord Chamberlain happens to disapprove of it.

George Bernard Shaw ${ }^{140}$

\subsection{Zensur}

Die beiden Zitate von Lothar Schmidt und George Bernard Shaw weisen auf zwei Gemeinsamkeiten hin, die das Londoner und das Berliner Theater fast von ihren Anfängen bis zum Ende des Ersten Weltkrieges miteinander teilten: die Zensur und der Kampf der Theaterautoren gegen sie. Schmidt fühlte sich nach eigenem Bekunden als Dramatiker wie eine Prostituierte unter sittenpolizeiliche Aufsicht gestellt. Shaw empörte sich, dass das Theater überhaupt noch zensiert wurde, nachdem die Zensur in allen anderen Bereichen des öffentlichen Lebens abgeschafft worden war, und fast noch mehr darüber, dass ein Beamter des königlichen Hofes sie ausübte. Doch welche Gemeinsamkeiten, welche Unterschiede gab es zwischen der Berliner und der Londoner Zensur? Wie wurde die Zensur von wem ausgeübt und was wurde zensiert? War die britische Zensur liberaler, die preußische repressiver? Diesen Fragen geht das folgende Kapitel auf den Grund: in einem ersten Schritt anhand der Zensurgesetzgebung und in einem zweiten anhand der Zensurpraxis. Dabei baut es auf einer breiten Grundlage auf, denn die Zensur gehört zu den am gründlichsten aufgearbeiteten Bereichen der Theatergeschichte. ${ }^{141}$ Das populäre Theater, wie auch das Musiktheater, hat allerdings bei diesen Untersuchungen bislang allenfalls eine marginale Rolle gespielt. ${ }^{142} \mathrm{Oft}$ findet sich eine Konzentration auf spektakuläre Verbote einzelner Stücke, wie Die Weber von Gerhart Hauptmann oder Frühlings Erwachen von Frank Wedekind in Deutschland, Miss Warren's Profession von George Bernard Shaw oder Waste von Harley Granville-Barker in Großbritannien, also gerade auf solche Dramen, die

139 Lothar Schmidt, Polizei und Bühne, Die Gegenwart 80 (1911), 2. Bd., Nr. 44, S. 735-738.

140 SHAw, The Shewing-Up of Blanco Posnet, S. 35.

141 Zur Geschichte der britischen Theaterzensur siehe Fowell und PALMER, Censorship in England; FIndlater, Banned; STEPHENS, The Censorship; Johnston, The Lord Chamberlain's; DE Jongh, Politics, Prudery and Perversions; Shellard und Nicholson (Hrsg.), The Lord Chamberlain Regrets; Nicholson, The Censorship; Thomas et al., The Censorship; FresHWATER, The Censorship; zur preußischen Theaterzensur siehe KleEFelD, Theaterzensur; Heind, Die Theaterzensur; LohKamp, Das Recht der Theaterzensur; Houben, Polizei und Zensur; SOMMer, Zur Geschichte der Berliner Theaterzensur; WALACH, Das doppelte Drama; STARK, Banned in Berlin. Mit europäischem Fokus: GoldsteIn, Political Censorship; ders. (Hrsg.), The Frightful Stage.

142 Vgl. Weisstein, Böse Menschen singen keine Arien, insbes. S. 49-51. 
heute als kanonische Werke dieser Zeit gelten. ${ }^{143}$ Sofern das unterhaltende Theater überhaupt Beachtung fand, kamen Zeitgenossen wie Nachwelt meist zu dem Schluss, dass die Zensur mit diesem wesentlich milder verfuhr. Lothar Schmidt beispielsweise mokierte sich darüber, dass man einerseits ernsthaften Dramatikern wie ihm das Leben schwer machte, andererseits trotz der Zensur „die Möglichkeit fast unbegrenzter Schweinereien auf der Bühne“ bestand. ${ }^{144}$ Denselben Vorwurf richtete Shaw an den Lord Chamberlain, der seine Stücke verbot, „but unintentionally gives the special protection of its official licence to the most extreme impropriety". ${ }^{145}$ Während Schmidt und Shaw nicht ausführten, welche ,Schweinereien` sie meinten, benannte ihr Kollege, der Dramatiker Henry Arthur Jones, Ross und Reiter: „The whole body of a musical comedy may reek with cockney indecency and witlessness, and yet no English mother will sniff offence, provided it is covered up with dances and songs". ${ }^{146}$ Noch mehr als die Tatsache, dass es überhaupt eine Zensur gab, empörten sich die Dramatiker darüber, dass diese nur für das ,ernsthafte‘ Drama zu gelten schien, nicht jedoch für populäre Formen wie Farce und Musical Comedy. Ob diese mehr empfundene als ernsthaft belegte Ungerechtigkeit eine Grundlage in der tatsächlichen Unterscheidung der Zensurbehörden zwischen Hoch- und Populärkultur hatte, ist deshalb eine weitere Frage, der im Folgenden nachgegangen wird.

\section{Zensurgesetzgebung}

Die Geschichte der britischen Theaterzensur reicht zurück bis in 16. Jahrhundert. So verfügte ein Statut aus dem Jahr 1574, dass alle „comedies, tragedies, interludes, and stage-plays“ vor einer Aufführung dem Master of Revels, einem dem Lord Chamberlain untergeordneten Beamten des königlichen Hofstaates, vorzulegen seien. ${ }^{147}$ Von einer umfassenden Zensur kann jedoch keine Rede sein schon gar nicht für die Zeit nach der Wiedereröffnung der Theater im 17. Jahrhundert. So war Thomas Killigrew, einer der beiden Höflinge, die von Charles II. das Patent zum Theaterspielen erhielten, gleichzeitig für die Zensur zuständig. ${ }^{148}$

Dass Theaterunternehmen und -zensur in einer Hand lagen, führte dazu, dass die Bühnen in den dreißiger Jahren des 18. Jahrhunderts ungehindert satirische Kritik an der Regierung üben konnten. Das bekam vor allem Robert Walpole zu spüren, der als Finanzminister und Premierminister avant la lettre die Regierung führte. Seine Position war zu dieser Zeit von vielen Seiten her bedroht, nicht zuletzt durch den König, dessen Rückhalt er zu verlieren drohte. Um wenigstens seine Spötter loszuwerden, holte Walpole zum Schlag gegen die Theater aus.

\footnotetext{
143 Vgl. Plachta, Zensur, S. 141f.; STARK, Banned in Berlin, S. 72-78, 126, 135f.; ThOmas et al., Theatre Censorship, S. 77 f., Sova, Banned Plays.

144 Schmidt, Polizei und Bühne, Die AKTiOn 1 (1911), Nr. 38, S. 736.

145 SHaw, The Shewing-Up of Blanco Posnet, S. 53.

146 JONES, Foundations of a National Drama, S. 214.

147 Vgl. Fowell und Palmer, The Censor, S. 25-29; Thomas et al., Theatre Censorship, S. 6-13.

148 Vgl. Thomas et al., Theatre Censorship, S. 18.
} 
Durch geschicktes Taktieren gelang es ihm, 1737 den Licensing Act durch das Parlament zu bringen, der die Vorzensur aller Theaterstücke einführte. ${ }^{149}$ In Artikel III des Gesetzes hieß es:

[...] no Person shall for Hire, Gain, or Reward, act, perform, represent, or cause to be acted, performed, or represented, any new Interlude, Tragedy, Comedy, Opera, Play, Farce, or other Entertainment of the Stage, or any Part or Parts therein, or any new Prologue, or Epilogue, unless a true Copy thereof be sent to the Lord Chamberlain of the King's Household for the time being fourteen Days at least before the acting, representing, or performing thereof, together with an account of the Playhouse or other Place where the same shall be, and the Time when the same is intended to be first acted, represented, or performed $[\ldots]^{150}$

Der Licensing Act verpflichtete also die Theaterdirektoren, eine Kopie jedes Stücks 14 Tage vor dessen Aufführung zur Zensur einzureichen unter Angabe des Aufführungsortes und -zeitraums. Einen Unterschied zwischen Kunst und Unterhaltung, Tragödie und unterhaltenden Stücken machte er nicht, vielmehr betonte er durch die Aufzählung nahezu aller damals bekannten Gattungen, dass sämtliche Stücke gemeint waren. Allerdings sicherten sich die patent theatres weiterhin das Monopol auf Tragödie und Oper. ${ }^{151}$ Zuständig für die Zensur war der Lord Chamberlain. Artikel IV des Licensing Act gab ihm die Möglichkeit, „to prohibit the acting, performing or representing any Interlude, Tragedy, Comedy, Opera, Play, Farce or other Entertainment of the Stage“.152 Das Gesetz beschränkte das Recht des Königs, Privilegien (patents) für Theater zu vergeben, aber auf die City of Westminster, weshalb mehrere dort gelegene Theater ohne königliches Patent schließen mussten, während gleichzeitig die Theatres Royals Drury Lane und Covent Garden ein faktisches Monopol auf Theaterunterhaltung im Zentrum von London erhielten. Die Beschränkung des Gesetzes auf Westminster hatte eigentlich das Ziel gehabt, jede Form von Theaterunterhaltung außerhalb dieses Distrikts zu unterbinden. Der 1752 verabschiedete Disorderly House Act erlaubte jedoch den Stadtbehörden (magistrates) außerhalb Westminsters, ihrerseits Theaterkonzessionen zu vergeben, sodass in den Vorstädten und Provinzen eine Reihe neuer Bühnen entstand, für die der auf die patent theatres beschränkte Licensing Act - und damit die Zensur - nicht galt. ${ }^{153}$

Der Licensing Act von 1737 war die Rechtsgrundlage, auf der die Theaterzensur in London in den nächsten hundert Jahren fußte - und nicht nur dort, denn es handelte sich um ein "model censorship device in modern Western society“.154

149 Vgl. LiesEnfeld, The Licensing Act, insbes. S. 4, 60f., 79-86, 129-137; Johnston, The Lord Chamberlain's, S. 23-26; STEPHENs, The Censorship, S. 5-7; ThOmAs et al., Theatre Censorship, S. 24-28, 36-42; siehe auch ConOlLY, The Censorship.

15010 Geo II, cap xxviii, abgedruckt in: ThOMAS und HARE (Hrsg.), Restoration and Georgian England, S. 207-210, hier S. 208.

151 Vgl. Moody, Theatrical Revolution; dies., Illegtimate Theatre, S. 51-55.

15210 Geo II, cap xxviii, abgedruckt in: THOMAS und HARE (Hrsg.), Restoration and Georgian England, S. 208f.

153 Vgl. Liesenfeld, The Licensing Act, S. 140; Moody, The Theatrical Revolution, S. 200f.; dies., Illegitimate Theatre, S. $16 \mathrm{f}$.

154 Liesenfeld, The Licensing Act, S. 3. 
Ein Einfluss auf die preußische Gesetzgebung ist allerdings nicht nachweisbar. Der 1843 verabschiedete Theatre Act hob den Licensing Act auf, übernahm dessen Bestimmungen zur Zensur aber fast vollständig. So hieß es in dessen Artikel XII:

And be it enacted, That One Copy of every new Stage Play, and of every new Act, Scene, or other Part added to any old Stage Play, and of every new Prologue or Epilogue, and of every new Part added to an old Prologue or Epilogue, intended to be produced and acted [...] at any Theatre in Great Britain, shall be sent to the Lord Chamberlain of Her Majesty's Household for the Time being, Seven Days at least before the first acting or presenting thereof, with an Account of the Theatre where and the Time when the same is intended to be first acted or presented $[\ldots]^{155}$

Der Theatre Act verringerte die Macht des Lord Chamberlain geringfügig, indem er die Frist, in der ein Stück vor seiner Aufführung eingesandt werden musste, von 14 auf sieben Tagen herabsetzte. Mehr noch, er durfte nach Artikel XIV Stücke nicht länger ohne Angabe von Gründen verbieten, sondern nur „whenever he shall be of opinion that it is fitting for the Preservation of good Manners, Decorum, or of the public Peace so to do, to forbid the acting or presenting any Stage Play". ${ }^{156} \mathrm{Ob}$ diese Einschränkung in der Praxis allerdings einen großen Unterschied machte, ist fraglich, lag es doch im Ermessen des Lord Chamberlain, ob ein Stück die guten Sitten und den öffentlichen Frieden gefährdete. Eine Berufungsinstanz gab es nach wie vor nicht. Vor allem dehnte das Gesetz die Befugnisse des Lord Chamberlain erheblich aus, denn dieser war nun nicht mehr nur für die City of Westminster, sondern für das gesamte Land zuständig. Jedes Stück „intended to be produced for hire at any theatre in Great Britain“ - musste von nun an vorab zur Zensur vorgelegt werden. ${ }^{157}$

In den folgenden Jahrzehnten geriet die Zensur mehr und mehr ins Kreuzfeuer der Kritik. Bei den Beratungen des Untersuchungsausschusses von 1866, dem Select Committee on Theatrical Licenses and Regulations, hatte sie noch eine eher untergeordnete Rolle gespielt. Abgesehen von den Schriftstellern zeigten sich alle Befragten zufrieden mit den Zensurbestimmungen und stimmten für ihre unveränderte Beibehaltung und ihre Übertragung auf die Music Halls. Das Komitee kam deshalb zu dem Ergebnis: „That the censorship of plays has worked satisfactorily, and that it is not desirable that it should be discontinued". ${ }^{158}$ Der nächste Untersuchungsausschuss, das Select Committee on Theatres and Places of Entertainment von 1892, befasste sich aufgrund der Kampagne der Bühnenautoren gegen die Zensur eingehender mit dieser Frage. Wortführer war der Theaterkritiker William Archer, der die Zensur als Anomalie und Anachronismus bezeichnete. In seinen Augen war sie in doppeltem Sinne von Übel, weil sie einerseits nicht für die Sittlichkeit der Bühne sorgte, andererseits aber ernsthafte dramatische Werke

1556 \& 7 Vict. cap 68, abgedruckt in: Roy (Hrsg.), Romantic and Revolutionary Theatre, S. 2731, hier S. 30 .

156 Ebd.

157 Vgl. Fowell und Palmer, Censorship in England, S. 43-46; StePhens, The Censorship, S. 9 f.; ThOMAs et al., Theatre Censorship, S. 59-64.

158 RePORT (1866), S. iv. Für eine völlige Abschaffung der Zensur trat fast nur der Schriftsteller Charles William Shirley Brooks ein, vgl. ebd., S. 158. 
unterdrückte. ${ }^{159}$ Archer sprach jedoch nur für eine kleine Minderheit. Das Komitee kam zu einem Beschluss, der dem seines Vorgängers von 1866 im Wortlaut glich: „that the censorship of plays has worked satisfactorily, and that it is not desirable that it should be discontinued". 160

Nach diesem Misserfolg intensivierten die Schriftsteller ihren Protest, in dessen Folge ein weiterer Untersuchungsausschuss einberufen wurde, das Joint Select Committee of the House of Lords and the House of Commons on the Stage Plays (Censorship), das sich primär mit der Zensur befasste. ${ }^{161}$ Das Komitee lud erneut William Archer vor, der seine Argumente von 1892 weitgehend wiederholte und in seiner Schlussfolgerung den Lord Chamberlain persönlich angriff. Der Zensor, so meinte er „keeps serious drama down to the level of his own intelligence (and probably lower because of timidity) while he does not even pretend to keep the lighter drama up to the level of his own morality“. 162 Neben Archer sprach George Bernard Shaw auf der Seite derjenigen, die für eine Abschaffung der Zensur plädierten. ${ }^{163}$

Im Unterschied zu den Bühnenautoren und Kritikern setzten sich die Schauspieler und Theatermanager, die das Komitee vorgeladen hatte, für eine Beibehaltung der Zensur ein, allen voran George Edwardes. Auf den ersten Blick mag dies verwundern, doch gab es dafür handfeste Gründe. Wie Edwardes aussagte, fühlte er sich durch die Zensur vor juristischen Auseinandersetzungen geschützt. Zwar bedeutete eine Lizenz des Lord Chamberlain keineswegs, dass ein Autor oder Manager nicht wegen des Inhalts eines Stücks verklagt werden durfte, faktisch gesehen erhöhte sie aber die Hemmschwelle ungemein. Noch wichtiger war die Lizenz für die Theatertourneen, die Edwardes' Inszenierungen in viele Städte der britischen Inseln brachten. Dabei kam es immer wieder vor, dass lokale Behörden an einem Stück Anstoß nahmen. In der Regel ließen sie jedoch die Aufführung zu, wenn Edwardes eine Lizenz des Lord Chamberlain vorweisen konnte. ${ }^{164}$

William Archer, den Edwardes' Verteidigung der Zensur empörte, hatte schon 1892 einen weiteren Grund für dessen Haltung benannt: „Why, O simple-minded interviewer, should Mr Edwardes want the Censor ,interfered with', when the Censor never, to any practical purpose, ,interferes with' him? The Censorship is, and must be, the bulwark of frivolity; it is only the serious artist for whom it has any terrors“. ${ }^{165}$ Edwardes’ Haltung gegenüber der Zensur bestätigte Archers im-

159 Vgl. REPORT (1892), S. 256.

160 RePort (1892), S. vii. Zum Umgang der beiden Select Committees mit der Frage der Zensur siehe auch ThOmas et al., Theatre Censorship, S. 65-68.

161 Zur Vorgeschichte des Select Committee von 1909 und seinem Umgang mit dem Thema Zensur siehe auch Johnston, The Lord Chamberlain's, S. 58-65; DE JONGH, Politics, Prudery and Perversion, S. 29-44; Nicholson, The Censorship, S. 46-70; Thomas et al., Theatre Censorship, S. 69-107.

162 Vgl. RePORT (1909), S. 34-39, hier S. 38f.

163 Ebd., S. 46-53.

164 Ebd., S. 243; zu den Motiven der Manager siehe auch ThOMAs et al., Theatre Censorship, S. 93 sowie Goldstein, Political Censorship, S. 152.

165 ARCHER, The Theatrical,World' of 1893, S. 244. 
mer wieder vorgebrachten Eindruck, dass sie alle Frivolitäten passieren ließ, während es die ernsthafte dramatische Kunst sei, die eigentlich zu leiden hatte. Da Edwardes nichts von der Zensur zu befürchten hatte, sei es nur natürlich, dass er sich für ihre Beibehaltung aussprach.

Im Gegensatz $\mathrm{zu}$ den beiden vorangegangenen Untersuchungsausschüssen zeigte derjenige von 1909 durchaus Sympathie für die Beschwerden der Schriftsteller, ohne dabei allerdings die Bedürfnisse der Manager verletzen oder gar die Zensur vollständig abschaffen zu wollen. Das Komitee bemühte sich es allen beteiligten Parteien recht zu machen, indem es eine freiwillige Zensur vorschlug, die die Theatermanager nicht länger dazu zwang, jedes Stück einzureichen, es denjenigen unter ihnen, die einer offiziellen Lizenz zu bedürfen meinten, aber freistellte. Das hätte den Lord Chamberlain zu einem Dienstleister der Theater reduziert. ${ }^{166}$ Wiederum fanden die Vorschläge des Komitees keinen Eingang in den Gesetzgebungsprozess. Vor dem Hintergrund der schweren politischen Krise um 1910 hatte das Parlament mit größeren Problemen zu kämpfen als der Theatergesetzgebung. ${ }^{167}$ Der Erste Weltkrieg zementierte dann die bestehende Situation. Nach dem Krieg kam es nur insofern zu einer Veränderung, als der erste LabourPremier Ramsay MacDonald 1924 auf die Beteiligung an der Besetzung des Amtes des Lord Chamberlain verzichtete, wodurch es seine politische Bedeutung verlor. Allerdings blieb die Theaterzensur weiterhin unangetastet. Da der Inhaber des Amtes nun weniger häufig wechselte, wurde sie jedoch einheitlicher und berechenbarer. Während eine neue Generation junger Autoren wie Noël Coward immer noch mit der Zensur zu kämpfen hatte, ließ der Lord Chamberlain Stücke wie die damals skandalumwitterten Dramen von Shaw ohne Beanstandung passieren. ${ }^{168}$ Dem Theaterhistoriker Allardyce Nicoll zufolge war die Zensur wesentlich liberaler geworden und ließ nun Stücke zur Aufführung zu, die eine frühere Generation zutiefst schockiert hätte. ${ }^{169}$ Diese größere Toleranz mag ebenfalls dazu beigetragen haben, dass die Kritik leiser wurde.

Ebenfalls 1909, im selben Jahr, in dem der Untersuchungsausschuss zur Theaterzensur zusammentrat, wurde in Großbritannien der Cinematograph Act verabschiedet. Obwohl das Gesetzeswerk primär die Befugnisse zur Konzessionierung und Kontrolle der Kinos klären und eine einheitliche Rechtsgrundlage schaffen sollte, hatte es nebenbei und eher unabsichtlich die Einführung einer Filmzensur zur Folge. Denn die lokalen Behörden legten die ihnen durch das Gesetz beigemessene Überwachungsfunktion so großzügig aus, dass sie nicht nur die Einhaltung der feuerpolizeilichen Bestimmungen kontrollierten, sondern zum Teil auch

166 Ebd., S. xi.

167 Vgl. Thomas et al., Theatre Censorship, S. 104; zum politischen Hintergrund siehe Powell, The Edwardian Crisis.

168 Vgl. Nicholson, The Censorship, S. 149-177; Thomas et al., Theatre Censorship, S. 108-122, siehe auch Gale, The London Stage, S. 150f.; DeEneY, When Men were Men and Women were Women.

169 NiCOLL, English Drama, S. 21. 
die Filme, die von den Kinos in ihrem Zuständigkeitsbereich gezeigt wurden. ${ }^{170}$ Parallel dazu gab es Diskussionen über die Einführung einer nationalen Filmzensur. Um dieser vorzubeugen, gründete die britische Filmindustrie - mit der $\mathrm{Zu}$ stimmung des Home Office - eine eigene Zensurbehörde auf freiwilliger Basis, das British Board of Film Censors (BBFC). Es war kein Zufall, dass dessen erster Direktor, George Redford, zuvor als Zensor beim Lord Chamberlain's Office gearbeitet hatte, denn das BBFC war insgesamt nach dessen Vorbild aufgebaut, wobei Redford als Präsident die Funktion des Lord Chamberlain wahrnahm. Auch das BBFC übte eine Vorzensur aus. ${ }^{171}$ Hatte das Theater bereits bei den Bestimmungen zur Konzessionierung und Kontrolle der Kinos Pate gestanden, war seine Vorbildfunktion bei der Ausgestaltung der Filmzensur noch größer, denn diese oblag zwar einer neuen Behörde, orientierte sich aber in der Praxis stark an der Theaterzensur.

Die preußische Theaterzensur war weit jüngeren Datums als die britische. Eingeführt wurde sie durch eine Zirkularverfügung des Ministers des Innern vom 16. März 1820. Im Jahr zuvor hatten die Staaten des Deutschen Bundes die Karlsbader Beschlüsse verabschiedet, eine Reihe von Gesetzen, die die nationalen und liberalen Bewegungen im Keim ersticken sollten. Im Zentrum der Beschlüsse stand die Zensur der Presse. Die Zirkularverfügung vermied den Begriff der Theaterzensur zwar peinlichst, genau darauf liefen ihre Bestimmungen aber hinaus:

Da der Fall eintreten kann, daß ungeachtet der von der Zensurbehörde zum Drucke eines Theaterstücks ertheilten Erlaubniß, die öffentliche Aufführung desselben aus polizeilichen Rücksichten zu untersagen oder zu suspendiren ist, so soll künftig der Bestimmung des Königlichen Ministerii des Innern und der Polizei zufolge, auf keinem öffentlichen Theater, die für die Königliche Rechnung administrirten ausgenommen, irgend ein gedrucktes oder ungedrucktes Trauer-, Schau- Lust- oder Singspiel, ohne vorläufige Erlaubnis des Präsidiums der Königlichen Regierung oder derjenigen Personen welche dasselbe mit diesem Geschäfte beauftragen wird, aufgeführt werden. ${ }^{172}$

In den Augen der Polizei bedeutete also der Umstand, dass ein Theaterstück von den Zensurbehörden zum Druck freigegeben worden war, noch lange nicht, dass es auf der Bühne aufgeführt werden durfte. Da ein Theaterunternehmer dazu die ausdrückliche Erlaubnis des Polizeipräsidiums benötigte, trat neben die Zensur von Gedrucktem die Theaterzensur durch die lokale Polizei. Ausgenommen von dieser Bestimmung waren allein die Hoftheater, deren Sonderstellung damit abermals betont wurde. Kein Unterschied machte für die Polizei hingegen die Gattung eines Stückes.

Bis 1848 trat die Theaterzensur kaum in Erscheinung, gab es doch in Berlin abgesehen von dem Königsstädtischen Theater und dem Kroll'schen Etablissement keine weiteren Privattheater. Infolge der Revolution von 1848 wurde dann durch eine Verfügung des Ministers des Innern vom 25. September 1848 jede

170 Vgl. KuHn, Cinema, Censorship and Sexuality, S. 12-21.

171 Vgl. Aldgate und Robertson, Censorship in Theatre and Cinema, S.2; zum BBFC siehe auch KuHN, Cinema, Censorship and Sexuality, S. 21-27.

172 AmTSBlatt, 1820, Stück 14, S. 61. 
Form der Zensur - auch die des Theaters - aufgehoben. ${ }^{173}$ An der Pressefreiheit rüttelte auch die revidierte preußische Verfassung vom 31. Januar 1850 nicht. ${ }^{174}$ Das Theater hingegen wurde schon bald wieder polizeilich überwacht. Das bekam in Berlin vor allem Friedrich Wilhelm Deichmann zu spüren, der 1848 eine Konzession für eine Sommerbühne erhalten hatte. Sein Friedrich-Wilhelmstädtisches Theater im Norden der Stadt, das unter anderem satirische Possen spielte, gespickt mit indirekten oder direkten Anspielungen auf lokale und nationale Politik, war der Polizei, die mitunter selbst Gegenstand des Spotts war, von Anfang an ein Dorn im Auge. Generalpolizeidirektor Karl Ludwig von Hinckeldey ließ die Vorstellungen von seinen Schutzleuten überwachen. Mitunter verlangte er sogar die Vorlage des Textbuches zur vorherigen Begutachtung.

Die Polizei berief sich dabei auf ihre Ordnungsfunktion, bewegte sich aber auf rechtlich unsicherem Terrain. Da eine Wiedereinführung der Zensur per Gesetz im politischen Klima des Nachmärz als heikel galt, wählte Hinckeldey - wie schon das Innenministerium 1820 - den Weg der Verordnung, um die Theaterzensur wieder einzuführen. ${ }^{175}$ In $\$ 5$ der Polizei-Verordnung vom 10. Juli 1851 hieß es:

Die Erlaubnis zur Veranstaltung einer öffentlichen Theatervorstellung muss von dem Unternehmer unter Angabe der zur Aufführung bestimmten Zeit zeitig bei dem Königlichen Polizei-Präsidium schriftlich nachgesucht werden. Dem Gesuche muss, wenn nicht in einzelnen Fällen eine Ausnahme hiervon aus besonderen Gründen gestattet wird, das zur Aufführung oder zum Vortrage bestimmte Stück oder Gedicht, bei musikalischen Vorstellungen das Textbuch, bei mimischen oder plastischen Vorstellungen eine genaue Beschreibung des Gegenstandes derselben in zwei gleichlautenden Exemplaren beigefügt werden. [...] Endlich ist der Unternehmer verpflichtet, dem Königlichen Polizei-Präsidium auf Verlangen jede auf die Vorstellung bezügliche Auskunft zu erteilen, namentlich auch die Zulassung eines Beamten zur Generalprobe zu gestatten. ${ }^{176}$

Von jedem Theaterstück, das sie aufführen wollten, waren die Berliner Theaterunternehmer nun gezwungen zwei Textbücher bei der Polizei einzureichen, von denen das eine an den Unternehmer zurückging, das andere bei der Polizei verblieb. Betroffen waren alle „dramatischen, deklamatorischen, musikalischen, pantomimischen und plastischen Vorstellungen“, das heißt jede Form von Bühnenunterhaltung. ${ }^{177}$ Darüber hinaus waren mit dem Textbuch, Ort und Zeit der Aufführung anzugeben. Obschon diese Bestimmungen stark an den Theatre Act erinnern, lässt sich ein unmittelbarer Einfluss der britischen Gesetzgebung nicht

173 Die Verfügung ist nachgedruckt in: LenNARTZ, Theater, Künstler und die Politik, S. 154; siehe auch Houben, Polizei und Zensur, S. 103; Sommer, Die Einführung der Theaterzensur, S. 32; BRAUNECK, Literatur und Öffentlichkeit, S. 16; RIEDER, Die Zensurbegriffe, S. 73-75.

174 RÖNNE, Die Verfassungs-Urkunde, S. 61.

175 Zur Verordnung von 1851 und ihrer Vorgeschichte siehe: Houben, Polizei und Zensur, S. 109-113, 118-120; SOMMER, Die Einführung der Theaterzensur; dies., Zur Geschichte der Berliner Theaterzensur; KuTZSCH, Theaterzensur in Berlin, S. 206f.; RIEDER, Die Zensurbegriffe, S. 77 f.; WaLACH, Das doppelte Drama, insbes. S. 262-264; STARK, Banned in Berlin, S. $15 \mathrm{f}$.

$176 \$ 5$ der Verordnung des Königl. Polizei-Präsidii zu Berlin, über öffentliche Theater und ähnliche Vorstellungen, vom 10. Juli 1851, Ministerial-BlatT 12 (1851), S. 117 f., hier S. 117.

177 Ebd., $\$ 2$. 
nachweisen. Auch ging die Berliner Polizeiverordnung noch weiter, insofern sie nicht nur die "Zulassung eines Beamten zur Generalprobe“ verlangte, sondern bestimmte, dass „kein Darsteller in Wort oder Handlung von dem Inhalte des polizeilich gezeichneten Exemplars abweichen " darf. ${ }^{178}$ Während sich in Großbritannien die Zensur damit begnügte, das Textbuch zu kontrollieren, bestand die Berliner Polizei darauf, sicherzustellen, dass gestrichene Szenen oder Texte auch tatsächlich nicht aufgeführt wurden. Und das im Übrigen keineswegs nur bei Generalproben, vielmehr saß bei jeder Aufführung ein Beamter im Publikum, um zu kontrollieren, dass nur der genehmigte Text gesprochen wurde. ${ }^{179}$

Die Verordnung von 1851 bildete bis 1918 die Grundlage der Theaterzensur in Preußen. Überdies diente sie vielen Städten und Staaten des Reiches als Vorbild. In Dresden, Leipzig und München beispielsweise wurde sie nach 1871 fast unverändert übernommen. ${ }^{180} \mathrm{Zu}$ einer nationalen Regelung der Zensur durch den Reichstag kam es jedoch nicht. Stattdessen wurde in- wie außerhalb des Parlaments ausführlich über die Zensur und die Überwachung der Theater gestritten. Der bekannteste Konflikt drehte sich um die Lex Heinze. Dabei handelte es sich vordergründig um eine Ergänzung des Strafgesetzbuches zur härteren Ahndung von Prostitution, Zuhälterei und Kuppelei. ${ }^{181}$ Allerdings fügte die konservative Fraktion dem Gesetzesentwurf eine Reihe von Bestimmungen hinzu, die weit über den ursprünglichen Gegenstand hinaus gingen und sich vor allem gegen die moderne Kunst und Kultur richteten, insbesondere gegen das Theater.

Die Lex Heinze war zwar kein Zensurgesetz, sie hätte jedoch im Fall ihrer Annahme durch den Reichstag erhebliche Folgen für die Theaterunternehmer gehabt. Denn der sogenannte „Theaterparagraph“ bedrohte jeden mit einer Gefängnisstrafe von bis zu einem Jahr beziehungsweise einer Geldstrafe von bis zu 1000 Mark, „der öffentlich theatralische Vorstellungen, Singspiele, Gesangsoder deklamatorische Vorträge, Schaustellungen von Personen oder ähnliche Aufführungen veranstaltet oder leitet, welche durch gröbliche Verletzung des Schamund Sittlichkeitsgefühls Ärgernis zu erregen geeignet sind“. ${ }^{182}$ Gerade die letzte Formulierung hätte der Willkür Tür und Tor geöffnet. Neben die Überwachung der Theater durch die Polizei wäre eine Art öffentliche Zensur getreten, die es jedem erlaubt hätte, Anzeige zu erstatten, der sich durch irgendein Stück oder irgendeine Handlung auf der Bühne in seinem individuellen Moralempfinden verletzt gefühlt hätte. Deshalb rief der Antrag nicht nur Entrüstung bei Liberalen und Sozialdemokraten hervor, sondern stieß auch bei den Regierungen des Reichs und der Länder auf Ablehnung. Sie befürchteten eine Klagewelle, die der beste-

178 Ebd., $\$ 11$, S. 118.

179 Vgl. LOHKamp, Das Recht der Theaterzensur, S. 10.

180 Vgl. STARK, Banned in Berlin, S. 16.

181 Vgl. MAST, Künstlerische und wissenschaftliche Freiheit, S. 139-190, insbes. S. 150-154.

182 Entwurf eines Gesetzes betreffend Änderung und Ergänzung des Strafgesetzbuches, in: VERHANDLUNGEN DES ReICHSTAGES, 1898/1900, 10. Legislaturperiode, 1. Session, 5. Anlageband, Aktenstück 571, S. 3631-3637, hier S. 3635. 
henden Zensur gleichsam eine weitere Instanz hinzugefügt hätte. ${ }^{183}$ Den Antragstellern aber ging es primär darum, die Zensurbehörden, die in ihren Augen zu lax waren, zu größerer Wachsamkeit anzuhalten. So betonte der Zentrumsabgeordnete Hermann Roeren: „[W]enn auf der Bühne das Scham- und Sittlichkeitsgefühl durch die Darstellung in ärgernißerregender Weise verletzt wird, dann ist es der Polizei möglich, nun auch in wirksamer Weise [...] gegen diesen Unfug und gegen dieses Unwesen der Tingeltangel und Variété-Theater vorzugehen“.184 Wie schon bei der Verschärfung der Gewerbeordnung zielten die Konservativen auch bei der Lex Heinze weniger auf die Theater als auf die Varietés ab, die sich in diesen Jahren rapide vermehrten und als moralisch anrüchig galten.

Die Lex Heinze entfachte eine ideologische Debatte zwischen Liberalen und Konservativen und verlieh zugleich den Differenzen zwischen den politischen Lagern Ausdruck. Als Kristallisationspunkt politischer Gegensätze war sie „symptomatisch für die fortdauernde emotionalisierte Kulturkampferregung in Deutschland“, wie Thomas Nipperdey schreibt. ${ }^{185}$ Dies war keine rein politische Auseinandersetzung: die Politik bildete vielmehr gesellschaftliche Auseinandersetzungen und Ängste ab. So zogen zu dieser Zeit viele Gruppen gegen ,Schmutz und Schund' zu Felde, womit Groschen-, Kriminal-, Abenteuerromane und andere Produkte der aufkommenden Populärkultur gemeint waren. ${ }^{186}$ Wie Gary Stark in seiner Geschichte der deutschen Zensur beobachtet, suchten zahlreiche Privatleute und Vereine Einfluss auf den Gesetzgeber zu nehmen, um so eine Verschärfung der Zensur zu bewirken. ${ }^{187}$

Kaum war die Debatte um die Lex Heinze abgeklungen, da setzten die Liberalen zum Gegenschlag an. Der Reichstagsabgeordnete Ernst Müller-Meiningen brachte zusammen mit weiteren liberalen Abgeordneten 1901 einen Antrag in den Reichstag ein, der die „Aufhebung eines ungesetzlichen Zustandes“ vorsah. ${ }^{188}$ Da Artikel 27 der preußischen Verfassung von 1850 die freie Meinungsäußerung verfügt und die Wiedereinführung der Zensur verboten hatte, betrachtete er die Ausübung der Zensur als Verstoß gegen die Verfassung. Die Verteidiger der Theaterzensur hingegen beriefen sich auf $\$ 10$ II. 17 des Allgemeinen Landrechts für die Preußischen Staaten von 1794, in dem es hieß: „Die nötigen Anstalten zur Erhaltung der öffentlichen Ruhe, Sicherheit und Ordnung und zur Abwendung der dem Publico, oder einzelnen Mitglieder desselben, bevorstehenden Gefahr zu

183 Vgl. Verhandlungen DEs Reichstages, 1898/1900, 10. Legislaturperiode, 1. Session, Stenographische Berichte von der 52. Sitzung (9.3.1899), 2. Bd., S. 1405-1430; siehe auch MAST, Künstlerische und wissenschaftliche Freiheit, S. 153-154.

184 Verhandlungen des Reichstages, 1898/1900, 10. Legislaturperiode, 1. Session, Stenographische Berichte von der 142. Sitzung (7.2.1900), 5. Bd., S. 3946.

185 NipPERDEY, Deutsche Geschichte, 1866-1918, Bd. 2, S. 719.

186 Siehe dazu JäGER, Der Kampf gegen Schmutz und Schund; MAASE, Krisenbewußtsein und Reformorientierung; ders., Die Kinder der Massenkultur.

187 STARK, Banned in Berlin, S. 60-63.

188 Verhandlungen des Reichstages, 10. Legislaturperiode, 2. Session 1900/1903, 2. Bd., Stenographische Berichte von der 37. Sitzung (30.1.1901), S. 1016-1027, hier S. 1017. 
treffen, ist das Amt der Polizey“. 189 Nicht nur Müller-Meiningen bezweifelte, dass diese antiquierte Bestimmung zur Rechtfertigung der Zensur herangezogen werden konnte. Für den Juristen Wenzel Goldbaum, Syndikus des Verbandes Deutscher Bühnenschriftsteller, bestand gar kein Zweifel, „daß die Theaterzensur so wie sie geübt ist, überall ungesetzlich ist, da sie eine ganz speziell auf den Gewerbebetrieb des Schauspielunternehmers zugeschnittene, sehr spezielle Vorschrift ist, durch die der Gewerbebetrieb eingeschränkt wird“. 190 Die meisten seiner Kollegen betrachteten die Theaterzensur allerdings als rechtsgültig. ${ }^{191}$

Während die Diskussion um die Theaterzensur noch in vollem Gang war, wurde zugleich die Grundlage für die Filmzensur gelegt. Ähnlich wie in London wurde diese bis in die 1910er Jahre hinein von der jeweiligen Ortspolizei ausgeübt, die sich dabei auf $\$ 10$ des Preußischen Landrechts berief. In der Regel besuchte ein Polizist die erste Vorstellung jedes Films und stellte so sicher, dass dieser nicht die öffentliche Ordnung gefährdete. ${ }^{192}$ Seit 1910 führte der preußische Staat dann durch mehrere Erlasse schrittweise die Vorzensur ein und zentralisierte die Filmzensur immer stärker. ${ }^{193}$ Wie die Theaterzensur bestand sie aus einer Vorzensur, berief sich auf das Allgemeine Landrecht und wurde von den Ländern auf dem Verordnungsweg eingeführt.

Erst die Weimarer Republik brachte auf dem Gebiet der Zensur grundlegend Neues. Die Verfassung von 1919 sprach in Artikel 118 jedem Deutschen das Recht $\mathrm{zu}$, „innerhalb der Schranken der allgemeinen Gesetze seine Meinung durch Wort, Schrift, Druck, Bild oder in sonstiger Weise frei zu äußern“.194 Weiterhin hieß es: „Eine Zensur findet nicht statt, doch können für Lichtspiele durch Gesetz abweichende Bestimmungen getroffen werden". 195 Solche Bestimmungen wurden in Form des Lichtspielgesetzes vom 12. Mai 1920 erlassen. Demnach durften Filme nur öffentlich vorgeführt werden, wenn sie zuvor von der amtlichen Prüfungsstelle zugelassen worden waren. Die Erlaubnis war zu versagen, wenn die Prüfung ergab, „daß die Vorführung des Bildstreifens geeignet ist, die öffentliche Ordnung oder Sicherheit zu gefährden, das religiöse Empfinden zu verletzen, verrohend oder entsittlichend zu wirken, das deutsche Ansehen oder die Beziehungen Deutschlands zu auswärtigen Staaten zu gefährden“. ${ }^{196}$ Wie die Analyse der

189 Zit. nach KLEEFELD, Die Theaterzensur, S. 18.

190 GoldBaum, Theaterrecht, S. 55.

191 Vgl. Rieder, Die Zensurbegriffe, S. 78; siehe auch KLEEFELD, Die Theaterzensur, insbes. S. 2332; OpeT, Deutsches Theaterrecht, S. 140-150; LOHKAMP, Das Recht der Theaterzensur, S. 18.

192 Vgl. Hellwig, Rechtsquellen, S.22; BiretT (Hrsg.), Verzeichnis in Deutschland gelaufener Filme, S. 1.

193 Vgl. die Erlasse des preußischen Ministers des Inneren betreffend Filmzensur vom 16.12. 1910, 20.4. 1911 und 6.7.1912, abgedruckt in: HeLLWIG, Rechtsquellen, S. 43-46; siehe auch BiretT (Hrsg.), Verzeichnis, S. 7-9; STARK, Cinema, Society and the State.

194 Die Verfassung des Deutschen Reiches. Vom 11. August 1919, Reichsgesetzblatt, 1919, Nr. 125, S. 1383-1418, hier S. 1406.

195 Ebd.

196 Lichtspielgesetz vom 20. Mai 1920, abgedruckt in: HeLLWIG, Öffentliches Lichtspielrecht, S. 11-14, hier S. 14; siehe auch Petersen, Zensur in der Weimarer Republik, S. 50-55. 
Zensurpraxis noch zeigen wird, legte die Weimarer Filmzensur damit dieselben Kriterien an wie die kaiserzeitliche Theaterzensur. Da vom Theater in der Reichsverfassung nicht die Rede war, setzte sich die Meinung durch, dass die Theaterzensur in Form der vorherigen Prüfung des Textbuches aufgehoben war. ${ }^{197}$ Die unterschiedliche Behandlung von Theater und Kino durch den Gesetzgeber lässt darauf schließen, dass dieser in dem neuen Medium, dessen Reichweite mittlerweile stark zugenommen hatte, eine sehr viel größere Gefahr sah als im Theater. Doch bot die Einschränkung „,innerhalb der Schranken des Gesetzes“ den Behörden weiterhin die Möglichkeit, gegen das Theater vorzugehen.

\section{Zensurpraxis}

Der Theatre Act von 1843 und die Polizeiverordnung von 1851 verliehen den jeweils für die Zensur zuständigen Behörden, dem Lord Chamberlain sowie dem Berliner Polizeipräsidium sehr weitgehende Vollmachten, die bis zum völligen Verbot eines Stückes reichten, ohne dass der betreffende Theaterdirektor oder Schriftsteller die Möglichkeit hatte, dagegen Einspruch bei einer höheren Instanz einzulegen. Gleichwohl stellt sich die Frage, ob diese Möglichkeiten ausgeschöpft und wie sie in der Praxis gehandhabt wurden.

In London schwankte die Zahl der eingereichten Stücke zwischen den fünfziger und siebziger Jahren um 200, um dann sukzessive auf 1000 vor dem Ersten Weltkrieg anzusteigen. Die Zahl der verbotenen Stücke war im gesamten Zeitraum sehr niedrig. In allen Jahren lag sie unter einem Prozent, wobei in 16 Jahren kein einziges Stück verboten wurde (Tabelle 9). Ein Verbot war die Ultima Ratio, zu der der Lord Chamberlain nur selten griff. ${ }^{198}$ Allerdings gibt es keine Statistik, die darüber Auskunft gibt, bei wie vielen der zugelassenen Stücke Änderungen verlangt wurden.

Anders das Bild in Berlin. Hier nahm die Zahl der eingereichten Stücke zwischen 1891 und 1900 von knapp über 400 auf über 1000 zu. Der Anteil von neuen Stücken an dieser Gesamtzahl schwankte relativ konstant zwischen 200 und 300, was vermuten lässt, dass die vielen in diesem Zeitraum neu eröffneten Theater einen großen Teil ihres Repertoires durch ältere, bereits bewährte Stücke deckten. Geht man davon aus, dass nur neue Stücke verboten wurden, lag der Anteil der Verbote, der zwischen neun und 22 schwankte, bei knapp 10 Prozent. Darüber hinaus verlangte das Polizeipräsidium bei etwa der Hälfte aller eingereichten Stücke Streichungen oder Änderungen (Tabelle 10). Die Eingriffe der Zensur waren also sehr erheblich und lagen weit über denen des Lord Chamberlain. Dass die Berliner Zensur häufiger zu dem Mittel des Verbots griff, deutet

197 Vgl. Rieder, Die Zensurbegriffe, S. 122-127; Petersen, Zensur in der Weimarer Republik, S. 38f., 210-212; siehe auch BoETZKES und QueCK, Die Theaterverhältnisse, S. 707-709; zum Umgang mit der Zensur in verschiedenen Medien während der Weimarer Republik siehe auch JELAVICH, Berlin Alexanderplatz.

198 Vgl. Nicholson, The Censorship, S. 2. 
ebenfalls darauf hin, dass sie grosso modo strenger verfuhr als ihr Londoner Pendant.

Verbote und Streichungen werfen die Frage auf, nach welchen Maßstäben die Zensoren die Stücke begutachteten. Der Theatre Act und die Berliner Polizeiverordnung verlangten lediglich die Einreichung der Stücke, schwiegen sich jedoch darüber aus, welche Aspekte als streichungswürdig erachtet wurden. Zur Praxis der Zensur befragt, gab William Bodham Donne dem Untersuchungsausschuss von 1866 folgende Auskunft:

I read all those manuscripts, and if I find anything objectionable, I endorse on the license the objectionable passages, with a direction to omit them in the representation, and then I recommend them to the Lord Chamberlain, or if I am doubtful about the whole bearing of the piece, it is then referred to the Lord Chamberlain to confirm or reject my opinion against it; if his opinion coincides with mine, the play is refused a license. ${ }^{199}$

Donne las also alle Stücke im Hinblick darauf, ob sie anstößige Stellen enthielten, die er dann auf der Lizenz vermerkte mit der Aufforderung, sie vor der Aufführung auf der Bühne zu streichen. Wenn er hingegen grundsätzliche Bedenken gegen ein Stück hatte, konsultierte er den Lord Chamberlain persönlich, der, insofern er diese Bedenken teilte, das Stück verbot. Soweit zur Verfahrensweise innerhalb des Lord Chamberlain's Office. Unklar bleibt allerdings weiterhin, welche Stellen Donne und seine Kollegen als anstößig betrachteten. Einzige offizielle Richtlinie bildeten die 1881 erlassenen Rules and Regulations with Regard to Theatres in the Jurisdiction of the Lord Chamberlain, die zur Zensur folgende Bestimmungen enthielten:

20. No profanity or impropriety of language to be permitted on the stage.

21. No indecency of dress, dance, or gesture, to be permitted on the stage.

22. No personalities or representations of living persons to be permitted on the stage, nor anything likely to produce riot or breach of the peace. ${ }^{200}$

Damit waren zwar einige Kriterien genannt, dennoch hing viel vom persönlichen Empfinden des Zensors ab, denn welche Ausdrücke, Gesten, Bewegungen und Kostüme als anstößig gelten konnten, unter welchen Umständen ein Stück die öffentliche Ordnung gefährdete, lag ganz in dessen subjektivem Ermessen. Eindeutig war immerhin das Verbot, lebende Personen auf der Bühne darzustellen. Der Untersuchungsausschuss von 1909 gab dem Lord Chamberlain einige weitere Empfehlungen, in welchen Fällen einem Stück die Lizenz zu versagen war:

It should be his duty to licence any play submitted to him unless he considers that it may reasonably be held -

(a) To be indecent;

(b) To contain offensive personalities;

(c) To represent on the stage in an invidious manner a living person, or any person recently dead.

(d) To do violence to the sentiment of religious reverence;

(e) To be calculated to conduce to crime or vice;

199 Vgl. Report (1866), S. 76.

200 Rules and Regulations with Regard to Theatres in the Jurisdiction of the Lord Chamberlain, 1881, TNA, LC 1/385. 
(f) To be calculated to impair friendly relations with any Foreign Power; or

(g) To be calculated to cause a breach of the peace. ${ }^{201}$

Obschon diese Anweisungen für eine gewisse Konkretisierung sorgten, benannten sie noch immer keine klaren Kriterien. Vielmehr stellten sie die Wirkung auf das Publikum in den Mittelpunkt. An dem Interpretationsspielraum der Zensoren änderte sich dadurch kaum etwas, denn weiterhin waren sie es, die darüber entschieden, ob ein Stück als anstößig oder ein Charakter als anzüglich empfunden, eine lebende oder kürzlich verstorbene Person gehässig dargestellt, religiöse Gefühle oder ein ausländischer Staat beleidigt wurden. Einen guten Einblick in die Arbeit des Lord Chamberlain's Office bieten die Lord Chamberlain's Day Books, in denen jedes zur Zensur vorgelegte Stück unter genauer Angabe der gestrichenen Stellen eingetragen wurde. ${ }^{202}$ Entsprechend der Vorgaben des Untersuchungsausschusses stehen auch in ihnen vor allem drei Aspekte im Mittelpunkt: Sexualität, Religion und Politik.

Die meisten Kommentare beziehen sich auf sexuelle Zweideutigkeiten. So wurde der Manager des Philharmonic Theatre 1879 darauf aufmerksam gemacht, er dürfe keine unanständigen Kostüme und keine obszönen Doppeldeutigkeiten erlauben. ${ }^{203}$ Der Produzent der Musical Comedy The Gay Grisette wurde 1898 ermahnt, die darin enthaltenen Lieder gäben doch einige Möglichkeiten zu Zweideutigkeiten („nasty double meaning“), was keineswegs statthaft sei. ${ }^{204}$ Und über das Musical Play The Sandow Girl meinte der Zensor 1907 schlicht: „No character in the piece is to be allowed to appear on the stage without his trousers“ 205 Wie John Johnston, der als Examiner of Plays tätig war, meinte, vertrat die Zensur nach dem Ersten Weltkrieg eine nachsichtigere Einstellung gegenüber der Thematisierung von Sex auf der Bühne. ${ }^{206}$ Die Day Books bestätigen das hingegen nicht. Noch in den zwanziger Jahren mussten sich die Direktoren belehren lassen, dass Begriffe wie „my virginity“ oder „syphilis“ unzulässig waren. ${ }^{207}$

Das Verhältnis zwischen Theater und Kirche war in Großbritannien seit jeher gespannt. Die Schließung aller Bühnen zur Zeit Oliver Cromwells Mitte des 17. Jahrhunderts ist dafür der beste Beleg, doch auch noch im 19. Jahrhundert standen viele religiöse Gruppierungen dem Theater ablehnend gegenüber. Erst recht brachen die alten Konflikte wieder auf, wenn Bühnenautoren biblische Szenen oder Personen thematisierten. Völlig ausgeschlossen war etwa die Darstellung Gottes oder von Jesus Christus oder auch nur ihre Erwähnung in einem

201 REPORT (1866), S. xi.

202 Die Lord Chamberlain's Day Books befinden sich heute in der British Library. Zur Untersuchung herangezogen wurden die neun Bände zwischen 1877 und 1929 mit den Signaturen Add. MS. 53706 bis 53706 und Add. MS. 61952 bis 61957.

203 Eintrag vom 29.9. 1879, BL, Add. MS. 53706.

204 Eintrag vom 15. 8. 1898, BL, Add. MS. 53708.

205 Eintrag vom 12.8. 1907, BL, Add. MS. 61952.

206 Vgl. Johnston, The Lord Chamberlain's, S. 75.

207 Einträge vom 14.7. 1919 und vom 25.2.1921, BL, Add. MS. 61955. 
Stück. ${ }^{208}$ Oscar Wildes Stück Salome beispielsweise war ebenso wie die davon inspirierte Oper von Richard Strauss in London unaufführbar, weil darin Johannes der Täufer vorkam. ${ }^{209}$ Doch die Zensur schützte keineswegs nur biblische Figuren, sondern auch religiöse Institutionen und ihre Vertreter. Ein Theater in Surrey erfuhr 1885: „To represent the character of a drunken vagabond as clergyman, is a gross and unwarrantable libel on the English Church". ${ }^{210}$ Das Globe Theatre durfte 1894 einen Schauspieler weder durch seine Kleidung als Bischof kenntlich machen noch diesen Titel benutzen. ${ }^{211}$ Dennoch wäre es falsch anzunehmen, dass Religion gar keinen Platz auf der populären Bühne des viktorianischen und edwardianischen Londons gefunden hätte. Das Stück Ben-Hur beispielsweise, in dem Jesus nicht persönlich, sondern nur symbolisch in Form eines Lichtstrahls erschien, war ein ebenso großer Erfolg in London wie zuvor in den USA. ${ }^{212}$

Dass es sich von vornherein verbat, den Monarchen oder ein anderes Mitglied der königlichen Familie auf der Bühne zu porträtieren, scheint den Theaterdirektoren und -schriftstellern bewusst gewesen zu sein, denn dazu findet sich kein Eintrag. Geschützt waren wohl außerdem die königlichen Immobilien, denn die Lizenz für das Stück The Ambassador wurde nur unter der Bedingung gewährt, „that the suggestion of ,blowing up' Buckingham Palace and the Houses of Parliament be omitted“.213 Auf die Frage eines Mitglieds des Untersuchungsausschusses von 1909, ob am Gaiety Theatre politische Anspielungen in die Stücke eingefügt werden, antwortete George Edwardes kategorisch: „They are tabooed as a rule [...] on no account would a biased political allusion be permitted “. ${ }^{214}$ Dennoch gehörte das Gaiety Theatre, unter dem Management von Edwardes ebenso wie unter seinem Vorgänger John Hollingshead, zu den Theatern, die wiederholt ermahnt wurden, so 1888 mit der Anweisung, eine Anspielung auf Joseph Chamberlain zu unterlassen. ${ }^{215}$

Der Schutz von Politikern erstreckte sich nicht nur auf Premierminister und Kabinettsmitglieder, sondern ebenfalls auf die Vertreter ausländischer Staaten, selbst wenn die Mehrheit der Bevölkerung diesen feindlich gesonnen war. Dahinter stand die Furcht, dass die unvorteilhafte Repräsentation eines Staatsoberhauptes für außenpolitische Verwicklungen sorgen könnte. Beliebtestes Ziel der Theaterautoren war der deutsche Kaiser. Immer wieder musste der Lord Chamberlain die Theaterdirektoren ermahnen, Anspielungen auf Wilhelm II. zu unterlassen. Den Produzenten von The Ballet Girl beschied er 1897: „omit in Representation all personal References to the German Emperor".216 Bei Send him Victorious

\footnotetext{
208 Vgl. Stephens, The Censorship, S. 92-114; Foulkes, Church and Stage, insbes. S. 18-34.

209 Vgl. Sova, Banned Plays, S. 238-242.

210 Eintrag vom 30.3. 1885, BL, Add. MS. 53706.

211 Eintrag vom 20.6. 1894, BL, Add. MS. 53707.

212 Vgl. MAYER (Hrsg.), Playing out the Empire.

213 Eintrag vom 19.7.1913, BL, Add. MS. 61953.

214 REPORT (1866), S. 246.

215 Eintrag vom 22. 10. 1888, BL, Add. MS. 53707; dazu ausführlicher das folgende Unterkapitel.

216 Eintrag vom 30.3. 1897, BL, Add. MS. 53708.
} 
wurde 1908 sowohl die Darstellung Wilhelms II. wie auch jede Bezugnahme auf eine Verschwörung zur Herbeiführung eines Krieges zwischen Großbritannien und Deutschland verboten. ${ }^{217}$ Diese Regelung galt selbst noch während des Ersten Weltkrieges. Das patriotische Stück The Glorious Day erhielt nur unter der Voraussetzung eine Lizenz, dass „the characters representing the Emperor and Crown Prince in the last scene are not made up to represent the German Emperor and the Crown Prince of Germany“. ${ }^{118}$ Dasselbe galt für The Master Hun; auch hier durfte die Titelfigur keine Ähnlichkeit zum deutschen Kaiser aufweisen. ${ }^{219}$ Gerade das letztgenannte Beispiel illustriert aber die Inkonsequenz der Zensur: selbst wenn die Hauptfigur nicht wie Wilhelm II. aussah, wusste das Publikum, wer gemeint war.

Die Furcht, dass ein Theaterstück die Beziehungen zu einer anderen Nation gefährden könnte, mag aus dem Rückblick übertrieben wirken, sie war jedoch nicht ganz unberechtigt, wie mehrere Briefe in der Korrespondenz des Lord Chamberlain zeigen. Die meisten Beschwerden aus dem Ausland stammten von Vertretern des Osmanischen Reiches. So bedankte sich 1893 ein britischer Diplomat aus Konstantinopel beim Lord Chamberlain, dass dieser ein Stück auf einer Londoner Bühne nachträglich verboten hatte, in dem der Sultan karikiert wurde, mit dem Kommentar: „No one but an Oriental can feel so keenly the ridicule \& annoyance of being made the subject of Burlesque on a Public Stage ".220 Keine drei Jahre später beklagte sich der Botschafter des Osmanischen Reiches persönlich beim Lord Chamberlain über Stücke im Duke of York Theatre und im Shaftesbury Theatre: ,ayant pour base les incidents arméniens“.221 1900 schrieb er erneut wegen The Oriental Drama von Max Goldberg: „En résumé cette pièce est certainement de nature à donner au public anglais une impression déplorable et surtout à raviver l'agitation".222 In jedem dieser Fälle schritt der Lord Chamberlain ein. Es lässt sich nur spekulieren, warum so viele Beschwerden aus dem Osmanischen Reich kamen, jedoch kaum von europäischen Diplomaten. Dass diese unempfindlich gegen die Verspottung der eigenen Nation gewesen seien, erscheint zweifelhaft. Wahrscheinlicher ist vielmehr, dass die Zensoren bei Anspielungen auf europäische Nationen wesentlich sensibler waren als bei außereuropäischen, weshalb sie es gar nicht erst auf die Bühne schafften.

Wie diese Beispiele aus der Zensurpraxis bestätigen, achteten die Zensoren ganz besonders auf die Behandlung von Sexualität, Religion und Politik in den Textbüchern. Die Gattung eines Stücks war hingegen nicht von Bedeutung, denn die Bemerkungen in den Lord Chamberlain's Day Books betreffen alle Genres,

217 Eintrag vom 30. 12. 1908, BL, Add. MS. 61952.

218 Eintrag vom 12.2.1915, BL, Add. MS. 61954.

219 Eintrag vom 28. 1. 1915, ebd.; siehe das folgende Unterkapitel.

220 Brief Francis Clare Ford an das Lord Chamberlain's Office, 10. 11. 1893, TNA, LC 1/601.

221 Brief Ambassade Impériale de Turquie an Lord Chamberlain's Office, 18.3. 1896, TNA, LC $1 / 657$.

222 Brief Ambassade Impériale de Turquie an Lord Chamberlain's Office, 2.4. 1900, TNA, LC 1/730. 
darunter sogar überwiegend unterhaltende Stücke, die auch den größten Anteil unter den eingereichten Textbüchern stellten.

Dem Schriftsteller Lothar Schmidt zufolge legten die deutschen Zensoren ganz ähnliche Maßstäbe an wie ihre britischen Kollegen: „Drei Artikel geistiger Kontrabande sind es, nach denen prinzipiell und von berufswegen der Zensor den Thespiskarren durchstöbert. Sie tragen die amtlichen Rubra: a) Sexuelles; b) Religiöses; c) Politisches“.223 Ähnlich wie in Großbritannien stand Sexualität also ganz oben auf der Fahndungsliste. Auch dem Autor Kurt Weiss zufolge waren es „fast ausschließlich sittliche Bedenken“, die zu dem Verbot eines Stückes führten. ${ }^{224}$ Diese Einschätzungen bestätigten sich im Rückblick weitgehend. In seiner Untersuchung der Zensur in der Zeit des Deutschen Kaiserreichs kommt Gary Stark zu dem Schluss, dass mehr Dramen aus ,moralischen', denn aus irgendwelchen anderen Gründen verboten wurden, wobei es sich bei den betroffenen Stücken vor allem um Schwänke, Possen, Lustspiele und Komödien gehandelt habe. ${ }^{225}$ Letzteres lässt darauf schließen, dass keineswegs nur die ernsthafte dramatische Produktionen unter der Zensur zu leiden hatten.

Erschwert wird die Überprüfung der Berliner Zensurpraxis allerdings dadurch, dass es keine den Lord Chamberlain's Day Books vergleichbare Übersicht gibt, in der die gestrichenen Szenen gesammelt aufgeführt sind. Die Anmerkungen und Streichungen der Zensoren in den vom Metropol-Theater eingesandten Theaterzensurexemplaren, die im Folgenden als Stichprobe herangezogen werden, geben zumindest einen ungefähren Eindruck, sind aber nur bedingt repräsentativ und lassen sich auch nur schwer bestimmten Kategorien zuordnen. In der Posse Im Paradies der Frauen beispielsweise strich die Zensur in dem Satz: „Ich unterhalte mich übrigens großartig in diesem entzückenden sündigen Berlin!“, das Wort „sündig“.226 Des Weiteren verbot sie eine Ehebruchszene, den Ausdruck „ebenso adligen wie ekelhaften Gatten“ und die Bemerkung eines Studenten, der von einem Schutzmann verhaftet wird: „Wieso denn arretiren? Wir sind doch keine unbescholtenen Mädchen?“.227 Wie daraus deutlich wird gingen die Zensoren gegen abschätzige Anspielungen auf Polizei und Adel, in erster Linie jedoch gegen Stellen vor, die sie als obszön empfanden. Letzteres trifft tatsächlich auf die meisten Zensurstriche zu. In der Revue Der Teufel lacht dazu von 1906 fielen die folgenden Zeilen der Zensur anheim: „,Treibt det Fräulein ein Gewerbe?' frage ik, ,I natierlich' lacht se. ,Treibt sie's alleine?' frage ik. ,Nee' sagt sie ,es muss immer eener dabei sein!“'228 Prostituierte gehörten in den Augen der Zensoren nicht auf die Bühne, vor allem nicht, wenn sie Berliner Dialekt sprachen. ${ }^{229}$ Das erfuhr auch

223 Lothar Schmidt, Polizei und Bühne, Die Gegenwart 80 (1911), 2. Bd., Nr. 44, S. 735-738, hier S. 736.

224 WEISS, Deutsche Theaterverhältnisse, S. 6.

225 Vgl. STARK, Banned in Berlin, S. 209-210, 214.

226 Im Paradies der Frauen, 2. Bild, 4. Szene, LAB, A. Pr. Br. Rep. 30-05-02 Nr. 859.

227 Ebd., 5. Bild, 2. Bild, 4. Bild.

228 Der Teufel lacht dazu, 2. Bild, 7. Szene, LAB, A Pr. Br. Rep. 30-05-02 Nr. 3620.

229 Vgl. STARK, Banned in Berlin, S. 189-190, 196-197, 217. 
Rudolf Bernauer, der Direktor des Berliner Theaters, als er Taifun von Melchior Lengyel inszenierte. Darin war die Frau, an der die Hauptfigur zugrunde ging, „eine Berliner Prostituierte. [...] Aber kurz vor der Aufführung verlangte die Zensur aus politischen Gründen die Verlegung der Handlung nach Paris“.230

Streichungen von Stellen, die religiöse Gefühle verletzen, finden sich in den Theaterzensurexemplaren des Metropol-Theaters nicht, aber Religion wurde auf dessen Bühne auch kaum thematisiert. Generell befürchtete der preußische Innenminister bei allen Stücken, die Szenen aus der Bibel aufgriffen, dass sie als Profanierung empfunden werden könnten, weshalb er die Zensoren in diesen Fällen zu besonderer Aufmerksamkeit mahnte. ${ }^{231}$ Dennoch scheint die Berliner Zensurbehörde diesbezüglich liberaler gewesen zu sein als die Londoner. Oscar Wildes in London verbotenes Stück Salome etwa konnte in Berlin ohne Schwierigkeiten aufgeführt werden. Das legt den Schluss nahe, dass die Zensur religiöse Stoffe nicht von vornherein verbot, sondern nur, wenn sie kritisch oder gar satirisch behandelt wurden. Sofern ein Stück religiöse Gefühle nicht verletzte, passierte es die Zensur problemlos.

Was schließlich das dritte von Schmidts Rubra, die Politik, angeht, so finden sich in den vom Metropol-Theater zur Zensur eingereichten Texten ebenfalls nur wenige Streichungen. Anders als in London, wo es nahezu unmöglich war, einen Politiker wie Joseph Chamberlain auf der Bühne darzustellen, ließ die Berliner Zensur milde Formen von politischer Satire durchaus zu. Gleich in der ersten Jahresrevue, Neuestes! Allerneuestes! von 1903, traten in einer vor dem Reichstag spielenden Szene der erst fünf Jahre zuvor verstorbene Otto von Bismarck und sein ehemaliger Gegenspieler Ludwig Windthorst auf. ${ }^{232}$ Keinen Politiker erwähnten die Metropol-Revuen so oft wie den Sozialdemokraten August Bebel, der weniger karikiert als verhöhnt wurde. ${ }^{233}$ Wie im Fall der Religion wussten die Zensoren auch bei der Politik durchaus zu unterscheiden. Während Dramen mit progressiver oder gar sozialdemokratischer Tendenz der Weg auf die Bühne versperrt war, blieb, wie Lothar Schmidt sich empörte, die „sogenannte gute, die waschechte patriotische Gesinnung [...] natürlich unbehelligt. Hohnzollerndramen mit einem starken Zusatz von Byzantinismus sind sogar sehr erwünscht, werden leicht hoftheaterfähig und tragen dem Herrn Verfasser womöglich den Kronenorden vierter Klasse ein". ${ }^{234}$ Deshalb ist weniger von einer Zensur der Politik als von einer politischen Zensur zu sprechen. Die offen zur Schau gestellte Systemtreue konnte aber auch ein geschickter Schachzug sein, mit dem sich die Nachsichtigkeit der Zensur in anderen Dingen ,erkaufen' ließ. Das legt jedenfalls

230 Bernauer, Das Theater, S. 267.

231 Vgl. STARK, Banned in Berlin, S. 173.

232 Neuestes! Allerneuestes!, 3. Bild, 13. Szene, LAB, A Pr. Br. Rep. 30-05-02 Nr. 2638.

233 Siehe z. B.: Ein tolles Jahr, 1. Bild, 2. Szene und 2. Bild, 11. Szene, TSFU, NL Freund 97/02/ W172; für eine eingehende Analyse der Repräsentation von Politik auf der Bühne siehe das folgende Unterkapitel.

234 Lothar Schmidt, Polizei und Bühne, Die Gegenwart 80 (1911), 2. Bd., Nr. 44, S. 735-738, hier S. 737. 
eine Besprechung in der Berliner Morgenpost nahe, in der es über den Hausautor des Metropol-Theaters, Julius Freund, hieß: „Er teilt satirische Hiebe nach allen Seiten aus und läßt einen die Langmut der Zensur bewundern, bis er uns wieder durch einen gewissen Hurra-Patriotismus darüber belehrt, daß auch die Zensur in Berlin nachsichtig sein kann, wenn man, wie Freund, auf der andern Seite hübsch lieb und brav ist“.235

Auf praktischer Ebene unterschied sich die Berliner Zensur von der Londoner vor allem dadurch, dass sie nicht bei der Vorzensur, also der Kontrolle der Textbücher, haltmachte, sondern jede einzelne Vorstellung überwachte. Gleich bei der ersten Metropol-Revue, Neuestes! Allerneuestes!, monierte die Polizei eine Vielzahl von Punkten: Veränderungen an Figuren, das Kostüm einer Darstellerin, das „zu tief ausgeschnitten“ sei, und dass zwei Schauspieler extemporiert hätten. ${ }^{236}$ Nachdem ein Polizeirapport 1909 vermerkt hatte, Guido Thielscher und Fritzi Massary, die beiden Stars des Metropol-Theaters, hätten mehrfach Stellen vorgetragen, die von der Zensur gestrichen worden waren, stellte das Polizeipräsidium sogar Strafanzeige gegen Thielscher. ${ }^{237}$ Die Theaterleitung schien dies jedoch nicht abzuschrecken, denn bereits im folgenden Jahr beschied ihr die Polizei erneut:

Wie festgestellt worden ist, werden seit einiger Zeit im Metropoltheater bei der Aufführung der Revue vielfach Sätze gesprochen, die in der hier s. Zt. vorgelegten und genehmigten Fassung des Stückes nicht enthalten sind und sich meist auf actuelle, erst nach der ersten Aufführung des Stückes eingetretene, Ereignisse beziehen. Wie der Direktion bekannt ist, bedürfen alle Nachträge und Änderungen zu einem Stück gleichfalls der zensurpolizeilichen Genehmigung und dürfen vorher nicht vorgetragen werden. ${ }^{238}$

Solche Verstöße konnten nur festgestellt werden, wenn ein Polizeibeamter den Vorstellungen beiwohnte und im Textbuch mitlas. Es liegt auf der Hand, dass unter diesen Bedingungen Improvisation nahezu unmöglich war. Mehr noch, auch Veränderungen eines Stücks nach der Uraufführung, wie sie in London üblich waren, wurden erheblich erschwert und dasselbe galt für das Aufgreifen aktueller Ereignisse, wie es das Publikum gerade beim Genre der Jahresrevue erwartete.

Obwohl die Theaterzensur 1918 abgeschafft worden war, bestand auch in der Zeit der Weimarer Republik keine unumschränkte Theaterfreiheit. Die Vorzensur blieb zwar außer Kraft, doch gab es die Möglichkeit, gerichtlich gegen missliebige Stücke und Aufführungen vorzugehen. Das bekannteste Beispiel ist der ReigenProzess von 1920. Arthur Schnitzler hatte Reigen, ein Stück, das in zehn Dialogen von sexuellen Begegnungen zwischen Frauen und Männern von der untersten bis zur höchsten gesellschaftlichen Schicht handelt, bereits um die Jahrhundertwende geschrieben, seine Aufführung aber von vornherein ausgeschlossen. 1920 wurde es von Gertrud Eysoldt am Kleinen Schauspielhaus inszeniert, das sie zusammen mit Maximilian Sladek leitete. Nur wenige Stunden vor der Uraufführung erging

235 Berliner Morgenpost, 13.3. 1904; ähnlich: Die Welt am Morgen, 16. 9. 1907.

236 Brief Polizeipräsidium an Metropol-Theater, 8. 1. 1903, LAB, A. Pr. Br. Rep. 030-50-714.

237 Vgl. Das Theater Unter den Linden, LAB, A. Pr. Br. Rep. 030-50-709.

238 Brief des Polizeipräsidiums an das Metropol-Theater, 30.5.1910, LAB, A. Pr. Br. Rep. 03050-715. 
eine einstweilige Verfügung, die das Stück verbot und den Direktoren bei Zuwiderhandlung sechs Wochen Haft androhte. Eysoldt stand zu Stück und Inszenierung und die Premiere ging planmäßig über die Bühne, woraufhin die Staatsanwaltschaft Anklage gegen sie, Sladek und das ganze Ensemble erhob. Das Gericht sprach sie jedoch frei und verlieh ihrer Inszenierung sogar das Prädikat „eine sittliche Tat“ ${ }^{239}$ Eine Krawallaktion im Theater, an der ,junge Burschen mit Hakenkreuzen beteiligt" waren, führte zu einem zweiten Gerichtsverfahren im November 1921. ${ }^{240}$ Trotz einer groß angelegten Hetzkampagne kamen die Richter erneut zu dem Urteil, der Reigen verfolge einen „sittlichen Gedanken“ und hätte nicht „die Absicht [...] Lüsternheit zu erwecken“. ${ }^{241}$ Noch stellte sich die Justiz auf die Seite der freien Meinungsäußerung und die Polizei zeigte sich unbeeindruckt von den Hakenkreuzlern.

Seit den späten zwanziger Jahren hagelte es dann Verbote gegen Theaterstücke mit der Begründung, die öffentliche Sicherheit und Ordnung könne nicht gewährleistet werden, weil Proteste von rechter Seite zu befürchten seien. Peter Martin Lampels Stück Giftgas über Berlin verbot die Berliner Polizei nach nur wenigen, obendrein nicht-öffentlichen Vorstellungen und bei Marieluise Fleißers Pioniere in Ingolstadt verlangte sie die Streichung mehrerer Passagen. Beide Male berief sie sich auf $\$ 10$, Titel 17, Teil II des Allgemeinen Landrecht für die Preußischen Staaten, dieselbe Gesetzesgrundlage, auf der schon die Polizei-Verordnungen von 1820 und 1851 gefußt hatten. ${ }^{242}$ Obwohl die Theaterzensur 1918 abgeschafft worden war, übte die Polizei auf der Basis ihrer Ordnungsfunktion also weiterhin de facto eine Zensur über die Theater aus. Anstatt den Störenfrieden von rechts entgegenzutreten und die Werte der Republik zu verteidigen, benutzte sie die Störungen, um mit Verweis auf die Aufrechterhaltung der öffentlichen Ordnung, Theateraufführungen zu verbieten. Für den Theaterkritiker Ludwig Marcuse gehörte bereits der Ausgang des Reigen-Prozesses zur „Klasse jener Siege die Niederlagen sind“. 243 „In Wirklichkeit geht immer viel weniger unter, als siegreiche Revolutionäre glauben“, meinte er später und hatte damit nicht nur für die Zensur recht. ${ }^{244}$

\section{Zwischenfazit}

Im Laufe des 19. Jahrhunderts schafften nahezu alle europäischen Staaten die Zensur von Büchern und Presse ab. Gegen das Theater aber galt noch fast überall ein allgemeiner Vorbehalt, aufgrund dessen die Vorzensur der Theaterstücke, zum Teil auch die Überwachung der Vorstellungen üblich war. Aus heutiger Sicht ist

\footnotetext{
239 Marcuse, Obszön, S. 194.

240 Heine, Der Kampf um den Reigen, S. 159.

241 Zit. n. BOETZKeS und QUECK, Die Theaterverhältnisse, S. 708.

242 Vgl. Harry Kahn, Giftgase, Die Weltbühne 2 (1929), 1. Bd., S. 417-419; ders., Begleiterscheinungen, in: ebd., S. 568-571; siehe auch Petersen, Literatur und Justiz, S. 81-85.

243 Marcuse, Obszön, S. 240.

244 Ebd., S. 192.
} 
diese Anomalie nicht leicht zu verstehen. Zur Erklärung wird auf die Furcht der Zeitgenossen vor dem Theater verwiesen. Nicht nur versammelten sich hier, wie an kaum einem anderen Ort um 1900, Menschenmassen; das Theater konnte aufgrund seiner emotionalisierenden Wirkung unter Umständen auch die öffentliche Ordnung gefährden. Gustave Le Bon, einer der ersten Theoretiker der modernen Massengesellschaft, zeigte sich in seiner 1895 erschienenen Psychologie der Massen überzeugt, dass „Theatervorstellungen [...] auf die Massen stets einen ungeheuren Einfluß“ hätten, der leicht zum Aufruhr führen konnte: „Oft [...] sind die durch die Bilder ausgelösten Gefühle so stark, daß sie gleich den gewöhnlichen Suggestionen, die Tendenz zur Umsetzung in Handlung aufweisen “. 245 In den Augen Le Bons handelten Volksmassen nicht rational, sondern emotional: waren ihre Gefühle einmal geweckt, ließen sie sich nicht mehr kontrollieren.

Diese Logik überdauerte den Ersten Weltkrieg. Noch Mitte der zwanziger Jahre meinte ein Berliner Oberregierungsrat auf einer internationalen Polizeikonferenz: „Das Theaterpublikum steht unter der Einwirkung einer besonders suggestiven Kunstgattung mit der ganzen Resonanz, die Worte und Gebärde in einem geschlossenen Raum haben. Große geistige und politische Entwickelungen sind vielfach vom Theater ausgegangen“ 246 Beispiele für eine tatsächliche Gefährdung der öffentlichen Sicherheit und Ordnung, die im Theater ihren Ursprung genommen hätten, sind jedoch rar. Tatsächlich ging von der Bühne zu keinem Zeitpunkt eine wirkliche Bedrohung aus. Das heißt allerdings nicht, dass die Zeitgenossen eine solche nicht ernsthaft befürchteten. Womöglich hatte die Langlebigkeit der Theaterzensur aber noch einen anderen, trivialeren Grund: Gesetze sind leichter zu verabschieden als zurückzunehmen und in der Regel gibt kein Staat ein einmal etabliertes Instrument zur Kontrolle seiner Bürger freiwillig wieder auf. In Zeiten politischer Umwälzungen entstanden, bedurfte es schon tief greifender politischer Wandlungen wie der Revolution von 1918, um die Zensur wieder abzuschaffen.

Der Vergleich hat weitgehende Gemeinsamkeiten aufgezeigt: Abgesehen von ihrem späteren Beginn waren die Berliner Zensurbestimmungen denen in London sehr ähnlich. Ein wesentlicher Unterschied war dagegen, dass in Großbritannien die Zensur auf einem nationalen, im Parlament verabschiedeten Gesetz beruhte, während sie im Gebiet des Deutschen Reiches durch unterschiedliche lokale und regionale Polizeiverordnungen geregelt wurde. Dadurch war ihre Legitimation wesentlich anfechtbarer, zumal sie in den Augen ihrer Gegner im Widerspruch stand zur Gewerbefreiheit und zur preußischen Verfassung. Außerdem erweckte die unterschiedliche Handhabung der Zensur in verschiedenen Gebieten des Reiches den Eindruck von Willkür. ${ }^{247}$

Schon die Zeitgenossen trieb die Frage um, ob die Zensur in Preußen strenger war als in anderen Ländern, namentlich in dem als liberal geltenden Großbritan-

245 LE Bon, Psychologie der Massen, S. 44.

246 Adriani, Moderne Theaterpolizei. Zwei Vorträge auf der Internationalen Polizeikonferenz zu Berlin, Die Deutsche BüHne 14 (1926), S. 245-252, hier S. 248.

247 Vgl. etwa WEIss, Deutsche Theaterverhältnisse, S. 6. 
nien. Dafür spricht zum einen, dass sich die Berliner Polizei nicht mit der Vorzensur begnügte, sondern die Theatervorstellungen überwachte, zum anderen, dass in Berlin - absolut wie relativ - sehr viel mehr Stücke verboten wurden als in London. ${ }^{248}$ Dagegen ließe sich einwenden, dass der Lord Chamberlain eine ganze Reihe von Stücken verbot, die in Berlin ohne Schwierigkeiten aufgeführt werden durften. ${ }^{249}$ Auch wurden in London immer wieder Stücke verboten, die die Berliner Zensur ohne Beanstandung hatte passieren lassen. Gerhart Hauptmanns Drama Hanneles Himmelfahrt beispielsweise erlebte 1893 seine Uraufführung im Königlichen Schauspielhaus, der Lord Chamberlain hingegen erteilte dem Stück keine Lizenz mit der Begründung: „,it does not follow that a play licensed in German would be licensed in English". 250

Umgekehrt finden sich keine Beispiele für Stücke, die in Berlin verboten, in London aber erlaubt waren. Vor diesem Hintergrund wirkt nun wieder die preuBische Zensur liberaler als die britische. Dafür ließen sich noch weitere Indizien anführen. George Edwardes attestierte Großbritannien vor dem Untersuchungsausschuss von 1909, dass es „the cleanest stage in the world“ besitze und schwang sich zu der Behauptung auf, Frankreich, Deutschland und Österreich besäßen überhaupt keine nennenswerte Zensur. ${ }^{251}$ Ein Artikel in dem Branchenblatt The Era mit dem Titel „The Advanced German Drama. What Our Censor Saves Us From" kam nur wenige Jahre später zu einem ganz ähnlichen Ergebnis:

Any stranger visiting Berlin for the first time and doing a round of the so-called classical or intellectual theatres would, if he understood the language, ask the first competent German he met the question: ,Have you no censor, and, if so, what manner of person must he be?' As a matter of fact, the German censor is a figurehead and nothing more. The only end it serves is to give a free and very excellent advertisement to an author by the occasional prohibition of a play. Public curiosity is aroused - author and manager see to that - and the author poses as misunderstood or misjudged. When the piece, with some scarcely perceptible modifications, succeeds in appeasing the censorship (no very difficult task) he is sure of his audience. ${ }^{252}$

Auch der Autor dieses Artikels hatte den Eindruck, dass es in Berlin faktisch keine Zensur gäbe, beziehungsweise, dass sie im Dienst der Theater und Autoren stünde, für die ein Skandal die beste Werbung sei.

Mit Konstantin von Zedlitz trat auch ein deutscher Beobachter der verbreiteten Meinung entgegen, die britische Zensur sei liberaler. Nicht nur habe sie etliche Reformgesetze überstanden, schrieb er, sie verfahre obendrein „nach denselben Principien wie die preußische“, wobei sie „jedoch erheblich willkürlicher" sei, da sie keinen Widerspruch zulasse. Viele der in Berlin aufgeführten Stücke waren Zedlitz zufolge „auf einer Londoner Bühne schlechterdings undenkbar“.253

$248 \mathrm{Zu}$ diesem Schluss kommt auch STARK, Banned in Berlin, S. 221-222.

249 Vgl. SovA, Banned Plays, S. 238-242; ebd., S. 186-189; KNOLL, Produktive Missverständnisse, S. 121 .

250 Zit. nach Sova, Banned Plays, S. 112-113, hier S. 113.

251 Report (1909), S. 242-243,

252 The Advanced German Drama. What Our Censor Saves Us From, ThE ERA, 7. 12. 1912, S. 19.

253 Konstantin von Zedlitz, Die Theatercensur in England, Die ZeIT 33/34 (1902/1903), Nr. 443, S. 153-154. 
„Tauschten daher etwa der Berliner und der Londoner Censor einmal für ein Jahr die Rollen, so würde jener hier von den ihm vorgelegten Stücken schwerlich überhaupt eines, der diesige in Berlin dagegen sicherlich das Doppelte und Dreifache der üblichen Anzahl zurückweisen“, resümierte er. ${ }^{254}$ Auch in seinen Augen war folglich die Berliner Zensur toleranter als die Londoner. Dass er dafür in erster Linie die „Prüderie des großen englischen Publikums“ verantwortlich machte, deutet daraufhin, dass auch er den Unterschied primär in der Repräsentation von Sexualität auf der Bühne ausmachte. ${ }^{255}$ Die Handhabung der Zensur in London und Berlin war also nicht nur eine Frage von Strenge und Toleranz. Wenngleich die Zensurbehörden an beiden Orten auf die Themen Sexualität, Religion und Politik achteten, legten sie dabei doch unterschiedliche Maßstäbe an.

Die Zensurproblematik ist unmittelbar verknüpft mit der Unterscheidung von Hoch- und Populärkultur. Wie eingangs erwähnt, fühlten sich viele Dramatiker ungerecht behandelt, da sie das Gefühl hatten, dass die Zensur ihre Arbeit nahezu unmöglich machte, während populäre Genres nur so vor Zweideutigkeiten strotzten. Die Gesetzestexte trafen eine solche Unterscheidung nicht: weder der Theatre Act noch die Polizeiverordnung von 1851 differenzierten zwischen verschiedenen Genres. Auch die Zensurpraxis lässt nicht erkennen, ob die Zensoren zwischen Dramen und unterhaltenden Stücken unterschieden. In den Lord Chamberlain's Day Books finden sich ebenso viele Streichungen in Melodramen und Musical Comedies wie bei Stücken anderer Gattungen. Für den Vorwurf von William Archer, George Edwardes habe sich für die Zensur ausgesprochen, weil er nicht unter ihr zu leiden habe, findet sich kein Beleg. So taucht das Gaiety Theatre regelmäßig in den Zensurakten auf. Desgleichen geriet das Metropol-Theater immer wieder in Konflikte mit der Zensur.

Wenngleich überzogen war die Klage der Dramatiker dennoch nicht ganz unberechtigt. Manches deutet daraufhin, dass die Zensurbehörden in der Tat der populären Unterhaltung gnädiger gesonnen waren als dem sogenannten ernsthaften Drama. Walter Freund, der Sohn von Julius Freund, berichtet in seinen Erinnerungen, dass sein Vater 1909 von Traugott von Jagow, dem neuen Berliner Polizeipräsidenten, einbestellt wurde, der ihm gesagt habe: „Ich habe Sie zu mir gebeten, damit Sie aus meinem Munde hören: Mit mir können sie machen, was sie wollen“, woraufhin der Schauspieler Joseph Giampietro in der nächsten Revue als Polizeioffizier auftrat. ${ }^{256}$ Der von Jagow unterstellte und für die Theaterzensur zuständige Polizeichef von Glasenapp wiederum meinte im Rückblick, er habe „mit dem Unternehmer Richard Schulz [sic!] und dem Autor Julius Freund in bestem Einvernehmen gelebt [...], obgleich es in der damaligen Zeit sehr mißlich war, politische Witze und Satiren, wie die Revuen sie boten, auf der Bühne zu bringen“. 257

254 Ebd., S. 154.

255 Ebd.

256 Freund, Aus der Frühzeit, S. 63; siehe auch StARK, Banned in Berlin, S. 49-50, 215-216.

257 Von Glasenapp, Das Organ Der VArietéwelt, 21.1.1928, zit. nach Hahn, Das MetropolTheater, S. 102, Anm. 21. 
Solche Aussagen werden auch von der Zensurpraxis bestätigt. Für jede Anzüglichkeit, die das Polizeipräsidium in den Revuen strich, ließ es Dutzende durchgehen. Im Vergleich zu den Schwierigkeiten, die die Zensur Dramatikern wie Gerhart Hauptmann, Arthur Schnitzler und Frank Wedekind bereitete, konnte Julius Freund in der Tat recht unbekümmert arbeiten. Das war in Großbritannien nicht anders. Wie der actor-manager Herbert Beerbohm Tree berichtete, verbot der Lord Chamberlain die Aufführung eines renommierten französischen Dramas, weil es darin um Ehebruch ging - ein Thema, das im Unterhaltungstheater allezeit einen der ersten Plätze einnahm. Bei einem persönlichen Gespräch beschied der Zensor Beerbohm Tree: „if it could be made more comic, it would pass“. 258

In der Tat war die Art und Weise, wie ein Stoff dargestellt wurde, oft wichtiger als der Stoff selbst. Komik nahm in den Augen der Zensoren einem Gegenstand den Stachel. So wurde Wedekinds Drama Frühlings Erwachen von der Zensur verfolgt, eine Parodie dieses Stücks in der Jahresrevue Das muß man seh'n! wurde hingegen ohne Einwände gestattet. ${ }^{259}$ Obwohl das unterhaltende Theater rechtlich gesehen denselben Zensurbestimmungen unterlag wie das Kunsttheater, erfreute es sich doch einer gewissen Nachsicht. Das erklärt zumindest teilweise, warum die Berliner Zensur mehr Stücke verbot als die Londoner. Auf dem Kontinent spielte die sozialkritische Bewegung des Naturalismus ebenso wie der sich daran anschließende Expressionismus eine sehr viel größere Rolle als in Großbritannien.

Die Akten in den Archiven zeigen, dass von einer diametralen Frontstellung zwischen Theater und Zensurbehörden keine Rede sein kann. Keineswegs alle Bühnenangehörigen standen der Zensur so kritisch gegenüber wie die Autoren. Umgekehrt waren die Zensurbehörden oft um Vermittlung bemüht. Der für die Zensur zuständige von Glasenapp war eher liberal eingestellt und um Ausgleich mit den Theatern bemüht. Bevor er ein Stück verbot, besuchte er die Proben und sprach mit den Autoren. Mit Arthur Schnitzler und Frank Wedekind, zwei Schriftsteller, die besonders unter der Zensur zu leiden hatten, war er persönlich befreundet. Nachdem seine Abteilung 1918 abgeschafft worden war, wurde er sogar Geschäftsführer des Verbandes deutscher Erzähler, einer Interessenvertretung der Autoren. ${ }^{260}$ Auch standen der Lord Chamberlain wie die Berliner Polizei unter Druck vonseiten der Politik und der Öffentlichkeit. Wie die Theaterpolitik insgesamt, so war auch die Zensurpraxis Ergebnis eines komplexen Aushandlungsprozesses, an dem verschiedene Gruppen beteiligt waren.

Und schließlich ist zu berücksichtigen, dass die Theater und die Theaterautoren Selbstzensur übten. Aus Erfahrung und dem Umgang mit den Behörden wussten die Direktoren wie auch die Autoren, auf welche Aspekte die Zensoren

258 Zit. nach Fowell und PaLmer, Censorship in England, S. 246.

$259 \mathrm{Zu}$ Frühlings Erwachen siehe STARK, Banned in Berlin, S. 69, 218-222; parodiert wurde das Stück in: Das muß man seh'n!, 8. Bild, 4. Scene, LAB, A Pr. Br. Rep. 30-05-02 Nr. 3915.

260 Vgl. Stark, Banned in Berlin, S. 48-49. 
achten und welche Anspielungen sie geneigt waren durchgehen zu lassen. Da Theatern an nichts weniger gelegen war, als ihr Publikum vor den Kopf zu stoßen, bedurfte es keines Lord Chamberlain, um sie von allzu drastischen sexuellen, politischen oder sozialkritischen Kommentaren abzuhalten. Während sich aber der Einfluss der Zensur auf das Theater dank der erhaltenen Akten recht gut rekonstruieren lässt, entzieht sich die Selbstzensur der historischen Analyse. 
Politik im Theater bemüht sich, die Anhänger ins Theater hineinzuziehen, und es gelingt ihr, die Gegner aus dem Theater herauszutreiben. Die Gegner sind immer viel zahlreicher als die Anhänger.

Arthur Kahane ${ }^{261}$

We have not yet been educated properly as to the possibilities of politics on the stage. We are Party men. We cannot laugh as good humouredly at a palpable hit' against our own men and matters as we lustily cheer a ,hit' at the expense of our opponents.

W. B. Findon ${ }^{262}$

\subsection{Inszenierte Politik}

Angesichts einer Zensur, die jedes Stück der Überprüfung unterwarf, scheint die Behandlung von Politik auf der Bühne nahezu ausgeschlossen zu sein - zumal die Zensoren in Berlin und London auf politische Anspielungen besonders achteten. Noch ein zweiter Grund aber sprach dafür, diese zu vermeiden. Das populäre Theater der Jahrhundertwende war seinem Wesen nach kommerziell und zielte deshalb auf ein Massenpublikum ab. Massenpolitik aber war Parteipolitik, weshalb eine eindeutige politische Parteinahme fatal gewesen wäre, hätte sie doch das Publikum gespalten. Ergriff ein Stück, ein Autor oder ein Theater Partei für eine politische Richtung, lief er oder es stets Gefahr, den Unwillen seiner Gegner zu erregen und, wie Arthur Kahane es auf den Punkt brachte, die Gegner waren immer zahlreicher als die Anhänger.

Vor diesem Hintergrund scheint es doppelt unwahrscheinlich, dass populäre Bühnen wie das Gaiety Theatre und das Metropol-Theater sich zu politischen Themen äußerten: Selbst wenn die Zensur entsprechende Stellen passieren ließ, hätten sie riskiert, das Publikum oder Teile desselben gegen sich aufzubringen. Tatsächlich spielte Politik im populären Musiktheater eine im Vergleich zu anderen Themen untergeordnete Rolle. Trotzdem ignorierte es die Politik nicht völlig, wie das folgende Unterkapitel zeigt. Es fragt danach, welche Themen unter den Bedingungen der Zensur aufgegriffen, wie sie behandelt wurden und wie die offizielle Politik, die Zensurbehörden und das Publikum darauf reagierten. Um diese Fragen zu beantworten, wird die Repräsentation von Politik vor dem Ersten Weltkrieg anhand von vier Feldern untersucht: Innenpolitik, Außenpolitik, Imperialismus und Militarismus. Dabei wird den Gemeinsamkeiten und Unterschieden zwischen Berlin und London, aber auch der gegenseitigen Wahrnehmung nachgespürt. Der Erste Weltkrieg und seine Folgen stellen - vor allem in Deutschland, wo 1919 die Zensur abgeschafft wurde - einen so tiefen politischen Einschnitt dar, dass der Zwischenkriegszeit ein eigener Abschnitt gewidmet ist.

261 KaHANE, Theater, S. 66.

262 B. W. Findon, Everybody's Doing It, The Play Pictorial 21 (1913), Nr. 127, S. 70-71, hier S. 70 . 


\section{Innenpolitik}

Da die Rules and Regulations die Darstellung lebender Personen auf der Bühne ausdrücklich untersagten, war die Parodie eines Politikers durch einen Schauspieler eine der unwahrscheinlichsten Formen, Politik zu thematisieren. Doch selbst dafür lassen sich Beispiele anführen. Ein Politiker, der gleich mehrfach auf der Bühne des Gaiety Theatre auftauchte, war Joseph Chamberlain. Obgleich er nie das höchste Amt des Premierministers bekleidete, war Chamberlain eine der wichtigsten Figuren der britischen Innen- wie Außenpolitik vor dem Ersten Weltkrieg. Bereits in der Burleske Faust up to Data von 1888 gab es eine Anspielung auf ihn, die allerdings von der Zensur gestrichen wurde. ${ }^{263}$

Das hielt den Bühnenautor James T. Tanner jedoch nicht davon ab, eine ganze Musical Comedy um Chamberlain herum zu bauen. The Orchid, das erste Stück, das 1903 im neuen Gaiety Theatre gespielt wurde und bei dessen Premiere König Edward VII. zugegen war, handelte von der Rivalität zwischen dem Briten Aubrey Chesterton und einem französischen Grafen um eine besonders seltene Orchideenart. ${ }^{264}$ Bereits äußerlich erinnerte Chesterton an Chamberlain, denn der ihn verkörpernde Schauspieler Harry Grattan trug dessen weithin bekannte Markenzeichen: ein Monokel im rechten Auge und eine Orchidee im Knopfloch (Abbildung 1). George Edwardes leugnete zwar vor dem Untersuchungsausschuss von 1909 beharrlich, dass damit Chamberlain gemeint war, seine fadenscheinigen Ausreden überzeugten aber nicht. ${ }^{265}$

Chestertons Auftrittslied Pushing gab in vier Strophen den nur wenig verfremdeten Lebenslauf Chamberlains wieder. So berichtet Chesterton in der ersten Strophe, wie er durch Ehrgeiz und die Erfindung einer revolutionären Sicherheitsnadel zu Vermögen gekommen war. Chamberlain war als Achtzehnjähriger in die Fabrik seines Onkels eingestiegen und hatte diese zu einem großen kommerziellen Erfolg geführt. In der zweiten Strophe brüstet sich Chesterton dann, die Infrastruktur seiner Geburtsstadt reformiert zu haben, eine Anspielung auf Chamberlain, den Kommunalpolitiker, der 1873 als Kandidat der Liberalen zum Bürgermeister von Birmingham gewählt wurde und wichtige Reformmaßnahmen durchführte. Die dritte Strophe schließlich behandelt Chestertons Wahl ins Parlament in Analogie zu Chamberlains Einzug ins Unterhaus 1876, und die vierte Strophe thematisiert dessen politische Wandlung vom radikalen Liberalen zum überzeugten Imperialisten: ${ }^{266}$

Tho' my former friends at present

Are sarcastic and unpleasant

When they see that I am going into win, I ignore their aimless chatter

263 Vgl. Eintrag vom 22. 10. 1888, BL, Add. MS. 53707.

264 Vgl. The Orchid, BL, MSS LCP 1903/27; siehe auch GänZL, The Encyclopedia, S. 1097.

265 Vgl. RePort (1909), S. 247.

266 Zur Biographie Chamberlains siehe CrosBY, Joseph Chamberlain. 
Abbildung 1: Harry Grattan mit Monokel und Orchidee, den Markenzeichen des Politikers Joseph Chamberlain, als Aubrey Chesterton in der Musical Comedy The Orchid von 1903.

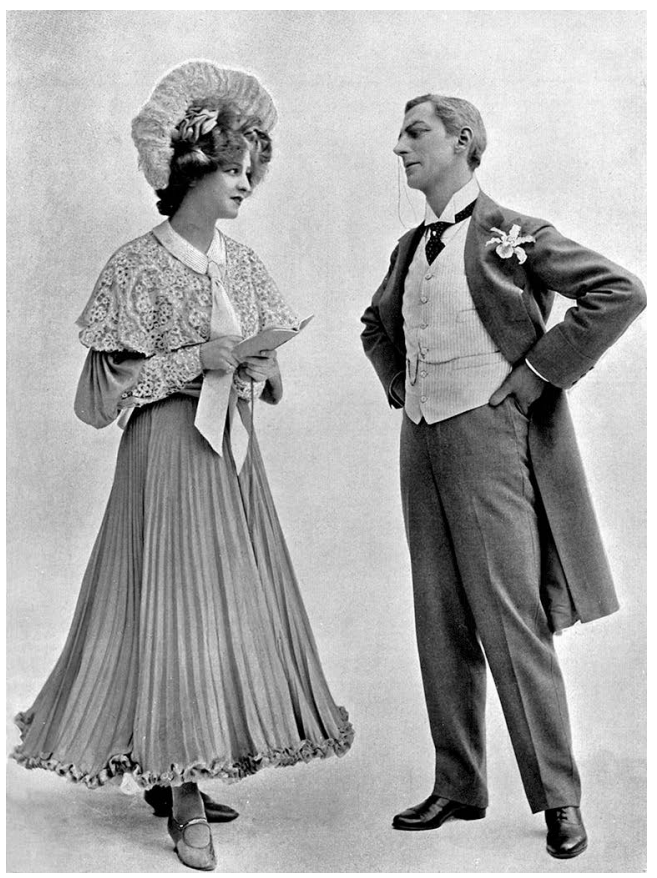

For I know it doesn't matter,

And I stand up for the Empire thick and thin!267

Die Spaltung der liberalen Partei durch die Gründung der Liberal Unionists 1886 hatte in der Tat viele seiner ehemaligen Freunde vor den Kopf gestoßen. Noch mehr Feinde machte er sich dadurch, dass er die neue Partei 1895 in eine Koalition mit den Konservativen führte und selbst als Kolonialminister in das Kabinett eintrat, um für die Interessen des Empires zu streiten. Der fiktive Wettlauf zwischen dem Briten Chesterton und dem französischen Grafen spielte auf die Faschoda-Krise von 1898 an, in der es aufgrund konkurrierender kolonialer Interessen in Nordafrika fast zum Krieg zwischen Großbritannien und Frankreich gekommen wäre. ${ }^{268}$ Letzte Zweifel, dass es sich bei Chesterton um Chamberlain handelte, beseitigte spätestens der Refrain, der in immer neuen Variationen auf Chamberlains Spitznamen „Pushful Joe“ anspielte: ${ }^{269}$

Pushful, pushful,

I'm so very pushful,

First I land the bird in hand, and then I bag the bushful.

If you'd try to rise as high in credit and appearance,

Pray pursue the pathway of a pushful perseverance. ${ }^{270}$

267 The Orchid, 1. Akt, 7. Song, BL, MSS LCP 1903/27.

268 Vgl. Massie, Dreadnought, S. 248-256; HiLDEBRAND, Das vergangene Reich, S. 224.

269 Vgl. Crosiy, Joseph Chamberlain, S. 2, 36, 67, 190.

270 The Orchid, 1. Akt, 7. Song, BL, MSS LCP 1903/27. 
Nachdem seine Behauptung vor dem Untersuchungsausschuss, mit Chesterton sei keineswegs der Politiker Chamberlain gemeint, widerlegt worden war, verteidigte sich George Edwardes damit, Pushful sei ,a topical song of the day, and [...] absolutely inoffensive. There was nothing against Mr. Chamberlain in the song “271 Auch das war nicht ganz richtig. Vielmehr war der Song so ambivalent wie der Spitzname ,Pushful Joe. Einerseits schmeichelte er Chamberlain, indem er ihn zu einem zentralen Protagonisten der britischen Politik des Jahres 1903 machte und seinen Aufstieg vom Unternehmer zum Politiker nachzeichnete, andererseits zeigte er ihn als einen Politiker, der rücksichtslos handelt, um „monstrous / Mephistophelean aims“ zu erreichen. ${ }^{272}$ Diese Doppeldeutigkeit, die es gestattete, ein und dieselbe Szene auf ganz unterschiedliche Arten zu verstehen, charakterisiert ganz grundsätzlich den Umgang des populären Theaters mit der Politik. Die Ambivalenz nahm der Satire ihre Spitze und verhinderte, das Publikum zu brüskieren.

Was Joseph Chamberlain für das Gaiety Theatre war, war August Bebel, der Mitbegründer und langjährige Vorsitzende der Sozialdemokratischen Partei Deutschlands, für das Metropol-Theater. Die beiden Politiker waren einander auch gar nicht so unähnlich, wie es vielleicht auf den ersten Blick scheinen mag. Bebel, nur vier Jahre jünger als Chamberlain, stammte wie dieser aus eher bescheidenen Verhältnissen, war als Fabrikant tätig und über Jahrzehnte hinweg die charismatische Symbolgestalt der politischen Opposition. ${ }^{273}$ Im Gegensatz zu Chamberlain sprach er sich zwar immer vehement gegen den grassierenden Imperialismus aus, doch machte unter seiner Führung die Sozialdemokratie eine erhebliche Wandlung durch, bis sie, wie Kurt Eisner meinte, „eine bis zur Karikatur getreue Volksausgabe des Staates, in dem sie lebt“, geworden war - noch unterstrichen durch die populäre Formel vom „Kaiser Bebel“. ${ }^{274}$ Es ist daher kein Zufall, dass kein anderer Politiker so oft in den Revuen des Metropol-Theaters vorkam wie Bebel.

In den Jahresrevuen fiel sein Name immer wieder. Gleich in der ersten, Neuestes! Allerneuestes!, muss sich der nach Berlin gekommene Serenissimus fragen lassen: „Haben Hoheit noch nie Bebeln gehört?“, woraufhin dieser antwortet: „O, ich habe in letzter Zeit sogar sehr viel pöbeln gehört“. ${ }^{275}$ Auf diese Weise wurde gleichermaßen die Ignoranz des Fürsten karikiert und die Sozialdemokratie auf Pöbel reduziert. Die konservative Lesart wurde noch dadurch unterstrichen, dass Serenissimus im weiteren Fortgang der Szene ausrief: „Ja, um Gottes Willen, gibt es denn hier Niemanden, der die Leute zur Raison bringen könnte?" Alsdann erschien der wenige Jahre zuvor verstorbene eiserne Reichskanzler auf der Bühne: „Ja! Einen gab's - der hätt' den Spuk gebannt, / Gebannt mit Eisenwort und

271 Vgl. REPORT (1909), S. 247.

272 The Orchid, 1. Akt, 7. Song, BL, MSS LCP 1903/27.

273 Zur Biographie Bebels vgl. SCHMIDT, August Bebel.

274 Eisner zit. n. NiPPERDEY, Deutsche Geschichte, 1866-1918, 2. Bd., S. 557, dort auch zum Übrigen.

275 Neuestes! Allerneuestes!, 3. Bild, 13. Szene, LAB, A Pr. Br. Rep. 30-05-02 Nr. 2638. 
Eisenhand!“.276 Damit trauerte die Revue den Sozialistengesetzen hinterher, mit denen Bismarck die Sozialdemokratie seit 1878 in die Illegalität gezwungen hatte. Deren Nichtverlängerung war einer der Streitpunkte, die 1890 schließlich zu seinem Sturz führten. ${ }^{277}$ In der Folgezeit hatten die Sozialdemokraten von Wahl zu Wahl an Mandaten im Reichstag hinzugewonnen.

Von dem Wortspiel Bebel - Pöbel war Julius Freund so angetan, dass er es in der folgenden Jahresrevue gleich noch einmal wiederholte: „Es träumt der Pöbel vom Bebel viel“, hieß es da. ${ }^{278}$ Wenige Szenen später trat dann „König Bebel“ höchstpersönlich ,in karrikiertem Ornat“ auf:

Ich bin der Bebel, der Bebel, der Bebel!

August der Erste

Der König vom Proletariat!

Ich bin der Bebel, der Bebel, der Bebel!

Ich bin Bebel der Erste

Und gründe den Zukunftsstaat!

[...]

Die Freiheit jedem Menschen garantier' ich,

Doch wer nicht will wie ich, den massakrir' ich. ${ }^{279}$

Bebel erscheint hier als Heuchler, der als Volkstribun die Freiheit verspricht, in Wirklichkeit aber nur sich selbst an die Stelle des Monarchen setzen will, wozu er über Leichen geht. Bei aller forcierten Komik verrieten die Revuen zwischen den Zeilen ein wachsendes Unbehagen gegenüber einer Sozialdemokratie, die zunehmend an politischem Gewicht gewann. Das entsprach dem Empfinden der Mittelschichten, aus denen sich das Publikum des Metropol-Theaters vor allem rekrutierte. In diesem Fall bestand also kaum Gefahr, dass die politische Satire Zuschauer brüskieren könnte. Nicht brüskiert fühlte sich aber auch der sozialdemokratische Vorwärts, der fast alle Metropol-Revuen besprach, und das überwiegend positiv. Der Jahresrevue Neuestes! Allerneuestes! beispielsweise, in der Bebel verspottet und die Sozialistengesetze heraufbeschworen worden waren, bescheinigte er: Sie „wird zu den Dingen gehören, die jeder gesehen haben muß“.280 In der Regel sah der Vorwärts über solche Anspielungen gutgelaunt hinweg getreu der Devise: „Ein schlechter Kerl, der nicht vertragen kann, daß man sich über ihn lustig macht."281 Womöglich aber registrierte er die Prominenz Bebels in den Revuen - kein anderer Politiker kam so oft in ihnen vor - mit Genugtuung als heimliche Anerkennung.

Dass die Berliner Zensurbehörde dem Metropol-Theater das gelegentliche Bebel-Bashing gutgelaunt durchgehen ließ, überrascht dagegen nicht, wendete es sich doch gegen den wichtigsten Vertreter der Opposition. Doch auch hoch-

\footnotetext{
276 Ebd.

277 Vgl. NipPERDEY, Deutsche Geschichte, 1866-1918, 2. Bd., S. 409-426; WeHLER, Deutsche Gesellschaftsgeschichte, 3. Bd., S. 993-1000.

278 Ein tolles Jahr, 1. Bild, 2. Szene, TSFU, 97/02/W172.

279 Ebd., 2. Bild, 11. Szene.

280 VORWÄrTs, 8. 1. 1903.

281 Metropol-Theater, VORWÄRTs, 29. 12. 1899.
} 


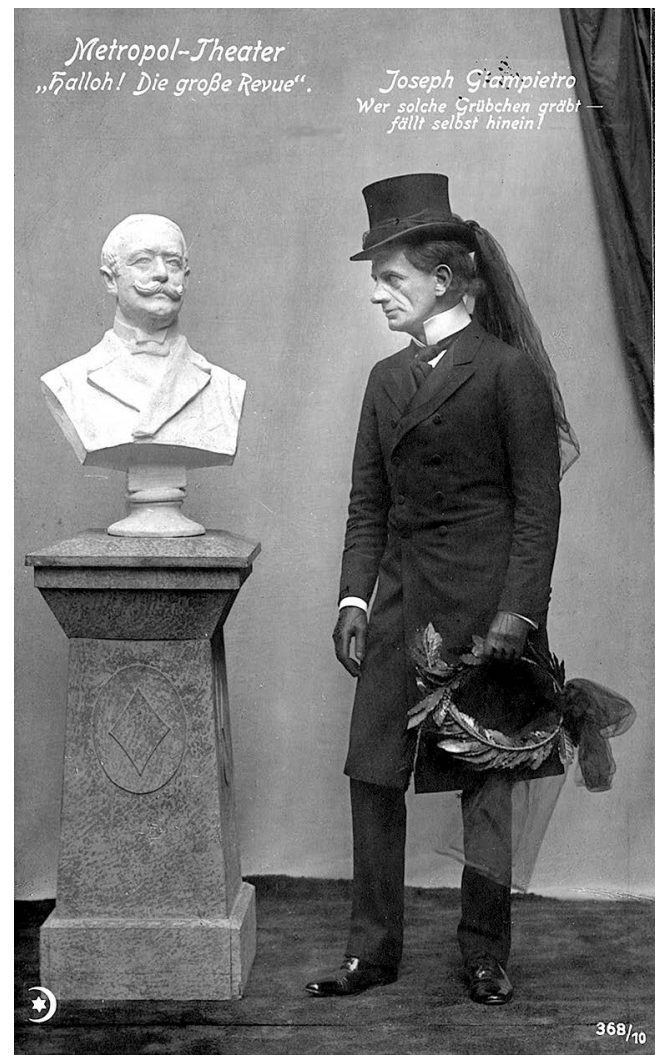

Abbildung 2: Joseph Giampietro vor einer Büste des abgesetzten Reichskanzlers Wilhelm von Bülow in der Jahresrevue von 1909 Hallo! Die große Revue.

rangige konservative Politiker sahen sich mitunter auf der Bühne in der Behrenstraße dem Spott ausgesetzt. Als Bernhard von Bülow 1909 von seinem Amt als Reichskanzler zurückgetreten war, widmete sie ihm das Kanzlerlied, das mit dem Reim endete: „Da leuchtet's eben wieder einmal ein: / Wer anderen ein Grübchen gräbt, fällt selbst hinein“ (Abbildung 2) - eine Anspielung auf die Daily Telegraph-Affäre, für die Bülow von konservativen Kreisen verantwortlich gemacht wurde und die schließlich zu seiner Entlassung durch Wilhelm II. führte. ${ }^{282}$ So lange Bülow fest im Sattel saß, hatte es das Metropol-Theater nicht gewagt, ihn zu attackieren, erst als er in Ungnade gefallen war, wurde er zum Freiwild für politische Satire. Einen geschassten, unpopulären Staatsmann zu karikieren, war alles andere als mutig, aber darum ging es dem Metropol-Theater auch nicht. Wie bei der Verspottung der Sozialdemokratie artikulierte es auch hier die Meinung seines Publikums.

282 Hallo! Die große Revue, 2. Bild, LAB, A Pr. Br. Rep. 030-05-02 Nr. 4559; vgl. Reinermann, Der Kaiser in England, S. 332-346; Kohlrausch, Der Monarch im Skandal, S. 243-263; GePPERT, Pressekriege, S. 262-266; BösCH, Öffentliche Geheimnisse, S. 406-412. 
Etwas mehr Mut bewies das Metropol-Theater im Fall von Elard von Oldenburg-Januschau, dem Prototyp des reaktionären ostelbischen Junkers. Er hatte 1909 vor dem Reichstag gesagt, der deutsche Kaiser müsse jeden Moment imstande sein, zu einem Leutnant zu sagen: „Nehmen Sie zehn Mann und schließen Sie den Reichstag!“, wodurch er die Sicht der Konservativen auf den Parlamentarismus auf den Punkt gebracht, aber auch einen Skandal ausgelöst hatte. ${ }^{283}$ Als er sich im Metropol-Theater von dem von ihm verursachten Eklat erholen wollte, erlebte er dort eine Überraschung:

Nach einigen Tagen wagte ich mich in eine Revue ins Metropol-Theater. Der damals sehr bekannte Schauspieler Thielscher hatte es sich nicht nehmen lassen, das Wort vom Leutnant und den 10 Mann zu einer besonderen Zugkraft für das Theater zu machen. Er trat in meiner Maske, gefolgt von 11 anderen uniformierten Schauspielern, einem Leutnant und 10 Mann, auf der Bühne auf und bekam einen Beifallssturm nach dem anderen. Das Unglück wollte es, daß die Besucher mich beim Verlassen des Theaters erkannten. Gott sei Dank war ich schon in der Nähe der Türe und erklärte, ich sei nur inkognito da und bäte, mich ungehindert meines Weges ziehen zu lassen. Diese Bitte hatte den gewünschten Erfolg, über den ich nicht wenig glücklich war, wußte ich doch nicht, welcher Art die Ovationen sein würden, die mir das Publikum unter Umständen bereitet hätte. ${ }^{284}$

Oldenburg-Januschau war in eine Vorstellung von Hurra! Wir leben noch! geraten, in der Julius Freund dieses aktuelle Ereignis auf die Bühne gebracht hatte. So sah sich Oldenburg-Januschau mit seinem satirischen Ebenbild konfrontiert, das seinen inzwischen berühmten Ausspruch wiederholte:

Als Landwirt, als sehr schlauer,

Komm' ich vom Reichstag her,

O hört' vom Januschauer

Die Januschauermär!

Ich übte Heldentaten,

Wie man sie nie geträumt!

Ich hab' mit zehn Soldaten

Die ganze Bude ausgeräumt!

Wir zogen in den Sitzungssaal

Und dort begann ich höchst jovial:

Nanu raus, raus, raus - bitte raus, raus, raus!

Ohne Mucken, ohne Zucken -

Denn wir schliessen jetzt das Haus!

Also geh'n Sie ganz hübsch sticke

Aus der Reichsgesetzfabrike

Ohne weitere Radaus

Nanu raus, raus, raus!!285

283 Verhandlungen des Reichstages, XII. Legislaturperiode, 2. Session, 1910, 259. Bd., Stenographische Berichte von der 26. Sitzung (29.1.1910), S.881-923, hier S.898; siehe auch WINKLER, Der lange Weg nach Westen, 1. Bd., S. 310.

284 Oldendurg-JanuschaU, Erinnerungen, S. 111. Anders als Oldenberg-Januschau behauptet, kann sich der Vorfall nicht „einige Tage“ nach seiner Reichstagsrede zugetragen haben, die er am 29.1.1910 gehalten hatte, denn Hurra! Wir leben noch! wurde erst acht Monate später, am 17.9.1910, uraufgeführt.

${ }^{285}$ Hurra! Wir leben noch!, 2. Bild, 2. Szene, TSFU, NL Julius Freund 97/102/W184. 
Die Revue nahm Oldenburg-Januschau beim Wort und versetzte ihn selbst in die Rolle des Leutnants, der den Reichstag schloss. Indem sie sowohl Zweifel an seiner Intelligenz wie an seinem vorgeblichen Heroismus weckte, behandelte sie ihn weitgehend respektlos. Das wird noch deutlicher, wenn Oldenburg-Januschau im Verlauf des Liedes immer wieder als jemand gezeichnet wird, der Politik nach Gutsherrenart betreibt und nach seinem Triumph über die ,Reichsgesetzfabrike auch gleich noch den Vatikan schließen will. Die Revue machte sich lustig über ihn und seine rhetorischen ,Heldentaten', aber sie tat es nicht auf verletzende Weise. Deshalb ist unklar, ob sie ,einen Beifallssturm nach dem anderen' erntete, weil sich das Publikum über die Parodie amüsierte, oder ob es damit Oldenburg-Januschau nicht auch feierte für seine Dreistigkeit. Wie dieser in seinen Memoiren zugab, war er sich selbst unsicher, ,welcher Art die Ovationen' gewesen wären, hätte das Publikum ihn erkannt. Sein fluchtartiger Abgang lässt aber eher darauf schließen, dass er das Gefühl hatte, dass der Spaß auf seine Kosten ging. Zugleich muss es ihm aber doch geschmeichelt haben, Gegenstand einer Metropol-Revue gewesen zu sein, sonst hätte er diese Episode nicht Jahre später noch in seinen Erinnerungen aufgezeichnet. Letztlich belegt auch dieses Beispiel die prinzipielle Ambivalenz der politischen Satire auf der populären Bühne: Sie war so vieldeutig, dass selbst die Betroffenen oft nicht wussten, ob sie kritisiert oder gefeiert wurden.

Schauspieler in die Rolle bekannter Politiker schlüpfen zu lassen, war eine der einfachsten Formen, Politik auf der Bühne zu thematisieren. Mitunter griff das populäre Theater aber auch politische Institutionen heraus. In In Town von 1892 beispielsweise, einer der ersten Musical Comedies, gab ein fiktionaler ,Duke of Duffshire' den Song The House of Lords zum Besten. Er begann mit der harmlosen (wenn auch historisch zweifelhaften) Behauptung, dass „England's august Constitution“" nur wegen seiner Peers die Jahrhunderte überdauert habe. Während die Abgeordneten des Unterhauses sich jeder populären Laune beugen müssten, hätten sie schon immer abgelehnt „whatever was like a reform“.286 Dies bezog sich auf die Obstruktionspolitik, mit der das Oberhaus, aufgrund seiner eingebauten konservativen Mehrheit aus Adeligen und Vertretern der Kirche, alle liberalen Reformvorhaben in spätviktorianischer und edwardianischer Zeit konsequent verhinderte. ${ }^{287}$ Die Kritik an dieser Haltung wird noch klarer in der zweiten Strophe, die den Ursprüngen des Oberhauses nachging:

Men say that its primitive founders

Were robbers and thieves of the worst,

A cargo of Normandy bounders

Imported by William the First.

And often a peerage is reckoned

To date its illustrious life

From Charles, who is numbered the second,

But not, it is said, from his wife.

For titles have served as rewards

To fellows who lived by their swords,

286 In Town, BL, MSS LCP 53509.

287 Vgl. Harrison, Late Victorian Britain, S. 217. 
And many a lady of character shady

Has founded a line of lords. ${ }^{288}$

In seltener Direktheit werden hier die Abgeordneten des Oberhauses als Räuber, Diebe und Schurken bezeichnet, die ihre Mitgliedschaft in dem elitären Gremium entweder ihrem Schwert oder einer der vielen außerehelichen Beziehungen Charles' II. verdankten. Wenngleich der Song nicht die Krone oder einen bestimmten Politiker direkt erwähnte, ist es doch mehr als bemerkenswert, dass der Lord Chamberlain eine solch gezielte Satire durchgehen ließ, die nicht nur die politische Institution des Oberhauses, sondern auch den britischen Adel insgesamt attackierte. Bemerkenswert ist ebenfalls, dass The House of Lords recht ungeschminkt Partei ergriff für die Sache der Liberalen, wenngleich die letzte Strophe unterstellte, dass liberale Abgeordnete im Oberhaus kaum anders handeln würden als die Tories.

Auch der deutsche Reichstag war hin und wieder Thema der populären Bühne, vor allem bei tagesaktuellen Ereignissen wie Wahlen. Der schon beschriebene Auftritt von ,König Bebel' in Ein tolles Jahr schloss sich unmittelbar an eine Szene an, die auf die Reichstagswahl von 1904 anspielte, bei der das Publikum zusehen konnte, wie Vertreter der einzelnen Parteien verschiedenfarbige Zettel in eine Wahlurne steckten. Obwohl darunter kein einziger roter war, entströmten ihr beim Leeren ausschließlich rote Wahlzettel. ${ }^{289}$ Das nahm Bezug auf die Wahl zum 11. Reichstag im Sommer des vorangegangenen Jahres, die, bei weitgehend unveränderten Ergebnissen für das konservativ-nationalliberale Bündnis und die katholische Zentrumspartei, der Sozialdemokratie einen erneuten Stimmenzuwachs beschert hatte. Prozentual konnte sie die meisten Stimmen auf sich vereinigen, dennoch blieb sie aufgrund des Konservative und Liberale begünstigenden Wahlsystems zweitstärkste Kraft. Ein tolles Jahr tat hingegen so, als sei genau das Umgekehrte passiert: Niemand hatte für die SPD gestimmt und doch war sie der größte Gewinner der Wahl - das brachte die bürgerliche Sicht auf die innenpolitischen Entwicklungen auf den Punkt.

Die nächste Reichstagswahl fand dann vorzeitig bereits 1907 statt, da Reichskanzler Bülow aufgrund des Krieges gegen die Herero und des parlamentarischen Streites über dessen Finanzierung den Reichstag aufgelöst hatte; sie ging als sogenannte „Hottentottenwahl“ in die Geschichtsbücher ein. ${ }^{290}$ Obwohl sie erneut die meisten Wählerstimmen auf sich versammelte, musste die SPD nun leichte Verluste hinnehmen, da die konservativen Parteien neue Wählerschichten mobilisiert hatten. Der vorausgegangene Wahlkampf war „einer der heftigsten in der Geschichte des wilhelminischen Kaiserreichs" gewesen. ${ }^{291}$ Das war auch in Das muß man seh'n!, der Jahresrevue von 1907, zu spüren. Nach einer ersten Szene, die „In

288 In Town, BL, MSS LCP 53509.

289 Ein tolles Jahr, 2. Bild, 11. Szene, TSFU, NL Freund 97/02/W172.

290 Vgl. NipPerdeY, Deutsche Geschichte, 1866-1918, 2. Bd., S.731-732; Wehler, Deutsche Geschichte, 3. Bd., S. 1009-1010.

${ }^{291}$ Heyden und ZeLler, Kolonialmetropole, S. 70. 


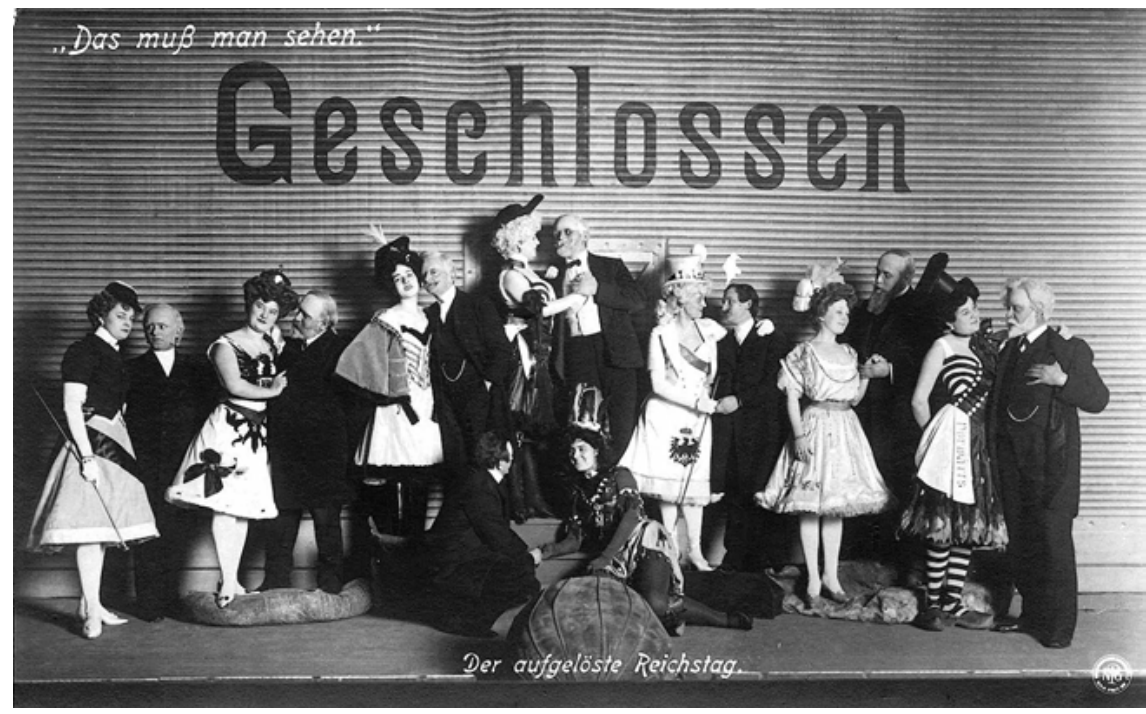

Abbildung 3: Die Szene ,Der aufgelöste Reichstag' in der Jahresrevue Das muß man seh'n! von 1907 zeigte die Vorsitzenden der großen Parteien und Allegorien derselben - ganz rechts August Bebel und die Sozialdemokratie.

Deutsch-Afrika“ gespielt hatte, zeigte die Bühne „Den aufgelösten Reichstag“. Durch eine Tür im eisernen Vorhang, auf dem in großen Lettern „Geschlossen“ zu lesen war, schritten nacheinander acht Schauspieler, die die „Typen bekannter Parlamentarier“ vorstellten, wobei jeder von ihnen „eine seine Partei verkörpernde Dame am Arm" führte (Abbildung 3). ${ }^{292}$ Daran schloss sich, ähnlich wie in Ein tolles Jahr, eine Wahlszene an, in die diesmal der Zuschauerraum miteinbezogen wurde. Schlepper zogen einen als Theaterbesucher getarnten Schauspieler aus dem Publikum: „Sie da, Herr Meyer, was ist denn das mit Ihnen? Sie haben noch nicht gewählt und es ist die höchste Zeit!“. Gewählt aber wurden nicht Abgeordnete, sondern die Hauptdarsteller der Revue: „Auf zu den Wahlen meine Herrschaften! Auf zu den Neuwahlen für die neue Revue! Wählt Massary! Wählt Giampietro! Wählt Josephi! Wählt Darmand!“'293 Auf diese Weise fing das Metropol-Theater das polarisierte politische Klima zur Zeit der „Hottentottenwahl“ ein, versuchte es aber zugleich ins Komische zu überführen, um so die Anspannung der vorangegangenen Monate aufzulösen.

\section{Imperialismus}

Mindestens genau so häufig wie die Innen- war die Außenpolitik Thema auf der Bühne des populären Theaters und diese stand um 1900 ganz im Zeichen des

292 Das muß man seh'n!, 3. Bild, 1. Szene, LAB, A Pr. Br. Rep. 30-05-02 Nr. 3915.

293 Ebd. 
Imperialismus. Das zeigt etwa die Musical Comedy An Artist's Model, die zugleich ein Beispiel dafür ist, dass diese Gattung bei spektakulären Ereignissen ebenso aktuell sein konnte wie die Revue. Zur Jahreswende 1895/96 hatte Leander Starr Jameson, eine der führenden Figuren der britischen South Africa Company, einen Überfall auf das von den Buren beanspruchte Transvaal-Gebiet in Südafrika unternommen. Der Vormarsch wurde bereits nach wenigen Tagen gestoppt, Jameson gefangen genommen und an England ausgeliefert, wo er bei seiner Ankunft wie ein Held gefeiert wurde. ${ }^{294}$ Nach der Niederschlagung des Aufstandes sandte Wilhelm II. ein Telegramm an Paul Krüger, den Präsidenten der Südafrikanischen Republik, um ihm zum Sieg über Jameson zu gratulieren. In Großbritannien heizte die ,Krüger-Depesche' die ohnehin schon seit Längerem schwelende antideutsche Stimmung weiter an. Insbesondere die konservative Presse reagierte mit einer Flut von Artikeln, die den deutschen Kaiser kritisierten und karikierten. ${ }^{295}$

In diesen Chor stimmte auch das populäre Theater mit ein. George Edwardes gab dem Autor Henry Hamilton den Auftrag, die gerade am Daly's Theatre laufende Musical Comedy An Artist's Model unter Bezugnahme auf die aktuellen Ereignisse zu überarbeiten. Von dem Ergebnis berichtete sogar die Times am nächsten Tag:

A singular scene occurred on Saturday night at Daly's Theatre during the performance of $A n$ Artist's Model. [...] During the first part of the play every reference made to the Transvaal was the signal for loud outbursts of applause, the name of the German emperor being loudly hissed and hooted, while cheer after cheer greeted the names of the Queen, Dr. Jameson, the Chartered Company, and Mr. Chamberlain. Several times cries of ,Three cheers for Dr. Jameson' and ,Groans for the Kaiser' were raised in the gallery and responded to. ${ }^{296}$

Wie dem Artikel zu entnehmen ist, reicherte Hamilton das Stück gezielt mit Anspielungen auf den Jameson Raid an, die ihre Wirkung bei den Zuschauern nicht verfehlten. Während die Erwähnung von Jameson, Chamberlain und Königin Hochrufe und Applaus auslösten, erntete der deutsche Kaiser Gezisch. Ihren Höhepunkt erreichte die Stimmung im zweiten Akt, als der Schauspieler Hayden Coffin, der auf die Rolle des schneidigen Offiziers spezialisiert war, in Uniform auf die Bühne trat, flankiert von weiteren als Soldaten kostümierten Schauspielern und den Song Hands Off! anstimmte. Dessen erste Strophe war ein Ruf zu den Waffen, der noch einmal die splendid isolation beschwor, in der England einer Liga aus habgierigen und hasserfüllten Feinden gegenüberstand. Darauf folgte der Refrain, der unmittelbar auf die aktuellen Ereignisse Bezug nahm:

Hands off, Germany! Hands off, all!

Kruger boasts and Kaiser brags; Britons, hear the call

Back to back the world around, answer with a will -

England for her own, my boys! It's ,Rule Britannia' still!297

294 MASsie, Dreadnought, S. 222-230; Clark, The Sleepwalkers, S. 146.

295 Vgl. ReinermanN, Der Kaiser in England, S. 145-179; Schramm, Das Deutschlandbild, S. 150-155; GePPerT, Pressekriege, S. 93f.; ClarK, The Sleepwalkers, S. 146f., 235.

296 London Audiences and the Transvaal Crisis, The TIMEs, 13.1.1896.

297 Lord Chamberlain's Correspondence, 14. 1. 1896, TNA, LC 1/657. 
Bei der Erregung über die Krüger-Depesche fiel offenbar niemandem auf, dass hier die realen Ereignisse umgedreht wurden. Vergessen war, dass mit Jameson ein Brite einen illegalen, von der eigenen Regierung nicht gedeckten Angriff auf eine unabhängige Republik unternommen hatte. Stattdessen erweckte der Song den Eindruck, das Deutsche Reich habe sich am britischen Besitz vergriffen. Hintergrund war die zunehmende Konkurrenz der europäischen Staaten um kolonialen Besitz sowie die Furcht vor der Bedrohung der eigenen Kolonien und der erreichten Weltmachtstellung. Dieser Furcht setzte der Song ein trotziges ,Rule Britannia' entgegen, womit er auf das klassischste aller patriotischen Lieder Großbritanniens rekurrierte, das seine Karriere 1740 ebenfalls als Teil eines Theaterstücks begonnen hatte. ${ }^{298}$ In der zweiten Strophe hieß es dann:

Let pinchbeck Caesar strut and crow,

Let Eagles scream of ,War!

No jot we bate, no right forego,

We've stood alone before.

When all the world was just as great

And we were half our size,

We faced the world in grim debate

And blacked the bully's eyes! !99 $^{29}$

Mit dem ,Talmi-Caesar` war natürlich der deutsche Kaiser gemeint, weshalb, wie die Times ihren Lesern mitteilte, der Lord Chamberlain auf Geheiß des Kolonialministeriums gegen das Lied eingeschritten war und diese Strophe gestrichen hatte, um eventuelle außenpolitische Verwicklungen zu verhindern. Die Times dagegen, die als gedrucktes Medium nicht der Zensur unterlag, konnte die gestrichenen Worte nachliefern, ohne Konsequenzen befürchten zu müssen. ${ }^{300}$

Während die zweite Strophe den Bedrohungen der Gegenwart vergangene Kriegserfolge gegenüberstellte, verwies die dritte Strophe auf Francis Drake und Walter Raleigh, denen sie in Form einer rhetorischen Frage Jameson an die Seite stellte: „Shall we then speak with bated breath / Of Jameson e'en as bold?“.301 Jamesons völkerrechtswidriger Überfall auf die Burenrepublik war demnach gerechtfertigt, insofern er nur eine moderne Variante jener Überfälle auf die Schiffe anderer Nationen war, mit denen die elisabethanischen privateers den Grundstein des britischen Empires gelegt hatten. Kurz: Etwas, das gut für das Empire war, konnte nicht moralisch schlecht sein. Darauf folgte noch eine letzte Strophe, in der die Mahnung an alle Gegner erging, dass England sich die Krone, die es auf seinem Haupte trage, nicht wegnehmen lassen würde, kulminierend in den Zeilen:

The Empire that our Fathers got,

It is not ended yet,

And on it, as the sun sets not,

No sun shall ever set! 302

298 Alfred von James Thomson und David Mallett, siehe dazu WiLson, The Island Race, S. 88f.

299 Hands off!, TNA, LC 1/657.

300 Vgl. London Audiences and the Transvaal Crisis, The Times, 13. 1. 1896.

301 Hands off!, TNA, LC 1/657.

302 Ebd. 
Die Beschwörung, dass das von den Vorvätern erworbene Empire noch nicht an sein Ende gekommen sei, lässt eine Verunsicherung über die eigene internationale Position und die imperiale Zukunft erkennen. Diese Haltung war bezeichnend für die Entstehungszeit des Liedes. Denn obschon das britische Weltreich erst in der Zwischenkriegszeit seine größte Ausdehnung erreichen sollte, erschien die lange unangefochtene Weltmachtstellung aufgrund der kolonialen Expansion anderer Staaten, insbesondere des ökonomischen und militärischen Aufstiegs des Deutschen Reiches sowie infolge von Unruhen innerhalb des Empires, vielen Briten zunehmend als bedroht.

Zeitgleich kam es in den deutschen Kolonien vermehrt zu Auseinandersetzungen zwischen der indigenen Bevölkerung und den Kolonisatoren. In DeutschSüdwestafrika führte die rasch voranschreitende Enteignung der Herero zugunsten deutscher Siedler 1904 zu einem überraschenden Aufstand, den Kolonialtruppen blutig niederschlugen. Noch im selben Jahr begannen die im Süden des Landes ansässigen Nama einen Guerillakrieg, der sich bis 1907 hinzog. ${ }^{303}$ Diese Vorgänge thematisierte das Metropol-Theater, das sonst negative Ereignisse eher mied, in der Jahresrevue von 1907, Das muß man seh'n!, deren zweites Bild „ein deutsches Feldlager während des Hererokampfes“ zeigte. ${ }^{304}$ Am Beginn der Szene kamen deutsche Truppen „völlig erschöpft an einer ausgetrockneten Wasserstelle“ an, woraufhin sich ein Dialog zwischen einem jungen Soldaten und dessen Leutnant entspann:

Der junge Soldat: Herr Leutnant - ich hab’s mir ganz anders gedacht!

Die gelben Stiefel, der kecke Hut -

Das sass mir so forsch, das stand mir so gut!

Ich meinte: nach der Montur, der schmucken,

Kotzdonner - da werden die Mädels gucken!

Und heute?? Müsst' sich ja jeder schämen,

So einen Kerl in den Arm zu nehmen -

Mit Tod und Teufel wollt' ich raufen -

Aber trinken muss ich - mein Pferd muss saufen!

Der Leutnant: Jungens werft mir den Kleinmut ab, Jungens werdet mir bloß nicht schlapp'!

Zeigt euch als Männer von deutschem Holz,

Geht's Euch auch dreckig - seid darauf stolz! ${ }^{305}$

Eine unheroischere Darstellung des Krieges hätte sich kaum denken lassen. Weit entfernt davon soldatische Tapferkeit zu demonstrieren, beklagt sich der junge Soldat über die Strapazen des Feldzugs. Offen gesteht er ein, dass er die Uniform nicht aus patriotischer Pflichterfüllung angelegt hat, sondern um ,die Mädels daheim zu beeindrucken. Der Leutnant wiederum weiß dem nichts Besseres entgegenzusetzen als abgenutzte Durchhalteparolen. Wer dies allerdings als Kritik an dem Kolonialkrieg verstand, wurde rasch eines besseren belehrt, denn der nüchterne Beginn diente lediglich dazu, den Heroismus der deutschen Soldaten

303 Vgl. CONRAD, Deutsche Kolonialgeschichte, S. $52 \mathrm{f}$.

304 Das muß man seh'n!, 2. Bild, LAB, A Pr. Br. Rep. 30-05-02 Nr. 3915.

305 Ebd. 
herauszustellen, die kurz bevor die rettende Verstärkung eintrifft aus dem Hinterhalt erschossen werden. Die Revue verdrehte so die realen Ereignisse bis zur Unkenntlichkeit, denn die Herero waren zwar zahlenmäßig überlegen, hatten aber gegen die professionellen, mit Maschinengewehren und Geschützen ausgerüsteten deutschen Truppen keine Chance. Nicht die deutschen Soldaten litten an Durst, sondern die in die Wüste abgedrängten Herero, von denen kaum ein Viertel den Aufstand überlebte. ${ }^{306}$

Diese Szene ist eine von wenigen Beispielen aus den Jahresrevuen, bei denen Julius Freund den gewohnten Boden der Satire verließ, um ein ernstes Thema auf ernsthafte Weise zu behandeln. Dabei drängt sich allerdings die Frage auf, wieso er, anstatt den deutschen Sieg zu betonen, eine Szene der Niederlage imaginierte, die dem realen Kriegsgeschehen und seinem Ausgang völlig widersprach. Verschiedene Antworten sind denkbar. Erstens löste der Sieg über die Herero keine patriotische Hochstimmung aus, sondern warf vielmehr Fragen nach seiner Legitimation auf und stärkte eher die Kolonialkritik. Nur schwer ließ sich ignorieren, dass hier eine gut ausgestattete, professionelle Armee über eine Rebellion gesiegt hatte, die durch die deutsche Siedlungspolitik überdies selbst verschuldet war. Da sich, zweitens, der Sieg deshalb nur schwer glorifizieren ließ, drehte Freund die Situation einfach um: Bei ihm waren die deutschen Soldaten die Unterlegenen, die, ihr eigenes Leben für das Vaterland aufopfernd, abgeschlachtet wurden. Indem er aus einem Vernichtungskrieg einen Verteidigungskrieg machte, löste er zugleich das Problem der Legitimation. Und drittens verfolgte die Szene eine, in den Jahresrevuen nur äußerst selten anzutreffende eindeutige politische Stoßrichtung, wie das Gespräch zwischen dem Leutnant und dem ihm untergeordneten Wachtmeister deutlich macht:

$\begin{array}{ll}\text { Wachtmeister: } & \text { Um Vergebung Herr Leutnant! Wie kann das nur sein, } \\ & \text { Dass wir hier einsam und allein, } \\ & \text { Unser'm Verderben entgegenzieh'n? } \\ \text { Leutnant: } & \text { Der Grund liegt nicht hier, der liegt in Berlin! } \\ & \text { Wo sie sich sträuben, wo sie sich spreizen, } \\ & \text { Wo sie mit Mitteln und Truppen geizen! } \\ & \text { Hätten die Herren nur eine Nacht } \\ & \text { - Eine einzige wie diese - mitgemacht } \\ & \text { In unserer Not und unser'n Gefahren - } \\ & \text { Sie würden weniger knausern und sparen. }{ }^{307}\end{array}$

Die Darstellung der verzweifelten Situation der deutschen Soldaten in Afrika mündete also in den Vorwurf, der Reichstag sei wegen seiner Nachlässigkeit, neue Truppen und Mittel für die Kriegführung zu gewähren, für die vermeintliche Niederlage verantwortlich. Die Debatten im Reichstag, auf die Freund hier anspielte, fanden in Wirklichkeit aber erst 1907 und damit nach der Niederschlagung des Aufstandes statt. Die Finanzierung des Feldzugs war nie wirklich bedroht gewesen, vielmehr hatten dessen nicht unbeträchtliche Kosten eine nachträgliche Billi-

306 Vgl. Conrad, Deutsche Kolonialgeschichte, S. $52 \mathrm{f}$.

307 Das muß man seh'n!, 2. Bild, LAB, A Pr. Br. Rep. 30-05-02 Nr. 3915. 
gung durch den Reichstag nötig gemacht. Dabei kam es vor allem von sozialdemokratischer und linksliberaler Seite zu Kritik an dem Krieg gegen die Herero und an der deutschen Kolonialpolitik insgesamt. ${ }^{308}$

Doch nicht an diesen offensichtlichen Widersprüche lag es, dass das Stück bei Erscheinen in der Presse ein eher geteiltes Echo fand. Am mildesten urteilte der Berliner Lokalanzeiger, demzufolge die Szene aus dem Herero-Krieg „zunächst ein wenig befremdete, deren patriotische Tendenz aber zuletzt die Wirkung nicht versagte“. ${ }^{309}$ Die Beschreibung der Szene als ,befremdend' zeigt, wie ungewohnt sie sich im üblichen Programm des Metropol-Theaters ausnahm. Die Vossische Zeitung verwarf sie deshalb ganz grundsätzlich als „verfehlt“. 310 Was das liberale Blatt störte, war allerdings weniger die Art und Weise, wie der Kolonialkrieg thematisiert wurde, als der Ort, an dem es geschah: „Es ist nicht Sache des Metropoltheaters, sich mit solchen Vorgängen zu beschäftigen".311 Einem Unterhaltungstheater kam es einfach nicht zu, sich einem so ernsten Thema wie dem HereroKrieg zuzuwenden. Eine völlig andere Erklärung für die Szene sah der Kritiker der Welt am Morgen, der dem Metropol-Theater eine „captatio benevolentiae der hohen Zensur" unterstellte. ${ }^{312}$ Demnach diente das ganze patriotische Pathos dem kühl-berechnenden Zweck, die Zensurbehörde gewogen zu stimmen, auf dass sie die Revue möglichst ohne Streichungen passieren ließ.

Solche Erwägungen sind nicht ganz von der Hand zu weisen. Sehr viel wahrscheinlicher ist jedoch, dass Freund nicht nur der Zensur, sondern auch dem Publikum entgegenkam, wenn er die Stimmung nach dem Herero-Krieg aufgriff und ihr Ausdruck verlieh. Dabei begab er sich auf ungewöhnliche Weise aus der Deckung. Wo sonst die satirische Ambivalenz verhinderte, dass sich Teile des Publikums angegriffen fühlten, riskierte Freund hier jene Minderheit abzuschrecken, die dem Kolonialkrieg kritisch gegenüberstand. Dass die Szene zu keinen größeren Konflikten führte und selbst die liberale Vossische Zeitung an ihr lediglich bemängelte, dass sie im Metropol-Theater aufgeführt wurde, zeigt allerdings, dass das Publikum sie trotz erstem Befremden letztlich goutierte.

Ging es in Das muß man seh'n! um einen Kolonialkonflikt, thematisierte Hallo! Die große Revue von 1909 die zunehmende Verschlechterung der internationalen Beziehungen. In ihr war die Rede von einem „gloriosen Finish, mit dem Deutschland und Oesterreich beim internationalen Hindernisrennen auf der Orientbahn im vergangenen Jahre Kopf an Kopf den Weltfrieden herausgeritten haben. [...] Die Bündnistreue zweier erlauchter Freunde hat der Welt mit unbesiegbarem Willen den Frieden diktiert!“.313 An dieser Übung in kontrafaktischer Geschichtsschreibung stimmte eigentlich nichts. Die beiden Ereignisse, auf die die Revue

\footnotetext{
308 Vgl. NipPERDEY, Deutsche Geschichte, 1866-1918, 2. Bd., S.729; WeHLER, Deutsche Gesellschaftsgeschichte, 3. Bd., S. 1008-1011.

309 BERLINER LOKALANZEIGER, 15.9. 1907.

310 Vossische ZeITUNG, 15.9. 1907.

311 Ebd.

312 Die Welt am Morgen, 16.9. 1907.

313 Hallo! Die große Revue, 5. Bild, LAB, A Pr. Br. Rep. 30-05-02 Nr. 4559.
} 
anspielte, hatten zum einen nichts miteinander zu tun, zum anderen waren sie alles andere als auf den Erhalt des Weltfriedens ausgerichtet gewesen. Der heute als bosnische Annexionskrise bekannte Einmarsch österreichisch-ungarischer Truppen in Bosnien und der Herzegowina, bei dem sich das Deutsche Reich hinter seinen Bündnispartner gestellt hatte, führte zu einer nachhaltigen Verschlechterung der Beziehungen zu Russland und kurbelte das Wettrüsten zwischen den Großmächten weiter an. ${ }^{314}$ Weit davon entfernt, den Frieden zu sichern, handelte es sich um die jüngste in einer Reihe von Krisen, durch die die deutsche Diplomatie zunehmend in außenpolitische Isolation geriet. Dazu trug zusätzlich noch das deutsche Engagement beim Bau der Bagdadbahn bei, das ebenfalls die Beziehungen zu Russland und Großbritannien belastete. ${ }^{315}$ Die Rhetorik der Revue zeigt, wie sich bereits Jahre vor 1914 jene „Einkreisungsrhetorik“ vorbereitete, der zufolge immer die anderen, nie aber Deutschland die Schuld an der Verschlechterung der internationalen Beziehungen - und schließlich auch am Ausbruch des Ersten Weltkriegs - trug. 316

Die zustimmende Haltung des Metropol-Theaters zum Imperialismus ist kaum überraschend, wurde dieser doch von weiten Teilen der deutschen Gesellschaft, insbesondere der Mittelschichten, geteilt. Dennoch gab es auch Szenen, die ein weit weniger eindeutiges Bild der Außenpolitik zeichneten. Ein Beispiel dafür ist Chauffeur - in's Metropol! von 1913. Als sich der Vorhang hob, blickte das Publikum in „Europas Kinderstube“, in der „als Spielzeug [...] überall Gewehre, Säbel, Fahnen, Trommeln" herumlagen und in dem sich Mutter Europa mit ihren missratenen Kindern Marianne, Michel, Johnny, Mahoment, Miezi, Italia, Espaniola und Iwanowitsch herumärgerte: „Keine Mutter hat soviel Klamauk und Trara / Als Frau Europa - die gute Staatsmama!“ 317 Am meisten Sorgen bereitet Mutter Europa der Streit zwischen dem deutschen Michel und dem britischen Johnny, die sich ständig um das Spielzeug zanken. So meint Johnny:

Und wenn ich den Ozean erweitern muss,

I make not finish - ich mach' kein Schluss!

Ich spiele mit Dreadnoughts von früh bis spät -

Will doch seh'n - wer zuerst von uns Pleite geht!!! 318

Hier verarbeitete Julius Freund die britische Aufrüstung auf hoher See, die in Deutschland als Reaktion auf das eigene Flottenbauprogramm verstanden wurde. Mit der HMS Dreadnought war 1906 ein Schiff vom Stapel gelaufen, das alle bis dahin existierenden Kriegsschiffe in jeder Hinsicht überholte und dessen Name für eine neue Generation von Schlachtschiffen stand. Anstatt sich geschlagen zu geben, setzte nun auch das Deutsche Reich auf den Bau von Dreadnoughts, was

314 Vgl. Clark, The Sleepwalkers, S. 83-87.

315 Vgl. ebd., S. 334-338.

316 Doering-Manteuffel, Militär, Politik und Öffentlichkeit, S. 250.

317 Chauffeur - in's Metropol!, 1. Akt, 1. Bild, TSFU, NL Julius Freund 97/02/W174.

318 Ebd. 
1909 wiederum in Großbritannien Bedenken auslöste. ${ }^{319}$ Als sich abzeichnete, dass das Deutsche Reich das Flottenwettrüsten verlieren würde, brachte Bethmann Hollweg eine Heeresvorlage zur Aufrüstung der Landstreitkräfte in den Reichstag ein. Und so antwortete Michel auf Johnnys Herausforderung:

Und Du glaubst, für mich sind die Dinger schädlich?

Ich bleib' auf dem Land und wehre mich redlich!

Und wenn deine Flotte auch noch so schön fährt,

Ich hab' meine Zinnsoldaten vermehrt! 320

In ihrer Not lässt Mutter Europa daraufhin zwei Ärzte kommen, den „deutschen Doktor" und Haldane. Gemeint war damit der britische Kriegsminister Richard Burdon Haldane. Im Februar 1912 war er nach Berlin gereist, um inoffizielle Gespräche mit Reichskanzler Bethmann Hollweg, Wilhelm II. und Alfred von Tirpitz über eine deutsch-britische Annäherung zu führen. Während Bethmann Hollweg ernsthaft an einer Détente interessiert war, unterstützte Wilhelm II. letztlich die unversöhnliche Position von Tirpitz, der nur gegen die Erklärung uneingeschränkter Neutralität bereit war, der britischen Diplomatie entgegenzukommen. Großbritannien aber, dessen Sieg im Flottenwettrüsten sich zu diesem Zeitpunkt klar abzeichnete, war nicht bereit ohne greifbare Gegenleistung auf diese Maximalforderung einzugehen. Am Ende gingen die Verhandlungspartner deshalb mit leeren Händen auseinander. ${ }^{321}$ Chauffeur - in's Metropol dagegen wertete die Haldane-Mission als einen ernst gemeinten Annäherungsversuch, der die immer prekärere Frontstellung der europäischen Nationen überbrücken sollte. So attestieren der britische Kriegsminister und der deutsche Doktor Johnny und Michel eine „Infectio invasionica“:

$\begin{array}{ll}\text { Haldane: } & \text { Sehr stark erhöht ist Michels Puls! } \\ \text { Der deutsche Doktor: } & \text { Höchst fiebrig geht der Puls John Bulls! } \\ & \begin{array}{l}\text { Die Sache scheint mit ziemlich bös'! } \\ \text { Die Bengels sind total nervös! }\end{array} \\ \text { Haldane: } & \begin{array}{l}\text { Jedoch das Auge blickt normal - } \\ \text { Die Seekraft ist ganz kolossal! }\end{array} \\ \text { Der deutsche Doktor: } & \begin{array}{l}\text { Die Zunge - bitte - jetzt heraus! } \\ \text { Das sieht nach Friedensbrechreiz aus! }\end{array}\end{array}$

Chauffeur - in's Metropol zeichnete also ein eher nüchternes und ausgewogenes Bild der internationalen Politik, das unterschwellig eine Sehnsucht nach Frieden erkennen ließ. Zwar erschien Großbritannien als Aggressor und Urheber des Streits, der deutsche Michel schnitt aber kaum besser ab. Mehr noch, anstatt die deutsche Aufrüstung auf See und Land zu verteidigen und die englische Haltung zu verurteilen, wie zu erwarten gewesen wäre, gab die Revue beiden Nationen, ihrem überseeischen Expansionsdrang und ihrer martialischen Rhetorik, die

\footnotetext{
319 Vgl. Mommsen, Großmachtstellung, S.277-280; RÜGER, The Great Naval Game, insbes. S.223f. Der Einfluss des deutschen Flottenbaus auf die britische Politik ist von Andreas Rose in Frage gestellt worden, siehe Rose, Zwischen Empire und Kontinent.

320 Chauffeur - in's Metropol!, 1. Akt, 1. Bild, TSFU, NL Julius Freund 97/02/W174.

321 Vgl. Mommsen, Großmachtstellung, S. 234f.; Clark, The Sleepwalkers, S. 318-321.

322 Chauffeur - in's Metropol!, 1. Akt, 1. Bild, TSFU, NL Julius Freund 97/02/W174.
} 
Schuld an der Verschlechterung der internationalen Beziehungen. Die Empfehlung der Ärzte für Mutter Europa lautete dementsprechend: „Vor allem - Madame - darum bitt' ich sehr: / Aus Krupps Apotheke kein Eisen mehr!“323

\section{Militarismus}

Das Zeitalter des Imperialismus mit seinen Kolonialkriegen und außenpolitischen Krisen war geprägt durch eine alle gesellschaftlichen Bereiche erfassende Militarisierung - insbesondere im Deutschen Reich, wo sich, anders als in Großbritannien, aufgrund von Wehrpflicht und Reservedienst Gesellschaft und Militär vielfach überlappten. ${ }^{324}$ Schon zeitgenössische Beobachter fanden den Militarismus in Deutschland ausgeprägter als in anderen Nationen - ablesbar an so banalen Details wie dem Stadtbild. Als der Theaterkritiker Alfred Kerr 1896 nach London kam, fielen ihm zuerst die Uniformen auf, „die man nicht sieht“. 325

Auch auf der Bühne nahm das Militär eine prominente Stellung ein. Einige Beispiele wurden bereits genannt, mitunter aber waren das Militär und seine Angehörigen selbst Gegenstand, so zum Beispiel in einer der allerersten Musical Comedies A Gaiety Girl von 1893. In diesem Stück kreierte der Schauspieler Hayden Coffin die Rolle des schneidigen Offiziers, die er dann noch viele Male, wie drei Jahre später in An Artist's Model, verkörpern sollte. ${ }^{326}$ In A Gaiety Girl spielte er einen Kavallerieoffizier der königlichen Leibgarde, sein wichtigstes Lied aber galt dem Gefreiten aus der Arbeiterklasse. Private Tommy Atkins schilderte das Leben des einfachen Tommy vom ersten Exerzieren bis zu seinem Tod für Königin und Vaterland an „India's coral strand“ und sicherte ihm die Dankbarkeit der Nation zu. ${ }^{327}$ Obwohl die umgangssprachliche Bezeichnung Tommy Atkins für den Gefreiten schon länger existierte, trug dieser Song, der nicht nur vom Publikum des Daly's Theatre mit „great enthusiasm“ aufgenommen wurde, erheblich zu dessen Verbreitung bei. ${ }^{328}$

In mehrfacher Hinsicht die Antithese zu Private Tommy Atkins war das Couplet Donnerwetter - tadellos! aus der gleichnamigen Jahresrevue von 1908. Der Text stammte wie immer von Julius Freund, die Musik von Paul Lincke. Dargeboten wurde es von Josef Giampietro, der - ähnlich wie Hayden Coffin in London - auf die Figur des forschen Leutnants abonniert war: ${ }^{329}$

323 Ebd.

324 NiPPERDEY, Deutsche Geschichte, 1866-1918, 2. Bd., S. 230-236; PrÖVE, Militär, Staat, Gesellschaft, insbes. S. 71f.; FÖRSTER, Ein militarisiertes Land?; zum Militarismus in europäischer Perspektive siehe Blom, Vertigo Years, S. 166-170; Clark, The Sleepwalkers, insbes. S. $214 \mathrm{f}$.

325 KerR, Wo liegt Berlin?, S. 194.

326 Vgl. Coffin, Hayden Coffin's Book; sowie SHORT und COMPTON-RICKeTt, Ring up the Curtain, S. 134; GÄNZL, The Encyclopedia, S. 290-291.

327 Ebd.

328 Coffin, Hayden Coffin's Book, S.99-102; siehe auch RiCHARDS, Imperialism and Music, S. 267-270; SuMMERFIELD, Patriotism and Empire.

329 Vgl. HaAs, Die literarische Welt, S. 117; Flatz, Krieg im Frieden, S. 157, 212; OtTe, Jewish Identities, S. 234-241. 
Garde meist sehr exclusiv,

Von feudalem Geist,

Sieht auf Bürgerpack nur schief,

Weil der Grundsatz heißt:

,Adelsprädikat bezweckt,

Daß kein Plebs uns naht!

Völlig wertlos so'n Subjekt -

Ohne Prädikat!

Besteigen wir keck die Schabracken,

Da geben wir allen was vor -

Man kennt die Manöverattacken

Der Jungens vom Garde du corps! ${ }^{330}$

Ging es in Private Tommy Atkins um den Gefreiten aus der Arbeiterklasse, besang in Donnerwetter - tadellos! das preußische Offizierskorps seine eigenen Bravourstücke. Im Gegensatz zu der von Blut, Krieg und Aufopferung geprägten Rhetorik von Private Tommy Atkins fallen diese nicht allzu rühmlich aus, da sie sich auf „Rennplatzattacken“, „Liebesattacken“ und Erfolge am Spieltisch beschränken. Noch dazu werden weniger patriotische als finanzielle Motive bei der Wahl der Offizierslaufbahn unterstellt („Holen uns im Sattel Renommée und Moos!“). ${ }^{331}$ Wilhelm II., dessen Lieblingsausspruch als Titel herhalten musste, sah denn auch in dem Couplet eine Verunglimpfung des Militärs und verbot seinen Offizieren das Metropol-Theater zu besuchen. ${ }^{332}$

Donnerwetter - tadellos! griff populäre Klischees über die Garde auf und übersteigerte sie ins Absurde. Walther Kiaulehn sah in dem Couplet deshalb eine Kritik an Kaiser und Militär: „Das ,Donnerwetterlied' [...] war große politische Satire im Stil der Thönyzeichnung aus dem ,Simplizissimus. Es verulkte den Adelsfimmel und die ,Sekt- und Weiberstimmung' der Gardeoffiziere. “333 In dieser Lesart ging Donnerwetter - tadellos! in die Annalen des deutschen Kabaretts ein. Der Kabarettist Dieter Hildebrandt etwa verstand es als „bösartiges, wunderbares Lied über die Garde, das nichts anderes zum Thema hatte als eben die lächerlich zu machen, die sich gebärden, als wären sie von Gott persönlich in die Welt gesetzt worden". 334

Doch diese Interpretation ist keineswegs die einzig Mögliche. Indem Freund nicht über die Garde schrieb, sondern diese selbst reden ließ, minderte er die satirische Stoßrichtung des Liedes ab. Trotz seines ironischen Untertons konnte das Couplet ebenso gut als Glorifizierung der Garde verstanden werden, die entgegen dem kaiserlichen Embargo auch weiterhin ins Metropol-Theater strömte, der

330 Donnerwetter - tadellos!, LAB, A Pr. Br. Rep. 30-05-02 Nr. 4214.

331 Ebd.

332 Vgl. BorN, Berliner Luft, S. 142.

333 KiauleHN, Berlin, S. 239.

334 Hildebrandt im Interview mit Katja Iken, Späße bis ins Grab hinein, EINESTAGES, 23. 1.2008, http://einestages.spiegel.de/static/authoralbumbackground-xxl/1260/_spaesse_bis_ins_ grab_ hinein.html [4.3.2009]. Überdies dient es als Titel einer Sammlung von Kabaretttexten aus der Kaiserzeit, siehe KüHN, Kleinkunststücke, 1. Bd. 
Kronprinz vorneweg. ${ }^{335}$ Für Franz-Peter Kothes ist deshalb Donnerwetter - tadellos! „das signifikanteste Beispiel für die Art, mit der einerseits den Kritikern scheinbar schneidige Satire geboten wurde, zum anderen aber die Angegriffenen sich noch verherrlicht fühlen konnten". 336 In der Tat brachte wohl kein anderes Lied die prinzipielle Ambivalenz der Metropol-Revuen derart auf den Punkt wie dieses Couplet, das sowohl als Ausdruck wie als Kritik des Militarismus gelesen werden konnte. Der Vergleich mit Private Tommy Atkins zeigt darüber hinaus, dass sich zumindest soweit es die Bühne angeht, nicht schlechterdings zwischen preußischem Militarismus und britischer Zivilgesellschaft unterscheiden lässt, sondern, dass es sich beim Militarismus um ein europäisches Phänomen handelte. Nicht nur in Preußen gab es vor dem Ersten Weltkrieg eine verbreitete „Anbetung des Militärs“, genauso wie es auch in Preußen Kritik am Militär gab - aber beides in derselben Szene, das bot nur das Metropol-Theater. ${ }^{337}$

\section{Erster Weltkrieg und Zwischenkriegszeit}

Es liegt nahe, dass der Erste Weltkrieg für die Behandlung politischer Themen eine Zäsur markierte. Der Kriegsausbruch führte in Großbritannien wie in Deutschland zunächst zu einer extremen Politisierung des Unterhaltungstheaters. Als die Bühnen nach einer kurzen Phase erzwungener Schließung ihre Pforten wieder öffneten, warteten die meisten von ihnen mit patriotischen Stücken auf, die die aktuellen Ereignisse aufgriffen. Auch das Metropol-Theater hatte die Zeichen der Zeit erkannt und spielte seit dem 25. Dezember 1914 die Kriegsrevue Woran wir denken. ${ }^{338}$ In London hingegen fügten die Direktoren nach dem Vorbild von An Artist's Model patriotische Szenen, Songs und Anspielungen in die gerade laufenden Stücke ein. ${ }^{339}$

Qualitativ gesehen brachte der Erste Weltkrieg nichts Neues. Nationalismus, Imperialismus und Militarismus, die in den ersten Monaten nach Kriegsbeginn die Bühnen dominierten, prägten, wie gezeigt, bereits die Unterhaltung in der Vorkriegszeit. Jetzt allerdings wurden sie zu den alles beherrschenden Themen. Da das Unterhaltungstheater in der Zeit des Ersten Weltkrieges gut untersucht ist, unterbleibt hier eine eingehende Analyse der Thematisierung des Krieges auf der Bühne. ${ }^{340}$ Überdies ebbte die Flut patriotisch-kriegerischer Stücke schon relativ bald wieder ab. Die beiden erfolgreichsten West-End-Produktionen während des Krieges trugen eher dem Wunsch des Publikums Rechnung, nicht auch noch im

335 Vgl. Born, Berliner Luft, S. 143.

336 Kothes, Theatralische Revue, S. 41.

337 Siemsen, Preussen, die Gefahr Europas, S. 49.

338 ARNOLD, Woran wir denken; siehe dazu SCHNEIDEREIT, Berlin, wie es weint und lacht, S. 186; Flatz, Krieg im Frieden, S. 108, 343; OTTE, Jewish Identities, S. 249.

339 Vgl. Williams, British Theatre, S. 19.

340 Vgl. Flatz, Krieg im Frieden; BAUMEISTER, Kriegstheater; KrIVANEC, Kriegspropaganda multimedial; dies., Unterhaltungstheater als Medium; dies. Kriegsbühnen; RƯGER, Entertainments; ders., Laughter and War in Berlin; Collins, Theatre; WiLliams, British Theatre; KosoK, Theatre. 
Theater mit der Realität des Kriegsalltags konfrontiert zu werden: Chu Chin Chow war eine sehr freie Bearbeitung des Stoffes von Ali Baba und den 40 Räubern, The Maid of the Mountains handelte von einer Gruppe Banditen in einem fiktiven italienischen Bergstaat. ${ }^{341}$ In Berlin war das nicht anders. Der Erste Weltkrieg löste hier eine Flut von Operetten aus, die mit dem Krieg nur insoweit zu tun hatten, als sie ihn nahezu völlig ausblendeten. ${ }^{342}$

Diese Tendenz setzte sich in der Zwischenkriegszeit fort. Der fortschrittsgläubige, optimistische Imperialismus, wie er, bei allen unterbewussten Ängsten über die Zukunft des Empires, prägend für die Musical Comedies des edwardianischen Zeitalters gewesen war, ließ sich nach dem Weltkrieg nicht mehr aufrechterhalten. ${ }^{343}$ Erst in den dreißiger Jahren kehrte der Patriotismus zurück, wenngleich er nun sehr viel weniger auftrumpfend war. Exemplarisch lässt sich diese Entwicklung an der Karriere von Noël Coward nachvollziehen. Die Revuen, an denen er zu Beginn der zwanziger Jahre mitarbeitete, lassen die verbreitete politische Apathie ihrer Zeit erkennen, insofern sie die aktuellen Ereignisse weitgehend ignorierten oder Politik an sich ablehnten. ${ }^{344} \mathrm{Zu}$ Beginn der dreißiger Jahre aber schrieb er mit Cavalcade ein Festspiel über die englische Nation und ihr Klassensystem. Anhand der Erlebnisse zweier Familien ließ Coward die britische Geschichte vom Burenkrieg über den Ersten Weltkrieg bis in die unmittelbare Gegenwart Revue passieren. ${ }^{345}$ Das Stück endete mit einem Toast auf das neue Jahr:

Now then, let's couple the future of England with the Past of England. The glories and victories and triumphs that are over and the sorrows that are over too. Let's drink to our sons who made part of the pattern and to our hearts that died with them. Let's drink to the spirit of gallantry and courage that made strange Heaven out of unbelievable Hell, and let's drink to the hope that one day this country of ours which we love so much will find Dignity and Greatness and Peace again. $^{346}$

Wie in den patriotischen Stücken und Songs der Vorkriegszeit wurde in Cavalcade die Gegenwart in die Kontinuität der imperialen Vergangenheit gestellt. Doch wie viel melancholischer war das Ende von Cavalcade verglichen mit dem robusten, optimistischen Imperialismus jener Stücke. Der Sieg existierte jetzt nur noch als Nachbar der Sorge und der Himmel als Gegenstück zur Hölle. Wenn hier der Hoffnung Ausdruck verliehen wurde, die Nation möge in der Zukunft einmal wieder Würde, Größe und Frieden erreichen, hat man fast den Eindruck, als habe Großbritannien und nicht Deutschland den Krieg verloren. Damit sagte Cavalcade

341 Chu Chin Chow, BL, MSS LCP 1916/18; siehe auch AsChe, Life, S. 160-165; SingLeton, Oscar Asche; PlatT, Musical Comedy, S. 109; Williams, British Theatre, S. 18-20.

342 Vgl. Hebestreit, Die deutsche bürgerliche Musikkultur; ders. Musiktheater; Baumeister, Kriegstheater, S. 146; JanSEN, Auf der Suche nach Zukunft, S.30-32; KRIVANEC, Kriegsbühnen.

343 Vgl. Moore, Girl Crazy, insbes. S. 88, 101, 110; BARKER, The Ghosts of War, insbes. S. 226230; Gale, The London Stage, 1918-1924, insbes. S. 144-146; siehe auch PlatT, Musical Comedy.

344 Vgl. LAHR, Coward, S. 93.

345 Vgl. ebd., S. 96f.; Richards, Imperialism and Music, S. 296-299; Cannadine, Tradition.

346 COWARD, Cavalcade, S. 134; auch abgedruckt in: ders., The Collected Plays, 1. Bd. 
einiges über die britische Mentalität auf dem Höhepunkt der Weltwirtschaftskrise aus. Aufgewogen und aufgefangen wurde diese depressive Stimmung durch die spektakuläre Beschwörung der eigenen Nation, mit der das Stück endete:

Suddenly it all fades into darkness and silence and away at the back a Union Jack glows through the blackness. The lights slowly come up and the whole stage is composed of massive tiers upon which stand the entire company. The Union Jack flies over their heads as they sing, God Save the King. - THE END ${ }^{347}$

Die Premiere von Cavalcade fand am 13. Oktober 1931 statt und damit kaum zwei Wochen vor den Parlamentswahlen, bei denen die Konservativen die absolute Mehrheit gewannen. Kurz nach der Wahl besuchte König George V. mit seiner Familie eine Aufführung des Stücks. Wie einst bei Hands off! stimmte das Publikum spontan die Nationalhymne an. ${ }^{348}$ Dennoch wehrte sich Coward später gegen die Behauptung, das Stück sei als Wahlwerbung für die Konservativen intendiert gewesen. Cavalcade fing wie kaum ein anderes Stück die Stimmung der Zeit ein: die Bedrückung über die Wirtschaftskrise, die Arbeitslosigkeit und die Sehnsucht nach nationaler Geschlossenheit, die den Tories zum Sieg an den Urnen verhalfen. Dem konservativen Tenor von Cavalcade, wie auch der meisten anderen Stücke Cowards, entsprach eine Tendenz zum Antikommunismus, die für das britische Theater der Zwischenkriegszeit generell bezeichnend war. ${ }^{349}$

In Deutschland war mit der Abschaffung der Theaterzensur 1919 erstmals die Möglichkeit gegeben, Politik ungehindert auf der Bühne zu thematisieren. Tatsächlich kam es in der Weimarer Republik zu einer „Politisierung des Theaters“, die von Direktoren wie Leopold Jessner, dem sozialdemokratischen Intendanten der preußischen Staatstheater, Regisseuren wie Erwin Piscator und dem Kommunismus zuneigenden Dramatikern wie Bertolt Brecht, Marieluise Fleißer und Ernst Toller getragen wurde, sich aber weitgehend auf das Kunsttheater beschränkte. ${ }^{350}$

Das Unterhaltungstheater hingegen machte eher die gegenläufige Entwicklung durch. Anders als die Jahresrevuen des Metropol-Theaters kamen die Revuen der zwanziger Jahre weitgehend ohne Bezüge zum aktuellen politischen Geschehen sowie ohne politische Satire aus und erhoben dies sogar zum Programm. In einer Revue von 1925 hieß es programmatisch: „Darum, Kinder, seid doch stieke, / Laßt den Quatsch, die Politike“.351 Allein das Kabarett und die Kabarett-Revuen von Rudolf Nelson und Friedrich Hollaender pflegten dieses Genre noch. Trotz geistreicher Texte und guter Kritiken in der Presse erreichten sie aber nie die Popularität der Metropol-Revuen oder der spektakulären Glanzrevuen, wie sie in der Komischen Oper, im Admiralspalast und im Großen Schauspielhaus zu sehen

\footnotetext{
347 Ebd., S. 138-139.

348 Vgl. McKibBin, Classes and Cultures, S. 5.

349 Vgl. Nicholson, British Theatre and the Red Peril.

350 Hermand und Trommler, Die Kultur, S. 200f.; siehe auch Kaes, Weimarer Republik, S. 413; FrEYDANK, Theater in Berlin, S. 404; FÄHNDERS, Avantgarde und Moderne, S. 225-227; BoETZKES und QUECK, Die Theaterverhältnisse; WilletT, The Theatre of the Weimar Republic.

351 Haller et al., Achtung! Welle 505 (unpaginiert).
} 
waren. ${ }^{352}$ Wenn diese Revuen doch einmal politisch wurden, dann auf konservativ-patriotische Weise wie in James Kleins Revue Die Welt ohne Schleier von 1923, in der eine in „Pleitanien“ spielende Szene suggerierte, dass die Kommunisten für die schlechte wirtschaftliche Lage Deutschlands verantwortlich waren. Sie endete mit einer Hymne auf Vater Rhein, die den passiven Widerstand gegen die Besetzung des Ruhrgebiets durch französische Truppen feierte. ${ }^{353}$ In der Revue des folgenden Jahres hieß es dann:

Sie hacken jetzt auf Deutschland alle

Und möchten es am liebsten sehn,

Daß wir auf diesem Erdenballe

So sukzessive untergehn.

Doch hab'n die, die uns Böses gönnen,

Die Rechnung ohne Wirth gemacht.

Denn deutsche Kraft und deutsches Können

Geht nicht zugrunde über Nacht. ${ }^{354}$

Dieses Narrativ, demzufolge alle anderen Nationen auf das friedliebende und schuldlose Deutschland einhacken, das sich trotzig durch ,deutsche Kraft und deutsches Können' zur Wehr setzt, ließ sich schon in den Metropol-Revuen der Vorkriegszeit finden. Angepasst an die aktuellen politischen Entwicklungen tauchte es in der Weimarer Zeit wieder auf. Wo Cavalcade die britische Nation als Gemeinschaft definiert hatte, die durch geteiltes Leid und Glück zusammengehalten wird, funktionierte der deutsche Nationalismus durch die Abgrenzung gegen einen äußeren Feind. Innenpolitik war nach dem Krieg bezeichnenderweise kein Thema mehr.

Arthur Kahane zufolge stand die Operette auch in der Zwischenkriegszeit noch auf dem Boden einer „streng monarchistischen Gesinnung“, man dürfe sich nicht davon täuschen lassen, dass sie „mitunter zu dem listigen Auswege eines Scheinbekenntnisses zur republikanischen Staatsgesinnung “ greife. ${ }^{355}$ Doch trotz einer gewissen Dosis Nostalgie für eine als stabil erinnerte Vorkriegszeit, trifft ,monarchistisch' es weniger als ,apolitisch' oder wie es in Die Blume von Hawaii hieß: „Doch genug der Politik, die Jazzband lockt, die Damen wollen tanzen!“356 Hatten in den zehner Jahren Operetten wie Autoliebchen, Filmzauber, Die Kino-Königin oder Die Tangoprinzessin aktuelle Moden aufgenommen und ein überwiegend positives Bild der Gegenwart gezeichnet, war ihr Optimismus inzwischen weitgehend verflogen. Nur selten noch spielte die Handlung in der Gegenwart, meistens war sie entweder in fernen Ländern oder in grauer Vergangenheit angesiedelt. Im politisch überhitzten Klima der Weimarer Jahre bot die Operette einen weitgehend politikfreien Raum oder um noch einmal Die Blume von Hawaii zu zitieren:

352 Vgl. JeLAVICH, Berlin Cabaret, S. 187. Zu den Revuen der Weimarer Zeit siehe JANSEN, Glanzrevuen; zu den Kabarett-Revuen von Friedrich Hollaender siehe Hollaender, Von Kopf bis Fuß; LAREAU, Tingel-Tangel; ders., Großstadträume, Großstadtreime.

353 Vgl. Berliner LoKalanzeiger, Berliner Börsen-Courier und Vossische Zeitung, 10.10. 1923; siehe auch JELAVICH, Berlin Cabaret, S. 188.

354 Abgedruckt in: JANSEN, Glanzrevuen, S. 58.

355 KAHNE, Theater, S. 153.

356 Grünwald und LÖHner-BedA, Die Blume von Hawaii, S. 15. 
„Exzellenz, Hawaii ist kein Land der Politik. Hawaii ist ein Land der Blumen.“357 Gerade diese Operette ist jedoch ein Beispiel dafür, dass Politik unterschwellig durchaus vorkam, handelt sie doch von dem Versuch Prinzessin Layas, die in Paris lebende Nachfahrin der hawaiianischen Königsfamilie, als Herrscherin über ein von den USA unabhängiges Hawaii zu installieren. Auch diese Handlung lässt sich ambivalent lesen: als Ausdruck der Sehnsucht nach der Rückkehr des deutschen Kaisers oder, da der Coup d'État scheitert, als Bestätigung der deutschen Republik.

Die Entpolitisierung des Unterhaltungstheaters muss vor dem Hintergrund der politischen Verhältnisse der zwanziger und dreißiger Jahre verstanden werden. Aufgrund steigender Kosten war es für die Geschäftstheater wichtiger denn je, ein Massenpublikum zu erreichen. Deshalb verbot es sich von selbst, Partei zu ergreifen, wie der Theaterkritiker Monty Jacobs für die Haller-Revuen beobachtete: „Sichtlich fürchtet sich die Direktion Haller vor einer Zeit, die wie die unsrige zum Bersten mit Konflikten geladen ist. Man will bewusst einen Massenartikel schaffen, man will niemand weder rechts noch links einbüßen. Deshalb wendet man sich an alle, und das heißt hier an niemand“. 358 Schon im Kaiserreich waren Politik und Gesellschaft bezüglich weltanschaulicher Unterschiede gespalten gewesen. Der Erste Weltkrieg hatte im Burgfrieden die politischen Lager von konservativ bis sozialdemokratisch vorübergehend vereint, die bestehenden Konflikte aber nicht gelöst, sondern bloß aufgeschoben. Nach Friedensschluss, Revolution, Abdankung des Kaisers und der Ausrufung der Republik brachen diese Konflikte, vermehrt um neue Streitpunkte, wieder auf und spalteten die Gesellschaft zutiefst. In dieser angespannten, durch Demobilisierung, Inflation und Arbeitslosigkeit noch weiter belasteten Situation führte nahezu jede politische Frage zu einem tief greifenden Konflikt. Selbst die harmloseste politische Satire war vor diesem Hintergrund im massentauglichen Unterhaltungstheater unmöglich geworden. „Vielleicht ist es in einem Land mit zwei Nationalflaggen schwerer als anderswo, die Probleme des Tages auf der heiteren Bühne zu glossieren“, meinte deshalb auch Monty Jacobs. ${ }^{359}$

Dennoch war das Unterhaltungstheater nicht völlig unpolitisch, es tendierte vielmehr zu einem diffusen, parteipolitisch nicht gebundenen Konservatismus. Weniger reaktionär als regressiv erlaubte es seinem Publikum, sich in die im Nachhinein glückliche und unbeschwerte Zeit vor dem Weltkrieg zurückzuträumen, wie es der Kritiker Siegfried Jacobsohn 1919 bei einem Besuch des Metropol-Theaters beobachtete:

Nach dem ersten Akt tat mein wohlbeleibter Hintermann einen tiefen Seufzer. Teilnahmsvoll fragte sein Gespons, wo's denn fehle. ,Ach,' erwiderte er, ,da hat man mal eine Stunde geglaubt, die letzten fünf Jahre seien garnicht gewesen!' Das ist das Geheimnis der Behrenstraße. Hier ragt der Tempel der wahrhaft zeitlosen Kunst. Von seinen Mauern prallen Weltkriege ab und Revolutionen. ${ }^{360}$

357 Ebd., S. 25.

358 Monty Jacobs, Hallers Revue, Vossische ZeITUnG, 20. 8. 1925.

359 Monty Jacobs, Von Mund zu Mund, Vossische Zeitung, 2. 9. 1926.

360 Siegfried Jacobson, Operetten-Helden, Die WeltbüHne, 16. 10. 1919, S. 483. 
Doch hier irrte Jacobsohn: Kriege und Revolutionen waren nicht abgeprallt am Unterhaltungstheater, sie hatten seine Haltung zur Gegenwart fundamental verändert. Die Revuen sparten das Politische aus und die Operetten, die vor dem Krieg kaum weniger aktuell gewesen waren, schufen alternative Räume zu einer als unerträglich empfundenen Gegenwart.

\section{Zwischenfazit}

Von allen Themen, die auf der Bühne des Unterhaltungstheaters verhandelt wurden, war Politik eines der unwichtigsten, wenigstens nahm sie sehr viel weniger Raum ein als andere Themen. ${ }^{361}$ Dennoch hat dieses Kapitel gezeigt, dass weder die Zensur noch die Furcht davor, das Publikum vor den Kopf zu stoßen, in einem generell unpolitischen Theater resultierte. Vielmehr stellt sich gerade die Frage, wieso trotz der Zensur so viele politische Anspielungen den Weg auf die Bühne fanden. Die Antwort darauf ist sowohl in der politischen Haltung der Theater als auch in der Inszenierung der Politik zu suchen. So bezog das Unterhaltungstheater fast nie explizit für oder gegen eine politische Richtung Stellung. In den Fällen, in denen es eine bestimmte Person herausgriff, handelte es sich fast immer um Repräsentanten einer politischen Minderheit, die - wie Chamberlain, Bülow, Bebel oder Oldenburg-Januschau - ohnehin in der Kritik standen.

Die politischen Werte und Ziele, für die das Unterhaltungstheater aber eintrat - die Monarchie, die Nation, der Erwerb von Kolonialbesitz - waren weniger einer einzelnen Partei, als einem breiten politischen Spektrum zuzuordnen, das von großen Teilen der Bevölkerung getragen wurde. Die Behandlung der nationalen und internationalen Politik in den Jahresrevuen des Metropol-Theaters entsprach dem „naiven, von wirklicher Kenntnis der realen Gegebenheiten im internationalen System relativ ungetrübten Nationalismus der aufsteigenden Mittelschichten“.362 Die Musical Comedy war „a mainstream culture, geared to the conservative centre“. ${ }^{363}$ Ein solches, nicht auf Umsturz, sondern im Gegenteil auf die Bestätigung der politischen und gesellschaftlichen Verhältnisse angelegtes Theater durfte Milde von der Zensur erwarten und bekam sie auch gewährt, wie die Zeitungen immer wieder monierten. Und nicht zuletzt wurde Politik fast durchweg auf äußerst ambivalente Weise inszeniert, sodass ein und dieselbe Szene als Kritik wie auch als Bestätigung gelesen werden konnte. Solange der Adressat der Satire nicht wusste, ob er sich verspottet oder geschmeichelt fühlen sollte, ging das Unterhaltungstheater keine Gefahr ein, sein Publikum zu verprellen. Vielmehr gelang es ihm so, selbst entgegengesetzte politische Lager für einen Moment miteinander im Lachen zu versöhnen.

361 Dies ist schon daran abzulesen, dass in den meisten Studien zum populären Theater Politik keine oder allenfalls eine äußerst marginale Rolle spielt, vgl. BAILEY, Musical Comedy; PLATT, Musical Comedy; Jelavich, Berlin Cabaret; OtTE, Jewish Identities.

362 Mommsen, Preußisches Staatsbewußtsein und deutsche Reichsidee, S. 688.

363 Platt, Musical Comedy, S. 106. 
Dass die Politik vermittels der Zensurgesetzgebung und -praxis einen ebenso unmittelbaren wie erheblichen Einfluss auf das Theater und die dort gebotene Unterhaltung, insbesondere auf die Repräsentation politischer Themen, ausübte, ist deutlich geworden. Weit schwieriger zu beantworten ist, ob das Theater umgekehrt auf die politischen Ansichten seines Publikums abfärbte. Diese Frage stellte sich während der langen Jahrhundertwende erstmals aufgrund des zeitgleichen Aufkommens von Massenpolitik und Massenmedien. In The Psychology of Jingoism meinte der liberale britische Ökonom John A. Hobson 1901, die Music Hall sei eine wichtigere Erziehungsinstitution als Schulen und Kirchen. In gewöhnlichen Zeiten sei die von ihr gebotene Unterhaltung weitgehend harmlos, doch „the glorification of brute force and an ignorant contempt for foreigners are ever-present factors which at great political crises make the music-hall a very serviceable engine for generating military passion “. 364 Was Hobson für die Music Hall beobachtete, lässt sich mühelos auf die Musical Comedy übertragen. Auch hier spielte Politik in der Regel eine untergeordnete Rolle, um bei aktuellen Anlässen umso vehementer auf die Bühne zu kommen. Doch Hobson zufolge reagierte die Music Hall nicht bloß, sie war es, die in weiten Kreisen der Bevölkerung überhaupt erst Xenophobie und Jingoismus hervorrief, eine These, die bis heute von Historikern diskutiert wird. ${ }^{365}$ Analog dazu warf Christa Hasche dem Metropol-Theater vor, dieses habe „einen nicht unbedeutenden Platz bei der Propagierung einer immer offener werdenden imperialistischen Anschauung“ eingenommen und letztlich sogar einen „Beitrag zur militaristischen Mobilisierung bei Ausbruch des 1. Weltkrieges" geleistet. ${ }^{366}$

Anders als die Auswirkung der Zensur, die anhand der Akten studiert werden kann, lässt sich die des Theaters auf sein Publikum nicht anhand von Quellen überprüfen. Die Frage, ob es Ansichten und Einstellungen seines Publikums reproduzierte oder generierte, gleicht der Frage nach der Henne und dem Ei. Dass sich eine Wirkung nicht nachweisen lässt, heißt jedoch nicht, dass es sie nicht gegeben hat. So ist davon auszugehen, dass das Theater im Verbund mit anderen Massenmedien und im engen Zusammenspiel mit seinem Publikum zur Ausbildung politischer Einstellungen und Mentalitäten beitrug. Wie eng dieses Zusammenspiel war, zeigt etwa die Interaktion zwischen Bühne und Zuschauerraum bei Hands off!. Die Texte des populären Theaters sollten aber nicht nur daraufhin gelesen werden, inwiefern sie unser Bild eines vergangenen Zeitalters bestätigen. Wer genau hinschaut, kann durchaus überraschende Funde machen, so zum Beispiel die - wenngleich ambivalente - Kritik am Militarismus in Donnerwetter tadellos! oder die unterschwellige Sehnsucht nach Frieden in Chauffeur - in's Metropol!.

Abschließend ist noch auf eine der Paradoxien der deutschen Theatergeschichte hinzuweisen: die Präsenz der Politik auf der Bühne vor 1914 trotz der Zensur

364 Hobson, The Psychology of Jinogism, S. 3.

365 Vgl. Summerfield, Patriotism and Empire.

366 HASCHE, Bürgerliche Revue, S. 27. 
und ihre weitgehende Absenz nach deren Abschaffung 1919. Kein Umstand macht deutlicher, welchen Stellenwert der Selbstzensur zukam. Weder der Lord Chamberlain noch das Berliner Polizeipräsidium konnten - oder wollten - das Unterhaltungstheater vor 1914 von allen politischen Anspielungen reinigen. Nach der Aufhebung der Zensur in Deutschland aber schreckten die Theater, die auf die große Masse abzielten, dann weitgehend davor zurück, Politik zum Thema zu machen. Nicht zufällig stammt Arthur Kahanes einleitend zitierte Warnung vor einem politischen Theater aus dem Jahr 1930. Welchen Stellenwert Politik auf der Bühne einnahm, wurde demnach immer wieder neu zwischen den Theatern, den Zensurbehörden und dem Publikum verhandelt. Diese Aushandlungsprozesse aber sagen ebenso viel über die politischen Verhältnisse wie über das Theater einer Zeit aus. 
